Genetic and transcriptomic analysis of postharvest decay resistance in Malus sieversii and the characterization of pathogenicity effectors in Penicillium expansum Wisniewski, M.E. USDA, Agricultural Research Service WV

Droby, S. Agricultural Research Organization

Norelli, J.L. USDA, Agricultural Research Service WV

Sela, N. Agricultural Research Organization

Levin, E. Agricultural Research Organization

Project award year: 2014

Three year research project 


\section{Abstract \\ Genetic and Transcriptomic Analysis of Postharvest Decay Resistance in Malus sieversii and the Characterization of Pathogenicity Effectors in Penicillium expansum}

Blue mold of apple caused by Penicillium expansum is a major postharvest disease. Selection for postharvest disease resistance in breeding programs has been ignored in favor of fruit quality traits such as size, color, taste, etc. The identification of postharvest disease resistance as a heritable trait would represent a significant accomplishment and has not been attempted in apple. Furthermore, insight into the biology of the pathogenicity of $P$. expansum in apple could provide new approaches to postharvest decay management.

Hypothesis: Postharvest resistance of apple to P. expansum can be mapped to specific genetic loci and significant quantitative-trait-loci (QTLs) can be identified that account for a major portion of the population variance. Susceptibility of apple fruit to $P$. expansum is dependent on the ability of the pathogen to produce LysM effectors that actively suppress primary and/or secondary resistance mechanisms in the fruit.

Objectives: 1) Identify QTL(s) and molecular markers for blue mold resistance in GMAL4593 mapping population ('Royal Gala' X Malus sieversii PI613981), 2) Characterize the transcriptome of the host and pathogen ( $P$. expansum) during the infection process 3$)$ Determine the function of LysM genes in pathogenicity of $P$. expansum.

Methods: A phenotypic evaluation of blue mold resistance in the GMAL4593 mapping population, conducted in several different years, will be used for QTL analysis (using MapQTL 6.0) to identify loci associated with blue mold resistance. Molecular markers will be developed for the resistance loci. Transcriptomic analysis by RNA-seq will be used to conduct a time course study of gene expression in resistant and susceptible apple GMAL4593 genotypes in response to $P$. expansum, as well as fungal responses to both genotypes. Candidate resistance genes identified in the transcriptomic study and or bioinformatic analysis will be positioned in the 'Golden Delicious' genome to identify markers that co-locate with the identified QTL(s). A functional analysis of LysM genes on pathogenicity will be conducted by eliminating or reducing the expression of individual effectors by heterologous recombination and silencing technologies. LysM effector genes will also be expressed in a yeast expression system to study protein function.

Expected Results: Identification of postharvest disease resistance QTLs and tightly-linked genetic markers. Increased knowledge of the role of effectors in blue mold pathogenicity. 


\section{Summary Sheet}

\section{Publication Summary}

\begin{tabular}{|c|c|c|c|}
\hline PubType & IS only & Joint & US only \\
\hline Book Chapter & 0 & 1 & 0 \\
\hline Reviewed & 0 & 4 & 0 \\
\hline
\end{tabular}

\section{Training Summary}

\begin{tabular}{|r|c|c|c|}
\hline \multicolumn{1}{|c|}{ Trainee Type } & Last Name & First Name & Institution \\
\hline Postdoctoral Fellow & Levin & Elena & ARO \\
\hline Ph.D. Student & Abdellfattah & Ahmed & University of the Mediterranean, Regiio Calabria, Italy \\
\hline M.Sc. Student & Hillenbrand & Molly & Shepherd University \\
\hline Ph.D. Student & Parafati & Lucia & Univesity of Catania \\
\hline
\end{tabular}




\section{Value of the Collaboration}

Dr. Droby and I have been involved in numerous BARD-funded projects and workshop proposals over the past twenty-five years. I cannot speak more highly of the value that collaboration has brought to me as a scientist and to my research. We work very closely together in the planning of research activities related to the project, speaking on average twice a week, and during our exchange visits. This planning, discussion, and collaboration also continues in the organization of international meetings, and our attendance at various scientific conferences. In fact, one of our BARD-funded workshops resulted in the formation of an international working group under the auspices of the Int. Soc. Hort. Sci, and the Int. Soc. Plant Pathology. Truly our collaboration has been synergistic in many ways.

Together, our research has been recognized in the forefront of postharvest biocontrol and two of our reviews on the subject, "Twenty-years of Postharvest Biocontrol Research: Is It Time for a New Paradigm", has been one of the most highly cited papers in the journal, Postharvest Biology and Technology. More recently, a thirty-year retrospective also appeared in a special issue of the same journal, entitled, "Biological Control of Postharvest Diseases: The Journey from Simplicity to Complexity." These accomplishments simply would not have been possible without BARD support of our collaboration.

In the recent approach, we took advantage of the apple planting located at the USDA-ARS, Apple Germplasm Repository, to conduct a genetic analysis of resistance to blue mold in a mapping population (GMAL4593) of Malus sieversii and identify for the first time a QTL for postharvest resistance to blue mold caused by Penicillium expansum. This was the first time ever a QTL for a postharvest disease has been described in apple. This aspect of the project also involved a RNA-seq analysis of the resistant and susceptible parents of the GMAL4593 population. Dr. Droby and the members of his lab were instrumental in analyzing and interpreting the data from this experiment. Dr. Droby's lab in the meantime explored the role of effectors in the pathogenicity of $P$. expansum, which led to the discovery of two effector gene families in $P$. expansum, the Lys-M family and the NLP family. While his lab conducted the bulk of this work, isolating the effector genes and creating knock-outs, my lab conducted yeast two hybrid studies to identify the apple proteins that interacted with two of the effectors. The Israeli lab also developed a bioinformatics database for the identification of effectors in fungi. The high quality of the research and the overall productivity simply would not have been possible without the BARD-supported collaboration.

In summary, the collaboration between Dr. Droby and myself was synergistic and highly valuable. It has, over the years, allowed us to push the boundaries of postharvest biocontrol research and create new paradigms. In every way, our relationship and collaboration represents the hallmark of what BARD is trying to achieve. 


\section{Accomplishments:}

Blue mold caused by Penicillium expansum is the most important postharvest disease of apple worldwide and results in significant financial losses. There are no defined sources of resistance to blue mold in domesticated apple. However, resistance has been described in wild Malus sieversii accessions, including plant introduction (PI)613981.There were two main objectives in the BARD-funded project on $M$. sieversii and blue mold resistance. 1) The first major objective was to create a genetic linkage map for $M$. sieversii and collect phenotypic data on blue mold resistance in order to identify QLT(s) and markers that would benefit breeders using marker-assisted selection. The second major objective was to develop a bioinformatics pipeline that would allow researchers to identify putative effectors in pathogenic fungi and determine their potential role in pathogenicity.

\section{QTL for blue mold resistance}

This portion of the project utilized the GMAL4593 mapping population (Malus sieversii PI613981 x 'Royal Gala') to conduct phenotypic and genetic analyses. PI613981 had been previously identified to be resistant to blue mold (Penicillium expansum) while 'Royal Gala', a commercial cultivar was known to be susceptible blue mold. Blue mold resistance was demonstrated to segregate in the population in a preliminary feasibility study funded by BARD. The one-year feasibility study and the three-year BARD project, allowed us to collect 4 years of phenotypic data on blue mold resistance in the GMAL4593, identify QTLs and genetic markers associated with the resistance, and compare the transcriptomic response of the two parents (PI613981-M. sieversii and 'Royal Gala') to infection by $P$. expansum. In the project, we provided the first detailed genetic map of $M$. sieversii and identified the first QTLs associated with blue mold resistance in apple. This was the first time that a QTL had been identified in apple for resistance to a postharvest disease. These markers are now being evaluated in crosses made with resistant and susceptible parents and are being further characterized as part of the RosBreed SCRI project funded by the USDA-NIFA program. We describe the first quantitative trait loci (QTL) reported in the Rosaceae tribe Maleae conditioning resistance to $P$. expansum on genetic linkage group 3 (qM-Pe3.1) and linkage group 10 (qM-Pe 10.1). These loci were identified in a M.× domestica 'Royal Gala' X M. sieversii PI613981 family (GMAL4593) based on blue mold lesion diameter seven days post-inoculation in mature, wounded apple fruit inoculated with P. expansum. Phenotypic analyses were conducted in 169 progeny over a four year period. PI613981 was the source of the resistance allele for qM-Pe3.1, a QTL with a major effect on blue mold resistance, accounting for $27.5 \%$ of the experimental variability. The QTL mapped from 67.3 to $74 \mathrm{cM}$ on linkage group 3 of the GMAL4593 genetic linkage map. qM-Pe10.1 mapped from 73.6 to $81.8 \mathrm{cM}$ on linkage group 10. It had less of an effect on resistance, accounting for $14 \%$ of the experimental variation. 'Royal Gala' was the primary contributor to the resistance effect of this QTL. However, resistance-associated alleles in both parents appeared to contribute to the least square mean blue mold lesion diameter in an additive manner at qM-Pe10.1. A GMAL4593 genetic linkage map composed of simple sequence repeats and 'Golden Delicious' single nucleotide polymorphism markers was able to detect qM-Pe 10.1, but failed to detect qM-Pe3.1. The subsequent addition of genotyping-by-sequencing markers to the linkage map provided better coverage of the PI613981 genome on linkage group 3 and facilitated discovery of qM-Pe3.1. A DNA test for qM-Pe3.1 has 
been developed and is currently being evaluated for its ability to predict blue mold resistance in progeny segregating for qMPe3.1. Due to the long juvenility of apple, the availability of a DNA test to screen for the presence of qM-Pe3.1 at the seedling stage will greatly improve efficiency of breeding apple or blue mold resistance.

Another aspect of this objective was to try and determine genes or the expression of genes that were associated with resistance response observed in $M$. sieversii. The goal was to characterize the transcriptomic response of susceptible 'Royal Gala' and resistant PI613981-M. sieversii apple fruit to wounding and inoculation with $P$. expansum using RNA-Seq. Transcriptomic analyses 0 to $48 \mathrm{~h}$ post inoculation suggest a higher basal level of resistance and a more rapid and intense defense response to wounding and wounding plus inoculation with $P$. expansum in M. sieversii - PI613981 than in 'Royal Gala'. Functional analysis showed that ethylene-related genes and genes involved in 'jasmonate' and 'MYB-domain transcription factor family' were over-represented in the resistant genotype. It is suggested that the more rapid response in the resistant genotype (Malus sieversii - PI613981) plays a major role in the resistance response. At least twenty DEGs were mapped to the qM-Pe3.1 QTL (M×d v.1: 26,848,396 - 28,424,055) on LG3, and represent potential candidate genes responsible for the observed resistance QTL in M. sieversii - PI613981. RT-qPCR of several of these genes was used to validate the RNA-Seq data and to confirm their higher expression in MS0. The basis of the more rapid response was not identified in the present study and further experiments are needed to determine if the rapid response is due to blocking of effector signals from the pathogen or due to the presence of unique alleles that function in resistance.

Bioinformatic identification of potential effectors and molecular identification and characterization of effectors with known (LysM and NLP) and unknown function in Pencillium expansum.

A bioinformatics approach was taken to identify putative effector genes in Penicillium expansum. A prediction bioinformatics pipeline was developed that can be used by the general research community to identify putative fungal effector genes and proteins in $P$. expansum. This was the first time that a bioinformatics approach was taken to identify effectors in postharvest pathogen.

Elucidating the pathogenicity mechanism of $P$. expansum is of utmost importance for the development of effective and safe management strategies. Although, many studies on possible role of cell wall degrading enzymes as well as mechanisms that modulate their expression during decay development were done, the interactions of $P$. expansum with fruit tissue during the early stages of infection and the virulence factors that mediate pathogenicity and virulence have not been fully defined. During the first hours after spore germination, $P$. expansum actively suppress induced resistance mechanisms in the fruit with secreted effectors. 
We report the exploration of potential effectors in $P$. expansum using an approach that combines common effector features with transcriptomic data and evidence for involvement in pathogenicity present in the literature. A pipeline for effectors predication in P. expansum was constructed and revealed the presence of 17 top effector candidate genes. Among these putative effectors, one subtilisin-related peptidase S8 (PePRT) was identified to have the most prevalent features of an effector as defined in our prediction pipeline. PePRT was characterized and functionally analyzed. Deletion of the PRT genes in P. expansum affected virulence on apples as well as mycelial morphology, cell structure and sporulation. This is the first study that identified and characterized the effects of subtilisin-related peptidase S8 in postharvest pathogen.

We have also identified and functionally analyzed additional two genes coding small-cysteine rich proteins with unknown function (PEX2_056460, PEX2_002470) that were named PeSCR1, $P e S C R 2$, respectively. The delection of PeSCR2 affected virulence of $P$. expansum on apples.

Effectors carrying LysM domain have been identified in numerous pathogenic fungi and their role in the first stages of infection has been established. We identified 18 LysM genes in the $P$. expansum genome. Amino acid sequence analysis indicated that $P$. expansum LysM proteins belong to a clade of fungal-specific LysM. Eleven of the discovered LysM genes was found to have secretory pathway signal peptide, among them, 4 (PeLysM1 PeLysM2, PeLysM3 and PeLysM4) were found to be highly expressed during the infection and development of decay of apple fruit. Effect of targeted deletion of the four putative PeLysM effectors on the growth and pathogenicity was studied. Possible interactions of PeLysM with host proteins was investigated using the yeast-two-hybrid system. This was the first study that has identified LysM effectors in $P$. expansum, identified their putative interacting proteins in apple, and characterized their role in pathogenicity.

Additional Data on NPL-effectors and a bioinformatics analysis of effectors in Penicillium have been uploaded in the appendix. Therefore, at least two more publications based on this data will be submitted for publication within the next two months 
Changes to the Project Plan

NO MAJOR CHANGES WERE MADE IN THE ORIGINAL PROJECT PLAN. 
Publications for Project US-4774-14C

\begin{tabular}{|c|c|c|c|c|c|c|}
\hline $\begin{array}{l}\text { Stat } \\
\text { us }\end{array}$ & Type & Authors & Title & Journal & $\begin{array}{l}\text { Vol:pg } \\
\text { Year }\end{array}$ & $\begin{array}{c}\text { Cou } \\
\text { n }\end{array}$ \\
\hline Published & Reviewed & $\begin{array}{c}\text { John L. Norelli, } \\
\text { Michael Wisniewski, } \\
\text { Gennaro Fazio, } \\
\text { Erik Burchard, } \\
\text { Benjamin Guiterrez, } \\
\text { Donna Lalli, Elena } \\
\text { Levin, Samir Droby }\end{array}$ & $\begin{array}{l}\text { Genotyping-By-Sequencing } \\
\text { Markers Facilitate the } \\
\text { Identification of Quantitative } \\
\text { Trait Loci Controlling } \\
\text { Resistance to Penicillium } \\
\text { expansum in Malus sieversii }\end{array}$ & PLoS One & $\begin{array}{c}12: \\
\text { e0172949. } \\
2017\end{array}$ & Joint \\
\hline Published & Reviewed & $\begin{array}{c}\text { Junyang Yue, } \\
\text { Danfeng Zhang, } \\
\text { Rongjun Ban, } \\
\text { Xiaojing Ma, } \\
\text { Danyang Chen, } \\
\text { Guangwei Li, Jia } \\
\text { Liu, Michael } \\
\text { Wisniewski, Samir } \\
\text { Droby, Yongsheng } \\
\text { Liu }\end{array}$ & $\begin{array}{c}\text { PCCPI: A comprehensive } \\
\text { Database for the Prediction of } \\
\text { Penicillium-crop protein-proein } \\
\text { interactions }\end{array}$ & Database & : 1-9 2017 & Joint \\
\hline Published & Reviewed & $\begin{array}{l}\text { Elena Levin, Ana } \\
\text { Rosa Ballester, } \\
\text { Ginat Raphael, Oleg } \\
\text { Feigneberg, } \\
\text { Yongsheng Liu, } \\
\text { John Norelli, Luis } \\
\text { Gonzalez-Candelas, } \\
\text { Jing Ma, } \\
\text { Christorpher } \\
\text { Dardick, Michael } \\
\text { Wisniewslki, Samir } \\
\text { Droby }\end{array}$ & $\begin{array}{c}\text { Identification and } \\
\text { characterization of LysM } \\
\text { Effectors in Penicillium } \\
\text { expansum }\end{array}$ & PLoS One & $\begin{array}{l}\text { 12(10): } \\
\text { e0186023 } \\
2017\end{array}$ & Joint \\
\hline Accepted & Reviewed & $\begin{array}{l}\text { Ana-Rosa Ballester, } \\
\text { John Norelli, Erik } \\
\text { Burchard, Ahmed } \\
\text { Abdelfattah, Elena } \\
\text { Levin, Luis } \\
\text { Gonzalez-Candelas, } \\
\text { Samir Droby, } \\
\text { Michael Wisniewski }\end{array}$ & $\begin{array}{l}\text { Transcriptomic response of } \\
\text { resistant (PI619831 - Malus } \\
\text { sieversii) and susceptible } \\
\text { ('Royal Gala') genotypes of } \\
\text { apple to blue mold (Penicillium } \\
\text { expansum) infection }\end{array}$ & $\begin{array}{l}\text { Frontiers In Plant } \\
\text { Science }\end{array}$ & : 2017 & Joint \\
\hline Published & $\begin{array}{c}\text { Book } \\
\text { Chapter }\end{array}$ & $\begin{array}{l}\text { Wisniewski, M., } \\
\text { Norelli, J., Droby, } \\
\text { S., Ballester, A-R., } \\
\text { Abdelfattah, A., } \\
\text { Levin, E. }\end{array}$ & $\begin{array}{l}\text { Genomic Tools for Developing } \\
\text { Markers for Postharvest Disease } \\
\text { Resistance in Rosaceae Crops }\end{array}$ & Acta Horticulturae & $\begin{array}{l}1144: 7- \\
152016\end{array}$ & Joint \\
\hline
\end{tabular}




\section{Subtilisin-related peptidase S8 (PePRT) is involved in virulence of Penicillium expansum on apples (Effector prediction pipeline in Penicillium expansum revealed subtilisin-related peptidase S8 (PePRT))}

\section{Introduction}

Penicillium is a diverse fungal genus with 354 accepted species today (Visagie et al., 2014b), occurring worldwide in various substrates, from soil to food. Among them, $P$. expansum is widely recognized as necrotrophic pathogen on wide range of fruits including pome and various stone fruit (Capellini et al., 1987 and Jurick et al., 2011). It infects fruit hosts through surface wounds where nutrients stimulate spore germination, which is then followed by penetration and colonization of fruit tissue. I general, necrotrophs promote host cell death and acquire nutrients for growth from dead cells. In recent years, there is a growing understanding of the fact that the interaction between necrotrophic fungi and plants is complex and involves sophisticated recognition and signaling networks. Plant innate immune systems has two layers of defense: pathogen-associated molecular pattern (PAMP)-triggered immunity or PTI, and effector-triggered immunity (ETI). PTI is the first layer of innate immunity and is initiated in plants when PAMPs are recognized by pattern recognition receptors; such recognition triggers broad-spectrum immune response to pathogen infection. In contrast, ETI is induced by direct or indirect recognition of highly variable pathogen avirulence effectors by host disease-resistance proteins. The recognition in this case leads to a rapid and robust response that is often referred to as a hypersensitive reaction (HR). Wide-range of virulence strategies are used by necrotrophic fungi to overcome host innate immune system. Among them, diverse phytotoxic compounds, cell-degrading enzymes and proteinaceous effectors (Wang et al. 2014). The necrotrophic pathogens Stagonospora nodorum and Pyrenophora tritici-repentis were found to produce multiple proteinaceous hostselective toxins which act in effectortriggered susceptibility (Manning et al. 2007, Liu et al. 2012, Friesen et al.2007, Abeysekara et al. 2009, Friesen et al.2012). For instance, S. nodorum SnTox3 gene that has little homology to other known genes was found to interact with the wheat susceptibility gene Snn3. SnTox3-disrupted mutants were avirulent on the Snn3 differential wheat line BG220. (Liu et al. 2009) Additionally, necrosis and ethyleneinducing peptide 1 (NEP1) -like (NLP) effectors produced by many plant pathogens were found also in necrotrophic fungi. NLPs from Sclerotinia sclerotiorum, named SsNep1 and SsNep2 induced necrosis when expressed transiently in tobacco leaves. Moreover, reduced or abolished SsNep2 expression coincident with a partial or total loss of virulence, respectively (Dallal-Bashi et al. 2009). BcNEP1 and BcNEP2, two paralogous of NLPs fromBotrytis cinerea caused necrosis in dicotyledonous plant species, although they role in $B$. cinerea 
virulence is still unclear (Schouten et al. 2007). The role of LysM effectors in pathogenicity and virulence in several pathogen-plant systems was also reported. Ecp6, a chitin-binding protein from Cladosporium fulvum, appears to prevent the activation of PTI by scavenging chitin oligosaccharides that act as pathogen-associated molecular patterns (PAMPs) (Bolton et al. 2008, de Jonge et al. 2010) In our previous work, we characterized the role of four LysM proteins in virulence of $P$. expansum on apples. Although, single knockout of each of the four genes revealed no significant effect on the pathogenicity and virulence, $\mathrm{Y} 2 \mathrm{H}$ studies utilizing the LysM domain as a bait, identified a wide range of interacting apple proteins with diverse functions, including plant defense processes highlighting the possibility that P. expansu LysM effector proteins may play potential role modulating cellular processes in host tissue and subsequent development of decay. (Levin et al., 2017).

Still majority of protein effectors in necrotrophic pathogens are unknown and molecular mechanisms of the interactions between them and host plants are not yet elucidated. 
With the rising number of sequenced plant fungal pathogens genomes, there are several studies attempting to predict effectors using computational tools (reviewed in Sperschneider et al. 2015). Fungal effector prediction is challenging due to the lack of common features for effectors within and cross species. In general, parameters such as small size, presence of secretion signal and large number of cysteine are used as criteria in fungal effector prediction. However, this approach results in numerous false-positive and false-negative candidates. Recently, more sophisticated techniques for predicting apoplastic and cytoplasmic effector candidates were reported. To explore effectors that are involved in pathogenicity in S. nordorum, Syme et. al (2013) compared reference genome sequence of two different strains one of which is avirulent. The presence of genes in pathogenic strains and absence in non-pathogenic is added to computationally predicted properties of known proteins to produce a list of likely effector candidates (Syme et al. 2013). Sperschneider et al. (2013) used comparative hidden Markov model analyses followed by unsupervised protein clustering and has successfully uncovered conservation patterns of putative effectors and motifs of S. nodorum and Fusarium oxysporum (Sperschneider et al. 2013). In another work, application of an alternative analysis strategy that uses the signal of adaptive evolution as a line of evidence for effector function, combined with comparative information and expression data resulted in prediction of 42 effector candidates that are conserved only across pathogens, induced during infection and rapidly evolving(Sperschneider et al. 2014). Guyon (2014) reported the identification of 486 S. sclerotiorum secreted protein genes expressed in planta that may be involved in the interaction between the fungus and its hosts. Focusing on those showing (i) protein domains and motifs found in known fungal effectors, (ii) signatures of positive selection, (iii) recent gene duplication, or (iv) being S. sclerotiorum-specific, they identified 78 potential effector candidates (Guyon et al.2014).

In parallel with plant pathogens genome sequences, the number of experimental data and number of publications on pathogenicity and virulence associated genes are constantly growing. PHI-base is a web-accessible database that catalogues experimentally verified pathogenicity, virulence related genes in fungal, oomycete and bacterial pathogensin animal, plant, and insect hosts. Each entry in PHI-base is curated by domain experts and is supported by strong experimental evidence (Winnenburg et al. 2006). 
In this study, we report the exploration of potential effectors in $P$. expansum using an approach that combines common effector features with transcriptomic data and evidence for involvement in pathogenicity present in the literature A pipeline for effectors predication in P. expansum was constructed and revealed the presence of 17 top effector candidate genes.. Among these putative effectors, one subtilisin-related peptidase S8 (PePRT) was identified to have the most prevalent features of an effector as defined in our prediction pipeline. PePRT was characterized and functionally analyzed. Deletion of the PRT genes in P. expansum affected virulence on apples as well as mycelial morphology, cell structure and sporulation.

\section{Materials and Methods}

\section{Plant material and fungal cultures}

We used the $P$. expansum isolate PEX2, a strain isolated from the US from infected apple fruit, described by Ballester et al (2015) and Julca et al (2016). Apple fruits (cv. Golden Delicious) were harvested at maturity stage and used shortly after harvest or stored at $0^{\circ} \mathrm{C}$ until use. Prior to inoculation, fruit were disinfected by dipping in a in $0.05 \%$ sodium hypochlorite for $2 \mathrm{~min}$ and then washed thoroughly with tap water.

A culture of $P$. expansum was cultivated on potato dextrose agar (PDA) or in potato dextrose broth (PDB) at $25^{\circ} \mathrm{C}$. Spore suspensions were prepared by harvesting the spores from 2 to 3 -weeks-old PDA cultures with a sterile bacteriological loop, and suspending them in sterile distilled water. To remove residual mycelium, the suspension was filtered through four layers of sterile cheesecloth and spores were washed twice with sterile distilled water by centrifugation at $10,000 \mathrm{rpm}$ for $5 \mathrm{~min}$ and resuspension in sterile distilled water. Spore concentration was determined using hemocytometer and adjusted as needed.

\section{Secretome prediction and annotation}

We used the $P$. expansum isolate PEX2, a strain isolated from the US from infected apple fruit, described in Ballester et al (2015) and in Julca et al (2016). We followed a pipeline similar to that described by Müller et al (2008) to predict the secretome of Ustilago maydis with minor modifications. In silico prediction of extracellular proteins was performed using SignalP (v4.1; http://www.cbs.dtu.dk/services/SignalP/) to determine the presence of signal peptides. The TargetP server (v1.1; http://www.cbs.dtu.dk/services/TargetP/) was used to identiy and remove SSPs with either a chloroplast transit peptide or a mitocondrial targeting peptide (Loc=S and Reliability 
Class $\leqslant 2$ ) (Emanuelsson et. al 2000, Petersen et. al 2011) TMHMM software (v2.0; http://www.cbs.dtu.dk/services/TMHMM/) was then utilized to predict and remove transmembrane helices in proteins, except those with one TM in the N-terminal signal peptide. (Larsson et. al 2001). The remaining SSPs were screened for the presence of glycophosphatidylinositol (GPI) anchor proteins using big-PI (http://mendel.imp.ac.at/gpi/fungi_server.html). Finally, the selected SSPs were subjected to PFAM analysis using the PFAM database (v27.0; http://pfam.xfam.org/search\#tabview=tab1) and to InterProScan (v5.1;

http://www.ebi.ac.uk/interpro/). Evidence for in planta expression was derived based on the results of analysis of RNASeq generated from four different libraries: a cDNA library synthesized from a mixture of RNAs obtained from $P$. expansum PEX1 spores collected after 7 days of growth on PDA, healthy non inoculated fruits, and three libraries from P. expansum-infected apples at 24, 48, and 72 hours post infection (hpi), respectively (Ballester et. al 2015)

\section{Effector Prediction Pipeline}

Based on the results of secretome prediction and annotation, five groups of potential effectors were selected: 1) small, cysteine-rich - not annotated proteins smaller than 300 aa with 4 or more cysteines; 2) proteins highly induced in planta: genes which expression level, based on RNAseq results, is equal or larger than an average expression level plus two standard errors; 3) proteins with NLS signal: NLS presence was predicted by NLStradamus Revision r.9 (Nguyen et. al 2009);4) proteins that belong to known effector families or carrying effector-domains previously reported in the literature; 5) proteins homologous to gene-products proven to affect the outcome of pathogen-host interactions: BlastP against PHI-base v.3.8 (Urban et. al 2015, Winnenburg et. al 2008, Baldwin et. al 2006, Winnenburg, et. al 2006)

In order to select "top effector-candidates", we chose all the gene products belong to two or more of these five potential effector-groups.

\section{Fruit inoculation and disease assessment}

Apple fruits were wounded at four to six different sites around the stem end to a depth of $4 \mathrm{~mm}$ using a $1.25-\mathrm{mm}$ diameter needle. For inoculation, $10 \mu \mathrm{l}$ of a spore suspension of $P$. expansum $\left(10^{6}\right.$ spores $\left.\mathrm{ml}^{-1}\right)$ was pipetted into each wound. For each treatment, 8-12 fruits were used and each experiment was repeated three times. Inoculated fruit was placed in plastic trays lined with filter paper soaked with sterile water (150 $\mathrm{ml}$ per tray) and incubated in 
darkness at $25^{\circ} \mathrm{C}$. Percentage of infection and rot diameter were determined starting from the 3rd day after inoculation.

\section{RNA extraction from $P$. expansum-infected apple tissue and cDNA synthesis}

Total RNA was extracted from $P$. expansum-infected apple fruit tissue at different times after inoculation following the protocol described by Chang et al. (1993) [39]. Decayed tissues from the site of inoculation were removed from apples, frozen immediately in liquid nitrogen and then freeze-dried. For each sample, $1 \mathrm{gr}$ of lyophilized tissue was ground in liquid nitrogen using a mortar and pestle. The ground powder was suspended in $10 \mathrm{ml}$ of extraction buffer (2\% C-TAB, 2\% polyvinylpyrrolidone (PVP), 0.1M Tris-HCl (pH8), 25 mM EDTA, 2M NaCl, 2\% $\beta$ mercaptoethanol) preheated to $65^{\circ} \mathrm{C}$. After vortexing for $2 \mathrm{~min}$, the samples were incubated at $60^{\circ} \mathrm{C}$ for $15 \mathrm{~min}$ with occasional mixing. After incubation, an equal volume of Chloroform:Isoamyl alcohol (Chl:Iaa) (24:1 v/v) was added to each sample, vortexed for $2 \mathrm{~min}$ and centrifuged at $12,000 \mathrm{~g}$ for $20 \mathrm{~min}$ at $4^{\circ} \mathrm{C}$. The upper phase was transferred to a clean tube and the RNA was re-extracted with an equal volume of Chl:Iaa. The supernatant was then transferred to a clean $50 \mathrm{ml}$ tube, mixed with $1 / 3$ volume of $7.5 \mathrm{M} \mathrm{LiCl}$ and incubated overnight at $4^{\circ} \mathrm{C}$. RNA was precipitated by centrifugation at $12,000 \mathrm{~g}$ for $50 \mathrm{~min}$ at $4^{\circ} \mathrm{C}$. The pellets were washed with $5 \mathrm{ml} 75 \% \mathrm{EtOH}$, air dried, and dissolved in $500 \mu \mathrm{l}$ of preheated $\left(65^{\circ} \mathrm{C}\right) \mathrm{SSTE}$ buffer $(0.5 \% \mathrm{SDS}, 1 \mathrm{M} \mathrm{NaCl}, 10 \mathrm{mM}$ Tris- $\mathrm{HCl}(\mathrm{pH}$ 8), 1mM EDTA). The RNA was re-extracted again by adding an equal volume of Chl:Iaa, vortexed for 2 min and subjected to centrifugation at $14000 \mathrm{~g}$ for $10 \mathrm{~min}$ at $4^{\circ} \mathrm{C}$. The upper phase was transferred to a clean microcentrifuge tube. RNA was precipitated by the addition of 2 volumes of $100 \%$ ethanol, incubation at $-80^{\circ} \mathrm{C}$ for 30 min, and centrifugation at $14,000 \mathrm{~g}$ for $20 \mathrm{~min}$ at $4^{\circ} \mathrm{C}$. The pellets were washed with $1 \mathrm{ml} 75 \%$ ethanol, air dried, and dissolved in $50 \mu \mathrm{l}$ of nuclease-free water. The quality and concentration of total RNA was analyzed by gel electrophoresis and the use of a ND-1000 spectrophotometer (NanoDrop, Wilmington, DE, USA). First-strand cDNA was synthesized from $1 \mu \mathrm{g}$ of total RNA that had been pretreated with 0.25 units of recombinant DNase I (Takara Bio Inc., Shiga, Japan), using the Verso cDNA Kit (Thermo Fisher Scientific, Epson, UK) following manufacturer's guidelines.

\section{PCR and Reverse transcription - quantitative PCR (RT-qPCR)}

PCR reactions were done with standard thermocyler (Senso Quest, Göttingen, Germany). Each PCR reaction contained 1U DreamTaq DNA polymerase (Thermo Scientific), DreamTaq buffer, $0.2 \mathrm{mM}$ dNTPs, $0.4 \mu \mathrm{M}$ of each primer as detailed below and $1 \mathrm{ng}-1 \mu \mathrm{g}$ template DNA. Cycling conditions were: $5 \mathrm{~min}$ at $94^{\circ} \mathrm{C}$, followed by 40 
cycles of $30 \mathrm{sec}$ at $94^{\circ} \mathrm{C}, 15 \mathrm{sec}$ at $54-58^{\circ} \mathrm{C}, 1-3 \mathrm{~min}$ at $72^{\circ} \mathrm{C}$; and $10 \mathrm{~min}$ at $72^{\circ} \mathrm{C}$. Primer sequences utilized in the PCR reactions are listed in Table S1

RT-qPCR was performed with a StepOnePlus real time PCR system (Applied Biosystems, Foster City, United States). PCR amplification was performed with $4 \mu \mathrm{l}$ of cDNA template in $10 \mu \mathrm{l}$ of a reaction mixture containing 5 $\mu 1$ of Fast SYBR Green Master Mix (Applied Biosystems), and $300 \mathrm{nM}$ primers (PepI_F/PepI_R for PePRT and 28S_F/28S_R for 28S rRNA as detailed inTable S1).

Results were analyzed using StepOnePlus software. For the determination of gene expression as function of time, 28S rRNA served as endogenous controls. The sample collected at 0 hours post inoculation (hpi) were used to calibrate the expression levels. A mixture of cDNAs from all the samples was used in the analysis of all the treatments as a template to generate calibration curves designed for each pair of primers. Relative quantification was calculated using the mathematical model of Pfaffl (2001) in which the relative expression ratio of a target gene is calculated based on the efficiency and the cross point deviation of an unknown sample versus a control [40], and expressed in comparison to reference genes indicated above Each experiment was performed in triplicate, and three different biological experiments were conducted.

\section{Construction and analysis of PePRT knockout mutant}

Knockout mutants were constructed as described previously by Ballester et al. (2015). Flanking regions of the 5' upstream (promoter) and 3' downstream (terminator) of PePrt gene, were PCR amplified from genomic DNA of P. expansum (Pe100/PEX2), using Prt_Prom_F/Prt_Prom_R and Prt_Ter_F/Prt_Ter_R primer pairs (Table S1). The cycling protocol consisted of $4 \mathrm{~min}$ at $94^{\circ} \mathrm{C}$ for pre-incubation, then 40 cycles of $30 \mathrm{~s}$ at $94^{\circ} \mathrm{C}$ for denaturation, $15 \mathrm{~s}$ at $56^{\circ} \mathrm{C}$ for annealing, and $2 \mathrm{~min}$ at $72^{\circ} \mathrm{C}$ for extension, and a final elongation step of $10 \mathrm{~min}$ at $72^{\circ} \mathrm{C}$. DNA fragments corresponding to the promoter and terminator regions, and the pRFHU2 vector [42] were digested with $P a c I$ and $N t B b v C I$ (New England Biolabs), mixed together and then treated with USER enzyme (New England Biolabs) to obtain pRFHU2-PePrt plasmid. An aliquot of the mixture was used directly for chemical transformation of Escherichia coli JM109 cells (Promega) without prior ligation. Kanamycin-resistant transformants were screened by PCR for the presence of promoter and terminator with primer pairs RF-1/RF-6 and RF-2/RF-5, respectively (Table S1). Proper insertion was confirmed by DNA sequencing. The selected plasmids were introduced into chemically competent Agrobacterium tumefaciens AGL-1 cells, which were subsequently used to transform $P$. expansum PEX2, as described previously [43]. Analysis of transformants for gene disruption events was done by PCR. The insertion of the selection marker was checked with primer pair HMBF1/HMBR1 (Table S1). Integration of the T-DNA by homologous recombination was examined using primer 
pairs HPH1F/Prt_center_F and HPHPRO4/Prt_center_R (Table S1). Further verification of deletion of the target gene was done with primer pairs Prt_center_f/Prt_center_R (Table S1). Real-time genomic PCR analysis was carried out in order to determine the number of T-DNA copies that had been integrated into the genome of the transformants, following the protocol described by Crespo-Sempere et al. (2013) [44], using PEX2 as the control. Primer pair, Prt_RT_F/Prt_RT_R was designed within the T-DNA in the promoter regions of PePrt, , close to the selection marker. The P. expansum $\beta$-tubulin gene (AY674401) [45] was chosen as reference gene using the primer pair PeTub_1F/PeTub_2R.

\section{Radial growth,sporulation and spore germination assays}

For radial growth assay, $5-\mu 1$ droplet of spore suspension of $10^{6} \mathrm{spore} / \mathrm{ml}$ was placed in the center of PDA plates, incubated at $25^{\circ} \mathrm{C}$ and culture diameter was recorded daily. For quantification of spore production, $5 \mathrm{ml}$ distilled water was added to 11 days-old plaits, the spores were collected using dregalsky stick and each plate was washed by additional $2 \mathrm{ml}$ distilled water to insure maximum spore collection. Spore suspension was diluted and and spore concentrations were counted by a hemocytometer. Number of spores per plate was calculated as follows: number of spores per plate $=$ spore concentration $($ spores $/ \mathrm{ml}) *$ dilution factor* $7 \mathrm{ml}$.

To examine the percent of spore-germination and germ-tube length, $15-\mu 1$ droplet of $10^{5} \mathrm{spore} / \mathrm{ml}$ were inoculated on water-agar plates ( $1.5 \%$ agar). After incubation at $25^{\circ} \mathrm{C}$ for $18 \mathrm{hr}$ the plates were observed under a microscope and image analysis and germ-tube length measurements were done using NIS-Elements BR Microscope Imaging Software (Nikon Instruments Inc., USA).

\section{Microscopy}

Scanning electron microscopy:

Segments were taken from 10 days old colony grown on PDA plates. The segment was immobilized using carbon tape and image acquisition was done using tabletop scanning electron microscope TM3030Plus (Hitachi).

Confocal microscopy:

Mycelium was grown on PDA medium in petri dish with glass bottom for one week. Image acquisition was done using a Leica SP8 laser scanning microscope ( Leica, Wetzlar, Germany), equipped with a solid state laser with $448 \mathrm{~nm}$ light and HCX PL APO CS 10x/0.40 dry or HC PL APO CS 60x/1.2 water immersion objective (Leica, Wetzlar, Germany) and Leica Application Suite X software (LASX, Leica, Wetzlar, Germany). Vacuoles were stained by immersing the mycelium in $5 \mu \mathrm{gr} / \mathrm{ml}$ FM4-64 (Molecular Probes) and 15 min incubation at room temperature. FM4-64 emission signals was detected with HyD (hybrid) detector in range of 580-680 nm. 


\section{Results and Discussion}

\section{Secretome analysis}

Genome sequence and annotation of $P$. expansum strain PEX2 was previously described (Ballester et al. 2015). Protein identity in this strain (isolated from the decayed apples in the US) and strain PEX1 (isolated from decayed apples in Spain) was 99.7\%, indicating a high similarity between these two strains (Ballester et al., 2015). Based on the similarity in protein identity between these two strains, relative to other sequenced strains, Ballester et al. (2015) suggested that these strains be placed in different sections and series within the subgenus Penicillium (Frisvad and Samson 2004). To predict the potential secreted effector proteins the present study presents a detailed analysis of the secretome of $P$. expansum strain PEX2, possessing 11,060 predicted proteins. SignalP v4.1 and TargetP v1.1 were used in combination to predict the total secretome (Fig. 1A). A total of 688 genes encoding secreted proteins were identified, representing 6.2\% of the P. expansum PEX2 proteome. This percentage is similar to the $7.7 \%$ predicted by $\mathrm{Li}$ et al (2015) for P. expansum strain T01, and for P. italicum (7.1\%) and P. digitatum (6.0\%). These values are slightly lower than those ascribed for two other plant necrotrophs: Sclerotinia sclerotiorum (9.8\%) and Botrytis cinerea (10\%) (Heard et al., 2015). Among the set of predicted secreted proteins, 617 were predicted, using TMHMM v2.0, not to possess a transmembrane domain (TM) or a single TM in, or just beyond, the signal peptides. Subsequently, 64 proteins were predicted by big-PI fungal prediction software (Eisenhaber et al. 2004) to harbor a GPI-lipid anchor, which likely represent surface proteins rather than secreted effectors and were removed from the list of potential secreted proteins, reducing the number of predicted secreted proteins to 553.

The largest group of enzymes among the predicted secreted proteins are similar to enzymes that are active against carbohydrates (37\% of total secreted proteins). Most of those are glycoside hydrolases (approximately half of the enzymes that are active against carbohydrates). P. expansum PEX2 also contains a large number of enzyme families, whose members are known to be involved in the degradation of plant material (Zhao et al., 2014). A total of 21 of the enzymes secreted by PEX2 are involved in the degradation of pectin, such as polysaccharide lyases (PL1, PL3, and PL4), polygalacturonases (GH28), rhamnosidases (GH78), and pectin esterases (CE8, and CE12).

Lignocellulose is a tight complex formed by cellulose, hemicellulose, and lignin, and is the most abundant plant biomass on the planet. In the current study, 40 secreted proteins were identified that are categorized by CAZymes 
as cellulases, xylanases, and hemicellulases (families GH6, GH7, GH10, GH11, GH12, among others). Two putative cutinases (CE5), involved in the degradation of the plant cuticle, were also present among the designated secreted proteins.

\section{Prediction of Potential effectors}

Most bacterial and fungal pathogen effectors are considered to be species or lineage-specific. This premise makes their prediction using universal features and/or functions difficult. Thus far, features such as secretion, differential expression in planta during infection, small size, and large number of cysteines have been used in different computational analyses in identifying putative effectors in fungal genomes (Sperschneider et. al 2015, Gohari et. al 2015, Sonah et. al 2016).

In the current study, all of the indicated features, as well as information available in PHI-database on known effectors were used to increase the likelihood of identifying genes relevant to processes associated with the infection of apples by P. expansum. Evidence of expression in planta was based on RNA-seq data reported by Ballester et al. (2015). This criterion reduced the number of secretome-related genes from 553 to 297 , on the basis that these genes are actively transcribed during infection and rot development on apples. The following strategies were employed to identify putative effectors in the $P$. expansum secretome: first, all small ( $<300$ aa) and cysteinerich (>4) proteins with unknown function were selected; second, proteins showing homology to known effectors and proteins containing PFAM domains found in fungal effectors described in the literature were identified, and third, all proteins with a nuclear localization signal (NLS) were determined. Additionally, proteins that were homologous to gene-products proven to affect the outcome of pathogen-host interactions were identified using BlastP against the PHI database. Concomitantly, to assist in selecting the best effector candidates, the expression level of genes were examined, looking for those that were highly induced in planta (expression level is equal or larger than an average expression level plus two standard errors) (Fig. 1 B). Gene-products having at least two of these effector-characteristics were selected as top effector-candidates (Table 1). Lastly, genes coding cell-wall degrading enzymes were identified and their potential contribution to virulence is further discussed below.

Applying this method, 25 small, cysteine-rich secreted proteins with unknown function were identified. Four of them (PEX2_002470, PEX2_038290, PEX2_056460, PEX2_092040) exhibited a high level of expression in planta. PEX2_056460 was induced during spore germination and the others during apple infection (Table S2). 
Another fifteen effector candidates were selected based on the presence of specific domains (Table S3). PEX2_012920 contains a chitin binding domain, (PF03067), PEX2_053590, PEX2_091440, and PEX2_064530 have a LysM domain (PF01476; IPR018392), PEX2_002570 and PEX2_105000 possess a WSC domain (PF01822.14), and PEX2_046410 has a carbohydrate binding domain (PF02018.12). Another two proteins (PEX2_021580, PEX2_041810) possess a L-like lectin domain (PF03388.8), and PEX2_028650 is annotated as a concanavalin A-like lectin/glucanase containing a peptidase A4 domain (PF01828.12). Two proteins (PEX2_043920, PEX2_092030) were found to have a CEFM cystein-rich fungal effector motif (PF05730), one protein (PEX2_027670) contained a peptidase inhibitor I-9 domain (PF05922.11), one (PEX2_065330) is a cerato platanin (PF07249.7), and one (PEX2_080220) is NPP1-like (PF05630.6). Only three of the designated effector candidates are highly induced during apple infection: PEX2_105000 (WSC-containing), PEX2_080220 (NPP1like), and PEX2_027670 (a sabtilase (peptidase S8) containing a protease inhibitor domain). PEX2_027670 also has an NLS and is homologous to SPM1, which was reported to play an important role in the pathogenicity of Magnaporthe oryzae (Saitoh et. al 2009). Nineteen genes with a putative NLS were identified within the predicted secretome of $P$. expansum (Table S4). The occurrence of both a secretion signal and a NLS in encoded proteins suggests that they may play an active role in the plant nucleus. Three of the NLS-carrying proteins are highly expressed in planta: PEX2_027670 was mentioned above, PEX2_056540, encoding a zinc finger DNA binding protein homologous to RING1 which is involved in the induction of cell death and the regulation of ubiquitination (Lee et. al 2011), and PEX2_084770 translocon-associated protein. A Blast against the PHI database revealed additional four NLS-carrying genes (PEX2_017860, PEX2_076710, PEX2_106730, PEX2_047400) that are homologous to genes reported to be involved in pathogenicity of Fusarium graminearum, M. oryzae, S. sclerotiorum and Salmonella enterica, respectively (Wang et. al 2011, Yi et. al 2009, Li et. al 2012, Sem X, Rhen M 2012). Interestingly, none of these proteins was shown to be active in the host nucleus. PX2_017860 is homologous to one of the 20 essential protein kinases in Fusarium graminearum (Wang et. al 2011), while PEX2_106730 is homologous to a SS-Ggt1 y-glutamyl transpeptidase in S. sclerotiorum that was shown to be involved in glutathione recycling during key developmental stages such as the production of apothecia and appressoria (Li et. al 2012).. PEX2_047400 is homologous to Thioredoxin-1 in Salmonella enterica, which was shown to enhance virulence via the generation of systemic oxidative stress in the host (Sem X, Rhen M 2012). PEX2_076710 is a member of the HSP70 family is homologous to the ER chaperone LHS1 in M. oryzae, and its deletion of resulted in mutants severely impaired in penetration and biotrophic invasion of susceptible rice (Oryza sativa) plants and the induction of the Pi-ta resistance gene-mediated hypersensitive response (Yi et. al 2009). LHS1, however, is not an effector by definition since it is localized in the ER and is responsible for the proper 
processing of secreted effector proteins. Overall, our work demonstrated that Blast against the PHI database revealed 47 gene products that may be relevant to pathogenicity of $P$. expansum on apple fruit (Table S5). This included genes coding for carbohydrate-degrading enzymes, peptidases and lipases, redox proteins (proteins with oxidoreductase activity, chaperones, and proteins involved in signaling, DNA modifications and polyketide synthesis. In addition to the genes already mentioned, (genes with an NLS and others with known effector-domain), there were also 1 three genes that exhibited strong induction during apple infection: PEX2_048400 is a homologue of gas-1 in Fusarium oxysporum where it plays an active role in fungal cell wall biosynthesis and morphogenesis (Caracuel et. al 2005). Additional two genes, PEX2_031340 and PEX2_107230 are homologs to genes coding for pectin-degrading enzymes, Bcpgl (Botrytis cinerea endopolygalacturonase) (ten Have et. al 1998) and pnll from Penicillium digitatum (Lopez-Perez et. al 2015).

The analysis of annotated genes in P. expansum revealed that 102 genes (35\% of the total predictive putative effectors???........) code for cell wall degrading enzymes (Table S3). The majority (73) of the secreted enzymes are carbohydrate degrading enzymes that enable $P$. expansum to breakdown fruit tissue and feed on the complex carbohydrates and other molecules. Some of these enzymes such as xylanases and pectin-degrading enzymes have been demonstrated to be important virulence factors in Verticillium fungicola (Amey et. al 2003), M. oryzae (Nquyen et. al 2011), Botrytis cinerea (Brito et. al 2006, ten Have et. al 1998, Akagi and Stotz 2007, Valette-Collet et. al 2003), Colletotrichum gloeosporioides (Yakoby et. al 2001), and Penicillium digitatum (Lopez-Perez et. al 2015). Five genes coding for pectin-degrading enzymes (PEX2_031340, PEX2_094840, PEX2_110470, PEX2_107230, PEX2_092020) are highly induced during apple infection and decay development caused by $P$. expansum on apples suggesting that they play an important role in pathogenicity and virulence.

Interestingly, another highly expressed gene, PEX2_048400, coding for a transglycosylase with a cysteine-rich, carbohydrate-binding domain was found in the predicted secretome. Members of this family are usually GPIanchored plasma membrane enzymes that elongate and remodel the $\beta-1,3$ glucan of the cell wall, thus playing an active role in fungal cell wall biosynthesis and morphogenesis. An essential role for this type of enzyme during infection of tomato by $F$. oxysporum was reported by Caracuel et. al (2005). F. oxysporum mutants lacking a functional copy of gas 1 exhibited a restricted-growth phenotype on solid substrates, which was indicative of structural alterations in the cell wall. The mutants also showed an increased resistance to cell wall-degrading enzymes and transcriptional activation of genes involved in cell wall biogenesis. In addition, the $\Delta g a s I$ strains exhibited significantly reduced levels of virulence on tomato plants, providing the first evidence for an essential role of $\beta$-1,3-glucanosyltransferase in the fungal pathogenesis on plants (Caracuel et. al. 2005). Further analysis of 
catabolic enzymes in $P$. expansum secretome revealed 18 peptidases, one cutinase, one lipase, one lysophospholipase, four enzymes that break down aromatic compounds, and four catabolic enzymes with no specific substrate (Table...S6).

Our analysis revealed four proteolytic enzymes that are strongly induced during apple infection: serine-protease PEX2_106910, asparginyl-peptidase PEX2_039390, aspartic-protease PEX2_009280, and sabstilin-like serineprotease PEX2_027670. Although, a homologue of PEX2_009280 was shown not to affect the pathogenicity of Leptosphaeria maculans on canola (Idnurm et. al 2003), it does not rule out an important functional role for this enzyme in virulence in $P$. expansum, since the two pathogens exhibit very different modes of infection. Catabolic enzymes that identified as homologues of proteins affecting pathogenicity are an amidase (PEX2_107240), an aspartic protease (PEX2_085170), and a phospholipase (PEX2_099670) homologous to Candida albicans effectors, a methalo-protease (PEX2_089670) homologous to an effector from the barley powdery mildew fungus Blumeria graminis f. sp. Hordei (Pliego et al. 2013), and lipase (PEX2_019000) showing homology to autophagylike lipase FgATG15 in F. graminearum, and its disruption was shown to severely attenuate wheat head infection (Nguyen et al. 2011). Moreover, three catabolic enzymes with a predicted NLS were detected: sabtilase (peptidase S8) (PEX2_027670), an abhydrolase (PEX2_061790) and an alginate lyase (PEX2_021730).

As was previously mentioned, gene-products having at least two of the five effector-characteristics e.g. 1) small, cysteine-rich - not annotated proteins, 2) proteins highly induced in planta, 3) proteins with NLS signal, 4) proteins that belong to known effector families, 5) proteins homologous to gene-products proven to affect the outcome of pathogen-host interactions, were selected as top effector-candidates. Remarkably, among the top effectors list a proteolytic enzyme peptidase S8 (PEX2_027670), was found to have four effector-characteristics described in pipeline. PEX2_027670 carry NLS, a pepitidase inhibitor I9 domain, and is highly expressed in planta. Moreover, PEX2_027670 is a homologous to a sabstilin-like serine-protease (SPM1) in M. oryzae, functioning in autophagy and required for pathogenicity (Saitoh et. al 2009). Targeted disruption of SPM1 was shown to affect a variety of infection processes, including spore germination, appressorium formation, host invasion, and post invasive growth. Moreover, AG1IA_07795 gene carrying peptidase inhibitor I9 and peptidase S8 domains was identified as putative effector in Rhizoctonia solani, aother major fungal pathogen of rice. AG1IA_07795 was shown to cause cell death phenotypes upon inoculation into rice, maize and soybean leaves (Zheng et al. 2013).

Based on these findings, we decided to further characterize PEX2_027670 and examine its contribution to $P$. expansum virulence on apples. PEX2_027670 was termed as PePRT henceforth. 


\section{Characterization of $\mathrm{PePRT}$}

PePRT is coding for 496 aa protein. At the $\mathrm{N}$-terminal of the protein, 16 aa are predicted by SignalP as signal peptide and TargetP analysis showed that PePRT is secreted protein. PePRT showed a high amino acid sequence similarity with various fungal vacuolar serine proteases (Table 2, Fig. 2A) as well as with Proteinase B from Saccharomyces cerevisiae.

Analysis of PePRT using InterPro show that it belongs to Peptidase S8, subtilisin-related family (IPR015500). S8 family of subtilisins is heterogeneous group of proteins with broad taxonomic distribution. Among them numerous secreted alkaline and serine proteases from various fungi as well as vacuolar protease B (cerevisin) from $S$. cerevisiae. The members of this family share a characteristic catalytic triad peptide (Asp, His and Ser) (Siezen and Leunissen 1997). PePRT was found to carry Inhibitor_I9 domain (PF05922) as well as Peptidase_S8 domain (PF00082) (Fig. 2B). The majority of the subtilases are synthesized as pre-proenzymes, subsequently translocated over a cell membrane via the pre-peptide (or signal peptide), and finally activated by cleavage of the pro-peptide. Inhibitor_I9 is propeptide domain at the $\mathrm{N}$ terminus of peptidases belonging to MEROPS family S8A, which is responsible for the modulation of folding and activity of the pro-enzyme. (Li et al. 1995) [PMID: 7559646].

The expression levels of PePRT in PEX2 during apple infection and in vitro growth were examined using qRTPCR. PePRT was found to be expressed in spores and during infection and decay development on fruit as well as during fungal growth in vitro. Effectors of various plant pathogen were shown to be expressed solely during host colonization (Motteram et al. 2009, Arenas et al. 2010, Dallal Bashi et al. 2010, Santhanam et al. 2013), however, putative LysM effectors from $P$. expansum were shown to express both on apples and during in vitro growth (Levin et al. 2017). Notably, relatively high levels of PePRT induction (4.5 fold increase) was measured at $24 \mathrm{~h}$ after inoculation of fruit wounds (Fig.3) indicating its possible involvement in the early infection processes in which the $P$. expansum mycellium starts to invade fruit tissue and establish infection. High levels of expression of effectors during early stages of infection prior to the appearance of symptoms were reported in several plant pathogens. For example, expression levels of NEP1-like, SnTox and LysM effectors from various fungi were the highest slightly before or corresponding with appearance of disease symptoms (Van Der Does et al. 2008; Santhanam et al. 2013, Dallal Bashi et al. 2010, Arenas et al. 2010, Motteram et al. 2009, Liu et al. 2012, Bolton et al. 2008, Marshal et al. 2011).

\section{Functional analysis of PePRT}


To further investigate the role of PePRT in P. expansum pathogenicity and virulence, knockout mutants in PEX2 were constructed using Agrobacterium tumefaciens-mediated transformation [41]. Figure S1A diagrammatically illustrates the respective wild-type and gene-disrupted loci. Proper T-DNA integration was checked by PCR (Fig. S1B) using locus-specific primers for i) the hygromycin resistance cassette which is present in both null mutants and ectopic transformants, but absent in the WT and the target gene, and primers for the target genes, which are absent in the null mutants and present in the WT and ectopic mutants, and ii) correct insertion of the T-DNA between the promoter and the terminator of the target gene. To this end, PCR reaction was done using one primer from the hygromycin resistance cassette and another primer located in the genome approximately $150 \mathrm{bp}$ upstream or downstream of the promoter or terminator respectively. In this case only in null mutants with correct insertion specific PCR product was obtained (Fig. S1B). Knockout mutant, containing a single T-DNA integration, was selected for further testing, along with an ectopic transformant possessing the wild-type (WT) gene.

peprt null mutants exhibited slightly lower rate of radial growth compared to the WT strain and the ectopic mutant (Fig. 4A). Similarly, the disruption genes coding for proteins homologous to PePRT in V. dahliae (Vd991) and Aspergillus fumigatus showed reduction in the growth rate (He et al. 2015, Reichard et al. 2000). Moreover, in the current work, the colony morphology of peprt null mutant was different from that of the WT and the ectopic mutant (Fig. 4B). The mycelium of peprt mutant appeared less dense and a production of brown metabolite/s was observed in mutant cultures growing in PDA plates (Fig. 4B). In addition to lower level of mycellium density, color change and slow growth rate in vitro, there was significant decrease in formation of conidia (Fig. 5A). Formation of conidia in the mutant was found to be less than $0.2 \%$ in comparison to the WT strain (Fig. 5B). SEM image of 10 days colony showed severe disruption of the spore production in the mutant (Fig. 6A). While the mycelium in the WT strain was heavily covered by conidiophores carrying long chains of spores, the, mutant cultures had much lower number of conidiophores carrying short spores chains (Fig. 6B). the hyphae of the mutant was observed to be significantly thicker, with no visible vacuoles as compared to the WT (Fig. 7A). To further visualize cell content we used FM dye that specifically label membrane-bound organelles. In contrast to WT strain that has large distinctive vacuoles, the hyphal content of peprt mutantcells was strongly stained with FM implying it has numerous small vesicles (Fig. 7B). This could be due to impaired autophagy or endocytosis. In the work done with SpmI coding vacuolar-localized protease, a gene homologous to PePRT in $M$. oryzae, spherical vacuoles were developed in both the wild type and the spml mutant, however while WT vacuoles were transparent and contained few detectable particles, granular particles were always observed in putative vacuoles in the spm 1 mutant. These findings suggested that vacuolar components were not degraded in the mutant, resulting in the accumulation of granular structures. Surprisingly, internalization of FM4-64 was not observed in conidia of the spm1 mutant (Saitoh 
et al. 2009).To further, examine the effect of PePRT deletion on the germination process, visual examination of germinating spores of both the WT, mutant and ectopic strains were performed using light microscopy. Following $18 \mathrm{~h}$ incubation on $1.5 \%$ agar plates, there was no significant difference in the percent germination of spores in WT and mutant strains (Fig. 8A) indicating that PePRT deletion did not have apparent effect on the germination process. However, germinating spores in the mutant were much larger and germ-tubes thicker and longer than those of WT and ectopic mutant (Fig. 8B). The average germ-tubes length of in mutant was more the two-fold of that of the WT or ectopic mutant (Fig. 8C). These findings together with the fact that peprt mutant hyphae appear to be thicker than that of the WT suggest PePRT deletion had an effect on cell-growth.

In general, disruption of PePRT gene had pleiotropic effects manifested by altered mycelial growth and morphology. Secretion of brown color metabolites, and reduced sporulation. Consistent with this, deletion of Proteinase B homologous genes in $V$. dahliae (Vd991) resulted in great decrease in the conidia production, significantly reduced growth rate and reduction in virulence compared to the wild type (He et al. 2015). Targeted disruption of the cellular serine proteinase ALP2-encoding gene in Aspergilus fumigatus resulted in a slightly decreased rate of vegetative growth and in a more than $80 \%$ reduction of sporulation in the alp2-negative mutants, correlated with an approximately $50 \%$ reduction of the median diameter of conidiophore vesicles (Reichard et al. 2000).

Disruption of the vacuolar structure in peprt mutant together with high homology level of PePRT to autophagy related proteins such as vacuolar protease B from S. cerevisiae and SPM1 from M. oryzae suggest its possible role in autophagy in P. expansum. The increased pigmentation of the mutant cultures in PDA plates and marked reduction in sporulation are consistent with the findings that autophagy in filamentous fungi is involved in cellular processes such as cell differentiation, pathogenicity and secondary metabolite production (Voigt and Poggeler 2013) For instance, atg 1 deletion mutants of $P$. chrysogenum that are impaired in autophagy and sporulation have significantly increased penicillin production (Bartoszewska et al. 2011b). Furthermore, the increase in the size of peprt mutant hyphae and its germinating spores compared to that of the WT could provide additional evidence for impaired autophagy since induced autophagy in drosophila cells was shown to reduce cell size (Scott at al. 2007). In cells unable to undergo autophagy, starvation induced cell size reduction was significantly inhibited (Hosokawa et al. 2006). In this response, mycelium of A. oryzae mutant $\Delta$ Aoatg8-1-1 defective in autophagy was shown to be thicker compared to WT (Kikuma et al. 2006)

The fact that PePRT carry signal peptide and is predicted to be secreted is not in a contradiction with its possible role in the vacuole. An examination of the derived amino acid sequences of secreted and vacuolar plant proteins shows that all have an amino terminal domain with the properties of a eukaryotic signal sequence, namely, there 
are no vacuole-specific and secretion-specific signal peptides (Chrispeels 1991). In this regard, Reichard et aI. (2000) claimed that, there is a possibility that cellular serine proteinase ALP2 of A. fumigatus is a natural component not just of the vacuole but also of the cell wall. Moreover, overexpression of vacuolar proteinase PrA in S. cerevisiae as well as overexpression of the corresponding enzyme PEP2 of A. fumigatus in the yeast Pichia pastoris, led to the occurrence of the enzymes in the fungal culture supernatants (Rothman et aI., 1986).

To examine the effect of PePRT deletion on pathogenicity, 'Golden Delicious' apples were inoculated with spores suspension of WT, ectopic and null mutants, and rate of infection and lesion development was recorded starting at 3 dpi. No significant differences of the infection incidence were found (data not shown). However, as presented in Fig. 9, lesion diameter of peprt mutant throughout the incubation period was approximately $20 \%$ lower than that of the WT and the ectopic mutants. The attenuation of the virulence of peprt could be a consequence of impaired autophagy as was reported in another pathogen-plant pathosystems (Voigt and Poggeler 2013). For instance, disruption of Smpl, a gene homologous to PePRT in M. oryzae, Saitoh et al. (2009) observed reduction in disease symptoms on seedlings of rice and barley inoculated with the spml mutant as compared with those inoculated with the wild-type strain at 7 days after inoculation. However, the possibility that PePRT is secreted and has direct function in host-pathogen interaction could not be ruled out. In fact, AG1IA_07795 gene carrying peptidase inhibitor 19 and peptidase S8 from $R$. solani was shown to cause cell death phenotypes upon inoculation into rice, maize and soybean leaves (Zheng et al. 2013).

\section{Conclusions}


Table 1: Top effector-candidates.

Gene name size \# Cys

annotation

NLS

PHI

High expression (hpi)

\begin{tabular}{|c|c|c|c|c|c|c|}
\hline PEX2_002470 & 273 & 5 & & & & 48,72 \\
\hline PEX2_038290 & 138 & 10 & & & & 48,72 \\
\hline PEX2_056460 & 176 & 4 & & & & spores \\
\hline PEX2_092040 & 297 & 4 & & & & 24 \\
\hline PEX2_105000 & 289 & 9 & WSC & & & 72 \\
\hline PEX2_080220 & 240 & 5 & NPP1 & & $\begin{array}{c}2342 \\
\text { B. elliptica }\end{array}$ & $24,48,72$ \\
\hline PEX2_065330 & 152 & 4 & Cerato-platanin & & $\begin{array}{c}3164 \\
\text { T. virens }\end{array}$ & \\
\hline PEX2_027670 & 496 & 3 & $\begin{array}{l}\text { Inhibitor_I9; } \\
\text { Peptidase_S8 }\end{array}$ & V & $\begin{array}{c}2117 \\
\text { M. oryzae }\end{array}$ & 48,72 \\
\hline PEX2_056540 & 515 & 9 & Zinc finger, RING-type & V & $\begin{array}{c}2401 \\
\text { X. campestris }\end{array}$ & 24 \\
\hline PEX2_017860 & 1138 & 13 & $\begin{array}{l}\text { Pkinase; } \\
\text { Ribonuclease_2-5A }\end{array}$ & V & $\begin{array}{c}1225 \\
\text { G. zeae }\end{array}$ & \\
\hline PEX2_076710 & 989 & 2 & HSP70 & V & $\begin{array}{c}2058 \\
\text { M. oryzae }\end{array}$ & \\
\hline PEX2_106730 & 1492 & 9 & DNA glycosylase & V & $\begin{array}{c}2411 \\
\text { S. sclerotiorum }\end{array}$ & \\
\hline PEX2_047400 & 492 & 6 & Thioredoxin & V & $\begin{array}{c}2644 \\
\text { S.enterica }\end{array}$ & \\
\hline
\end{tabular}




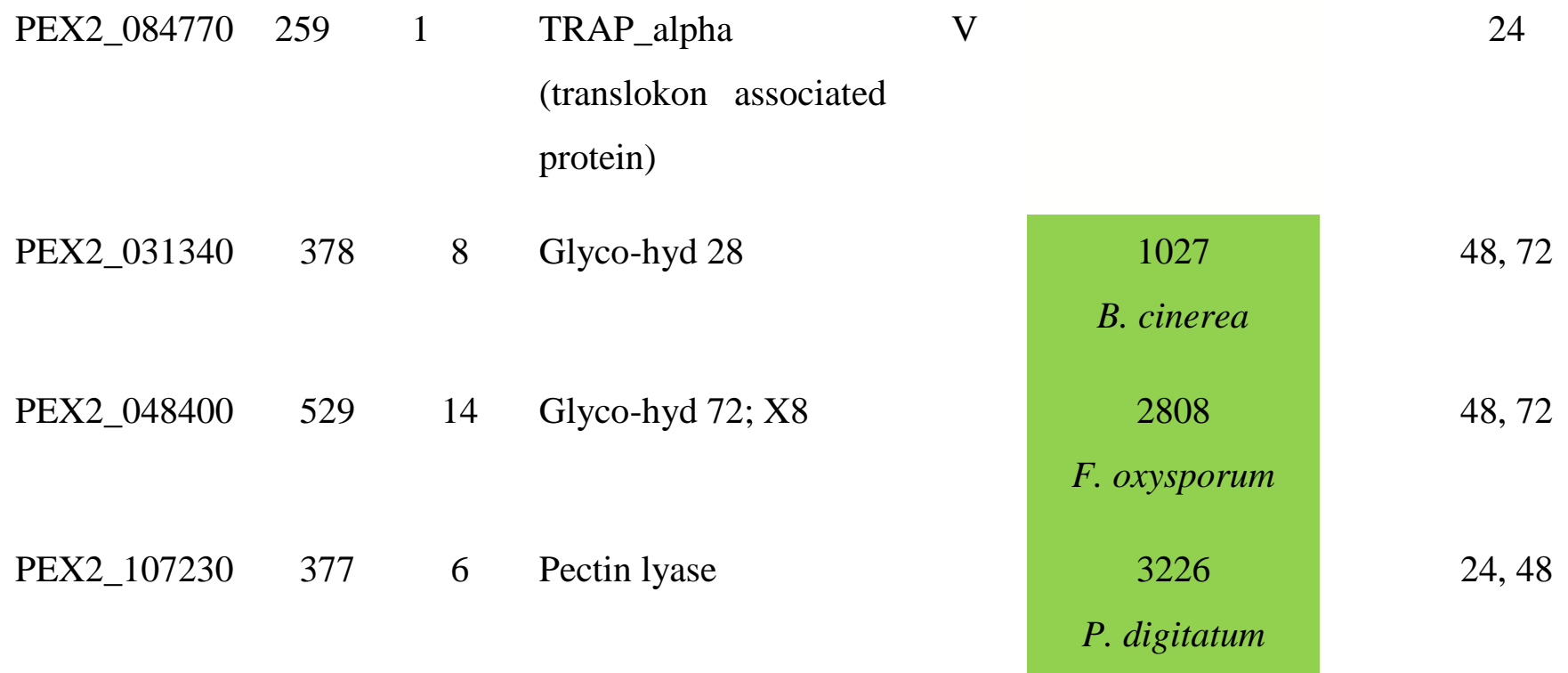

(PHI data: white - not available, grey - no effect on pathogenicity, yellow - mixed output, green - reduced pathogenicity, purple - lethal) 
Table 2: Fungal and yeast vacuolar serine protease showing high homology to PePRT

\begin{tabular}{|c|c|c|c|c|c|}
\hline Genus & Species & accession \# & Annoatation & $\begin{array}{l}\text { Function } \\
\text { charachterization }\end{array}$ & $\begin{array}{l}\% \text { dentity } \\
\text { to PePRT } \\
\text { (Penicillium } \\
\text { expansum) }\end{array}$ \\
\hline \multirow[t]{2}{*}{ Penicillium } & P. chrysogenum & AAG44693.2 & vacuolar serine protease & none & 93 \\
\hline & P. oxalicum & AAG44478.1 & vacuolar serine protease & none & 79 \\
\hline Aspargilus & A. fumigatus & CAA73782.1 & cellular serine proteinase & Reichard et al. 2000 & 76 \\
\hline Cladosporium & C. herbarum & AAX14379.1 & vacuolar serine protease & none & 67 \\
\hline Verticillium & V. dahliae & AGC74272.1 & Cerevisin & He et al. 2015 & 67 \\
\hline Magnaporthe & M. oryzae & EHA49897.1 & subtilisin-like proteinase & Saitoh et al. 2009 & 65 \\
\hline \multirow[t]{6}{*}{ Saccharomyces } & S. cerevisiae & GAX70862.1 & Proteinase B & Moehle et al. 1987 & 53 \\
\hline & & & & Moehle et al. 1988 & \\
\hline & & & & Moehle et al. 1989 & \\
\hline & & & & Hirsch et al. 1992 & \\
\hline & & & & Jones and Murdock & \\
\hline & & & & 1994 & \\
\hline
\end{tabular}




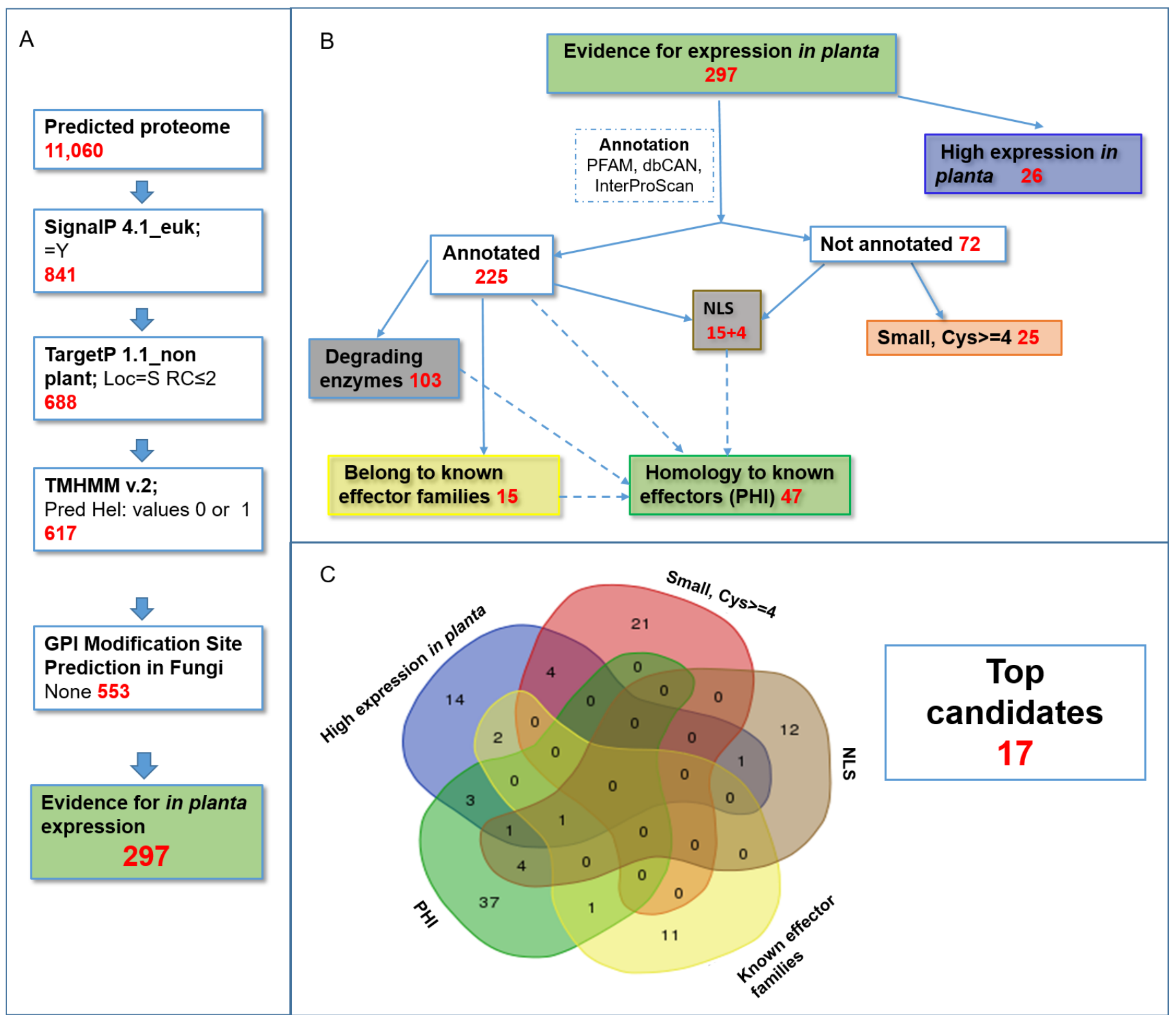

Figure 1: Secretome (A) and effectors (B) prediction pipelines of Penicillium expansum. Painted rectangles indicate potential effector-groups. Venn diagram representation of genes shared between potential effector-groups and considered as top effector-candidates $(\mathrm{C})$. 
A

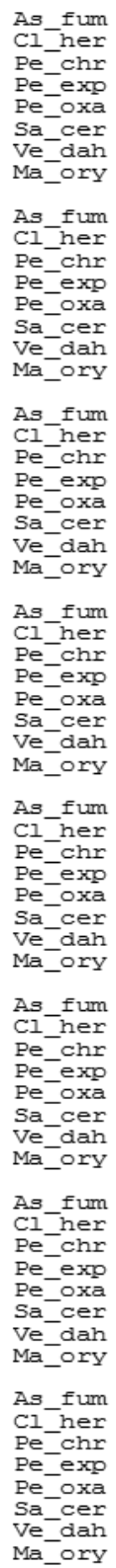

---------------MKGYLSISI LPLIVAASPVVVDS IHNGAAP ILSSMNAKEVP 41 MRGALAGLSIATLATASPVLVNS IHNDAAPIISASNAKEIA 41 MKGF LSLTLLPLLVAA SPVAVNS IHNDAAP ILSSMTSKDIP 41 $\begin{array}{lll}- & \end{array}$ PHHKGGCHENKVEEKKVKGKKVKGKKHHEKTLEKGRHHNRLAPLVSTAQFNPDA ISKI I P 18 $\begin{array}{ll}\text { MRVIASAVAVAAVVSAT PS FSSET IHRDAAPILSSSNAEAIP } & 42 \\ \text {-MKSVILI SLAACAVAAPTAGVET IHDGAAP ILSSSNAEAIP } & 41\end{array}$ DSYIVVFKKHVNA-ESAAAHHSW----VQDIHSAQNERV-ELRKRSLFGFGEEAYLGLKN 95 DNYMII DSYIVVFKKHVD-SSA.SAHQSW----LQEVHTAHTGRM-ELKKRSLFGFDFEAFMGLKH 95 DSYIVTHM NRYI IVEIRGAPOE NRYI IVFKRGAPQE I DFHKENVQQAQLQSVENLSAEDAF FISTKDTSLSTSEAGGIQDS 240 \begin{tabular}{ll|l} 
NAYI IKF KKHVDHKSAADHOMWI----QKVHGE REDERL-ELRKRGL FDSVNDAFT GLKH & 96
\end{tabular}

TFDIAGS LVGYSGHFHEDVIE QVRKH PDVEYIEKDSEVHTMEDPTV------------EK 143 TYNTAGGTMGYA GHFDFDVIEOIRRHPDVE TFHIAGSLLGYAGH FHEDVIEQIRRH PDVDYIEKDSEVRTMSEGSV----------EK 143 TFOIAGSITGYAGHFHEDVIEQIRRH PDVEYIEKDSEVRTMTDGTV----0-----0-EK 143 TF QIAGSLTGYAGH FHEDVIEQIRRH PDVEYIEKDSEVRTMTDGTV------------EK 143 FNIDNLFSGYIGYFTQEIVDL IRQNPLVDFVERDS IVEATEFDTQNS------------- 287 TYTLG-GFL GYSGH FDEAT IE EVRKHADVE FVE KDSIVHTMVPVQTEAQTEDKCDGEVEK 156 TYNVGSGFL GYA GH FDEET IE KVRRH PDVEAIERDTIVHTMRYEEVKKDECN PDI---EK 153

SAPWGLARISHRDSLSFGT FNKYLYASEGGEGVDAYTIDTGINVDHVDFEGRAQWGKTIP 203 NAPWGLARI SHRDSLS FGT FNKYLYTEDGGEGVDVYVVDTGTNVDHVDFEGRA.SWGKTI P 205 NAPW GLARI SHRESLSFGNFNKY LYAEEGGEGVDAYVIDTGANVKHVDF EGRANWGKTIP 203 NAPWGLARI SHRESLS FGNFNKYLYAEEGGEGVDAYVIDTGTNTKHVDFEGRATWGKTI P 203 NAPWGLARI SHRDSLS FGS FNKY LYAEDGGEGVDAYVIDTGTNVDHVDFEGRASWGKTIP 202 -APWGLARI SHRERLNLGS FNKY LYDDDAGRGVTSYVIDTGVNINHKDFEKRAIWGKTIP 346 SAPWGLARVSHRESLNFGNYNKYLFADNAGEGVDAYI IDTGTNVDHVDFEGRAKWGKTIP 216 GAPWGLSRVSHRESLSFSTYNKYLYSAEGGEGVDAYVIDTGTNIDHVDFEGRAHWGKTIP 213

TDDEDADGNGHGTHCSGTIAGRKYGVAKKANLYAVKVLRSSGSGTMSDVVAGVEWAVKSH 263 QGDADEDGNGHGTHCSGTVAGKKYGVAKKAHVKAVKVLRSNGSGSMSDVVKGVEYAAESH 265 QGDADEDGNGHGTHCSGTIAGKKFGVAKKANVYAVKVLRSNGSGTMSDVVKGVEWAAEAH 263 QGDADEDGNGHGTHCSGTIAGKKFGVAKKANVYAVKVLRSNGSGTMSDVVKGVEWAAEAH 263 QGDQDVDGNGHGTHCSGTI AGKKYGVAKKANVYAVKVLRSNGSGTMSDVVKGVEWAAEAH 262 LNDEDLDGNGHGTHCAGTIASKHYGVAKNANVVAVKVLRSNGSGTMSDVVKGVEYAAKAH 406

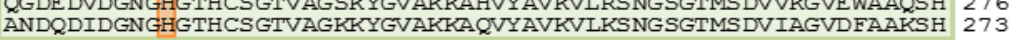

LKKVKDAKDGKIKGFKGSVANMSLGGGKSRTLEAAVNAGVEAGLHFAVAAGNDNADACNY 323 LE OVSIT KKGKRKG FKGST ANMS IGGGKSP ILDKAVNAAVDAGIH FAVAAGNDNADSCNY 325 IKKSKKGDKK----FKGSVANMS IGGGSSRTLDI.AVNAAVDAGIHFAVAAGNDNADACNY 319

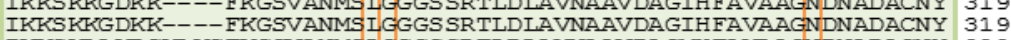
IKKSKAAKDGKAKG FKGSVANMSIGGGSSRTLDI_AVNAAVDAGMH FAVAAGNDNADACNY 322 QKEAQEKKKG ----FKGSTANMS IGGGKSPAIDLAVNAAVEAGIHFAVAAGNENQDACNT 462 LAVIVINM IGGGKTTALDRVVDAAVEAGIH FAVAAGNDI KAQVSAAKD GKR KG FKGSVANMS LGGGKTT LLDAAVNAAVDAGIHFAVAAGNDNADACNY

SPAAAENPITVGASTLQDERAYF SNYGKCTDIFAPGLNILSTWIGSKHAVNT ISGT SMAS 383 SPAAAENAVTVGASTLADERAYF SNYGKCNDIFAPGLNIQSTWIGSKYAVNT ISGT SMAS 385 SPAAAEKAITVGASTLADERAYF SNYGKCTDIFAPGLNILSTWVGSDHATNT IS GT SMAS 379 SPAAAEKAVTVGASTLTDSRAYF SNYGKCTDIFAPGLNILSTWVGSE HATNT IS GT SMAS 379 SPAAAEKAVTVGASTLADERAYF SNYGKCTDIFAPGLNILSTWIGSKYAVNT IS GT SMAS 382 SPAAAAOAVTVGATEIGDARSYF SNYGKCTDIFAPGTNIISTWIGSKYATNT TSGTSMAS 39 SPAAAAKAVTVGASALDDSRA YF SNWGKCT DIFAPGLN IQSTWIGSKTAINT ISGT SMAS 393

PH IAGLLAYFVSLQPSKDSA---FAVDELTPKKLKKDI IA IATQGALTDIPSDT PNLLAW 440 Q PH IAGLLAYYVSL.APAKDSA---YAVADVTPKQLKAAALISVATEGTLTDIPSDT PNLI.AW 436 PHIAGLLAYYVSLAPAKDSA---YAVADVTPKQLKAALINVATQGALTDIPSDT PNLLAW 436 PHIAGLLAYYVSLQPASDSA---YAVEE ITPKKLKDALITIATSGALSDIPSDT PNLIAW 439 PHVAGLLTYFLSLQPGSDSEFFELGQDSLT PQQLKKKLIHYSTKDILFDIPEDT PNVLIY 58 PH ICGLLAYYLSLQPATDSE---YSVAP ITPKKLKANLIAVGTIGALSGIPSDT PNILAW 453 PHIAGLLAYYLSLQPASDSE---YSLAT ITPEKLKADLIKVGTVGILTDIPKDT PNVLAW 450

$\mathrm{B}$
D $\mathrm{H}$
$\mathrm{LG} \widehat{\mathrm{N}}$

SS

Inhibitor_19

Peptidase_S8

Figure 2: Multiple alignment of PePRT with fungal vacuolar serine proteases and proteinase B from $S$. cerevisiae (A) and diagrammatic representation of its structure. Purple rectangle - signal peptide, orange lines mark amino acids from the active sight. Amino acids marked by orange flags are in the catalytic triad. 


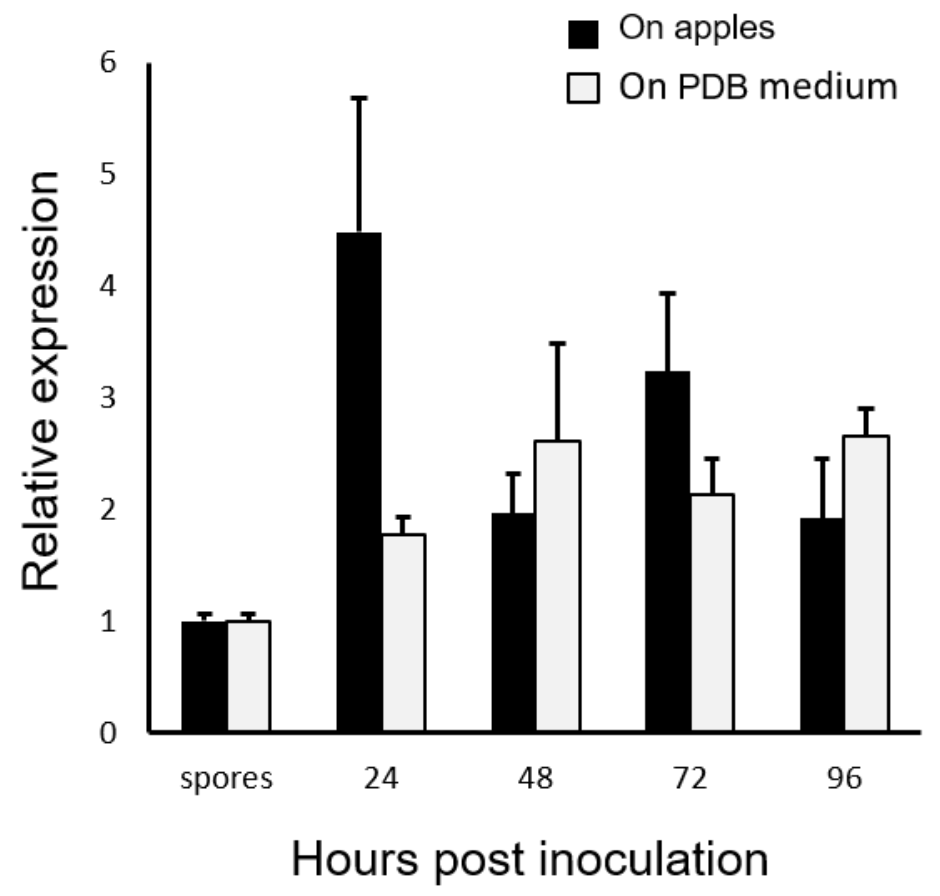

Figure 3: Relative expression of $P e P R T$ in vitro and during apple infection. 


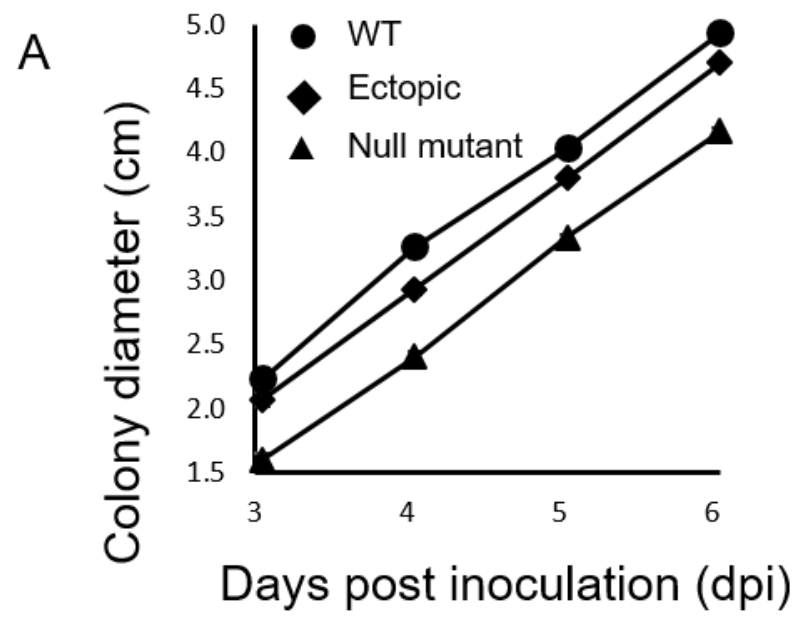

B

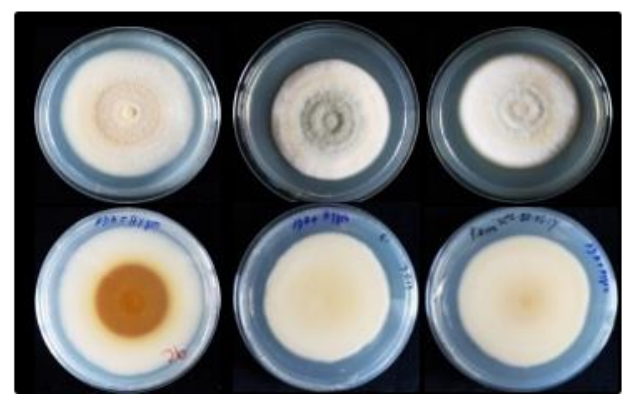

Figure 4. Radial growth (A) and colony morphology at 7 dpi (B) on PDA medium of the wild type, ectopic mutant, and knockout mutant of PePrt in Penicillium expansum. Radial growth results are an average of three independent measurements. Bars indicate standard error. 
A
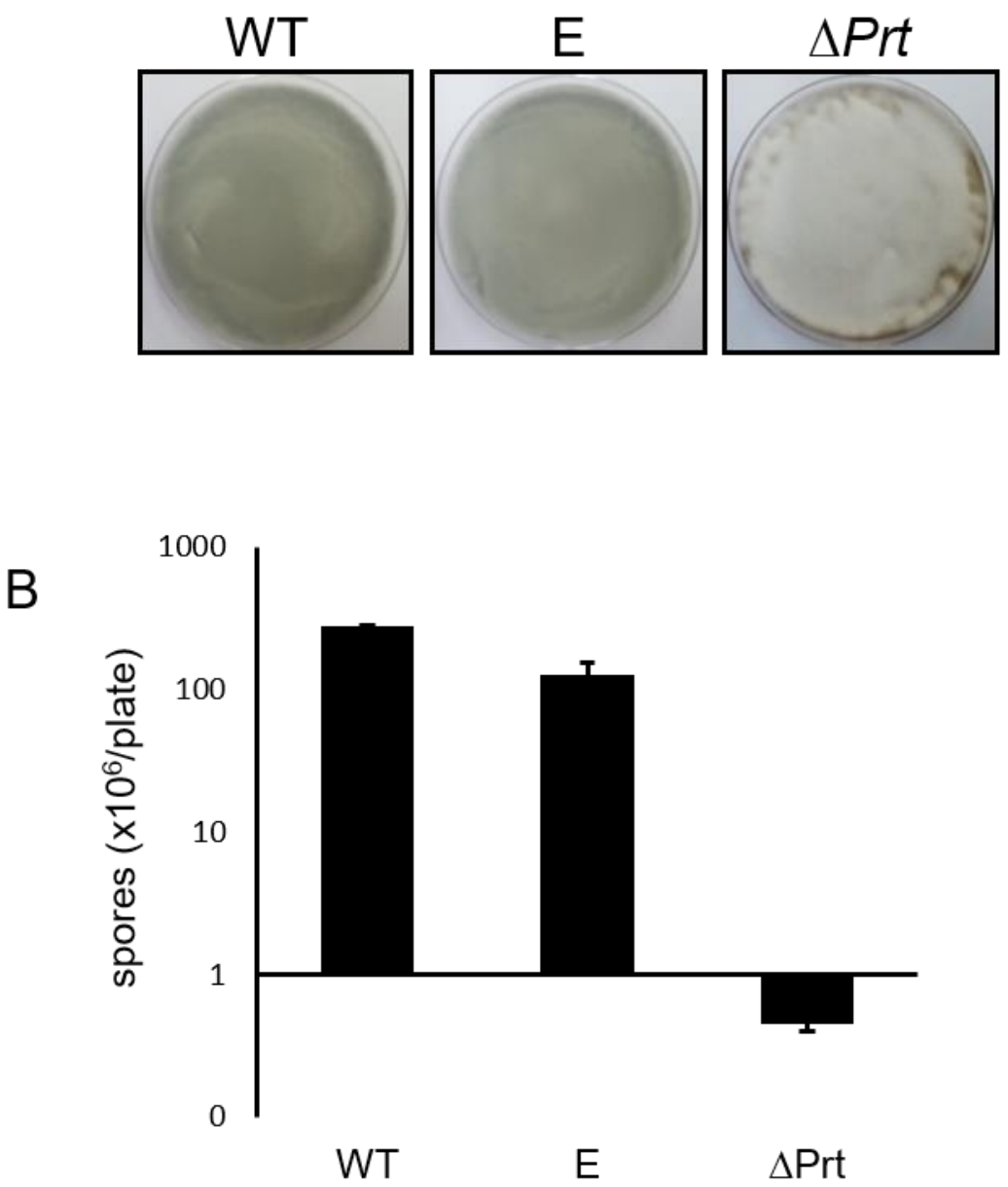

Figure 5: Effect of PePRT target deletion on spore production. Color change of the mature colonies (A), spore production (B) of PEX2 (WT), ectopics (E) and mutants of PePrt. Sporulation was calculated after 11 days growth. Results are an average of three independent measurements. Bars indicate standard error. 
WT
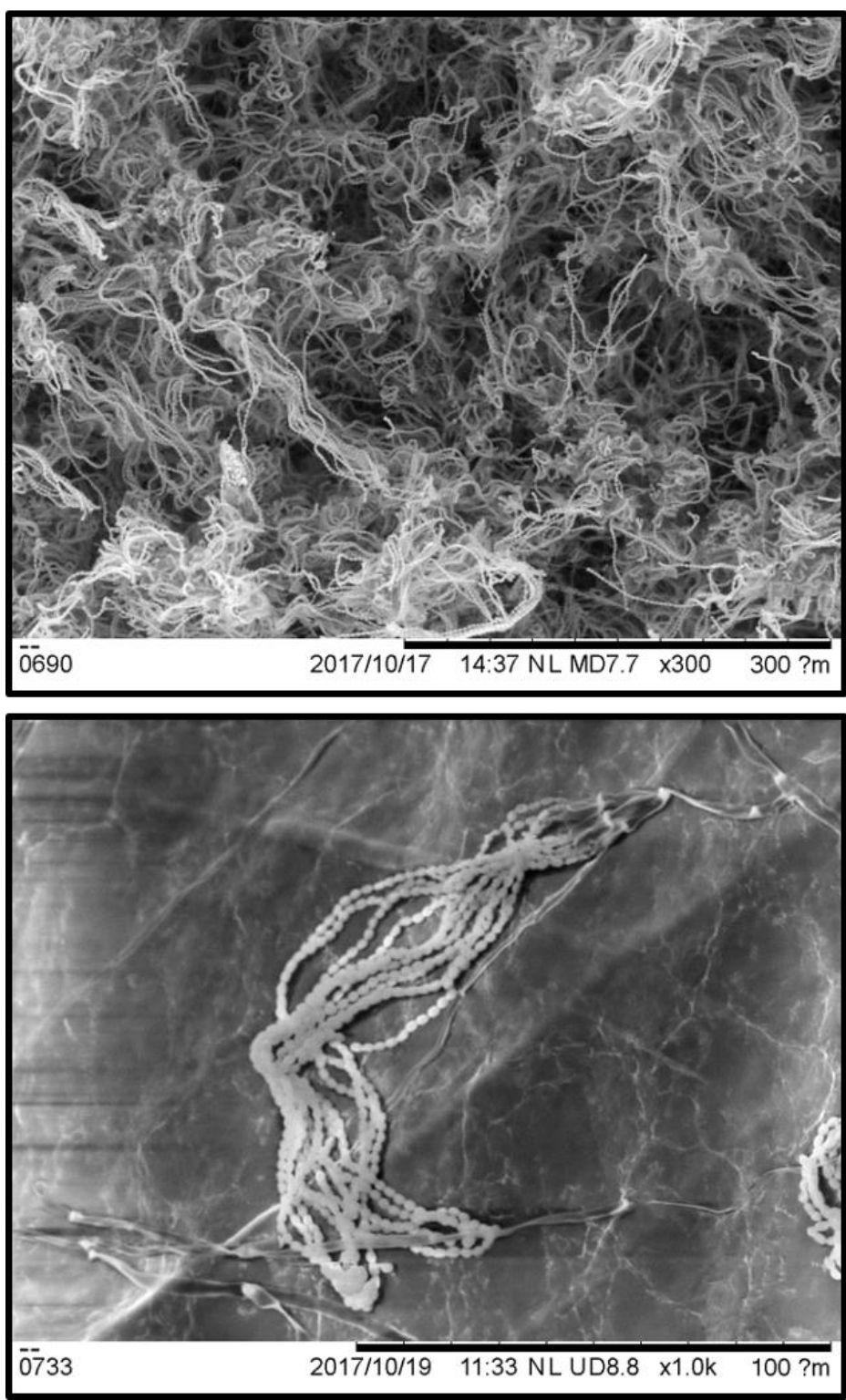

$\Delta P e P r t$
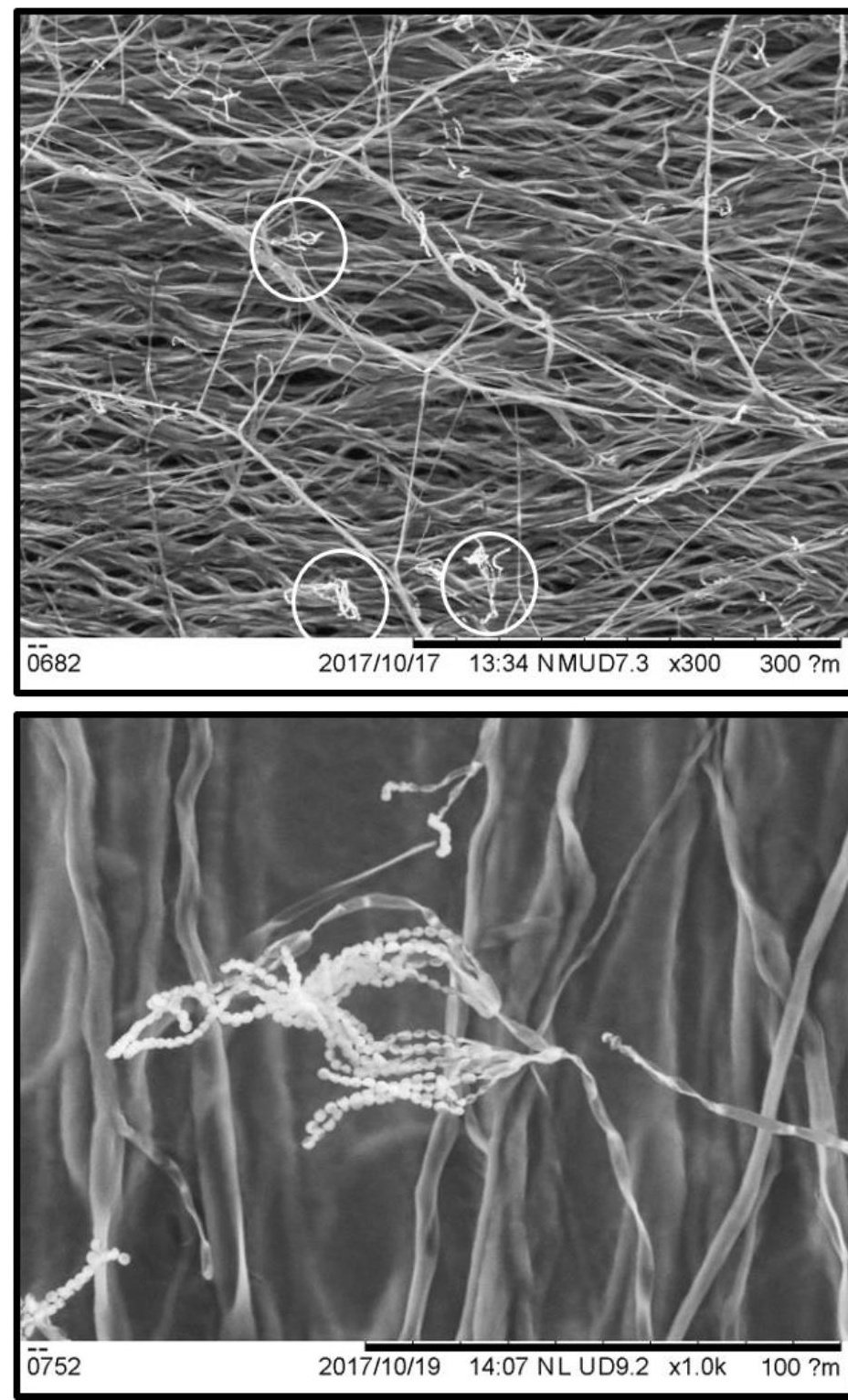

Figure 6: Scanning electron microscopy image of 10 days old colony grown on PDA plates. Conidiophores of PePRT mutant are marked by the white circles in the X300 magnification. 
A
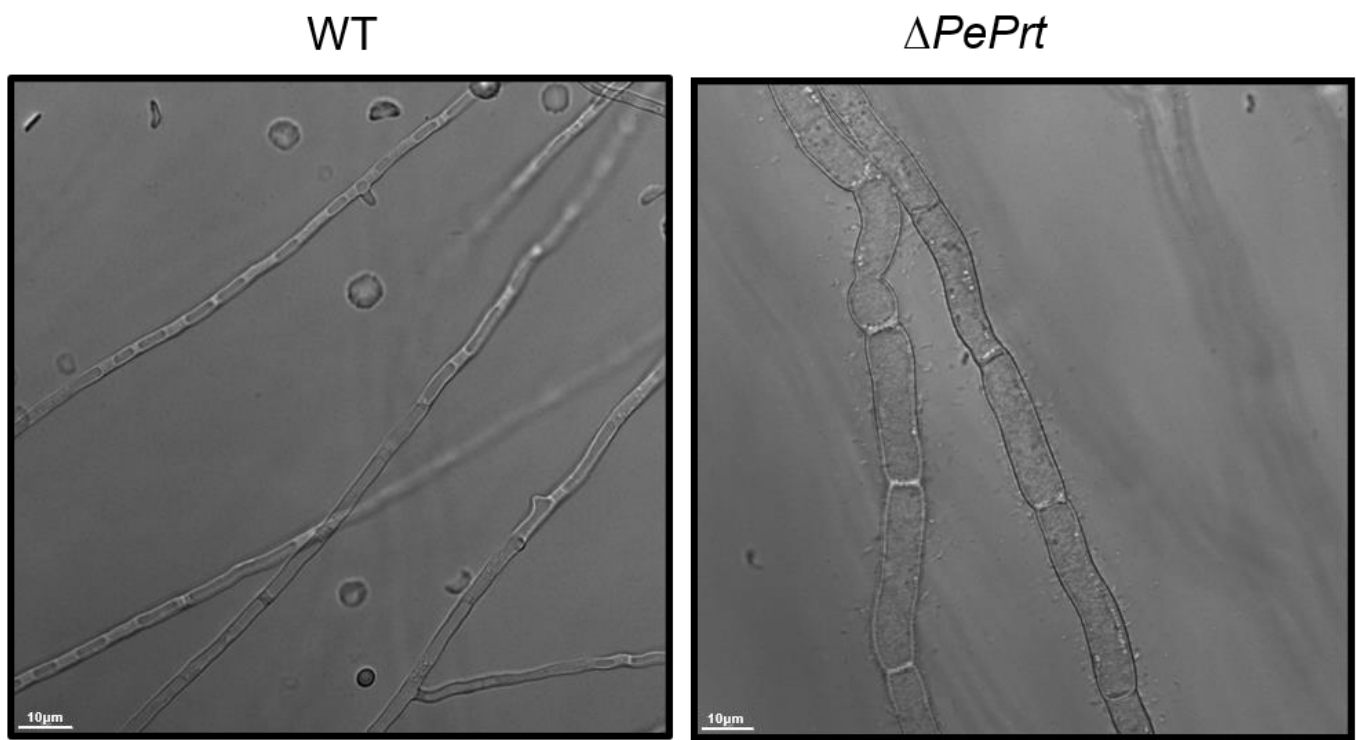

B
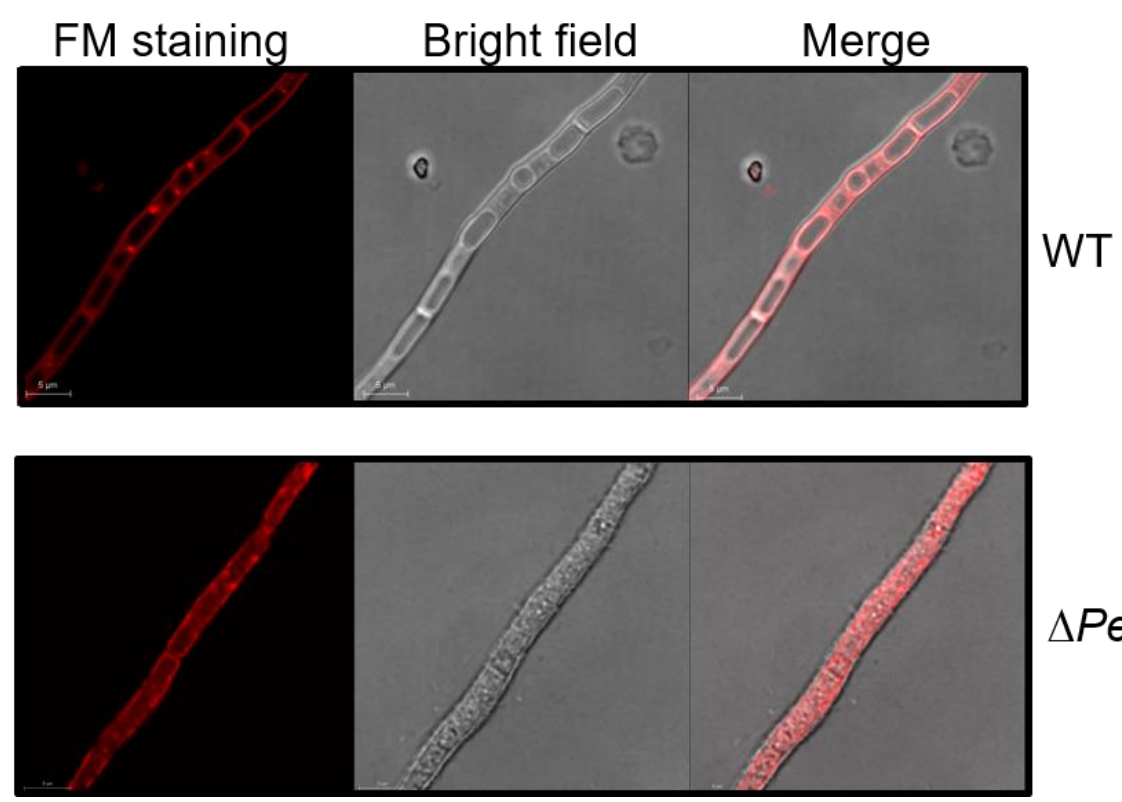

$\Delta P e P r t$

Figure 7: Confocal microscopy image (A) and staining of the vacuole membrane by FM4-64 (B) of one-week old hyphae. 


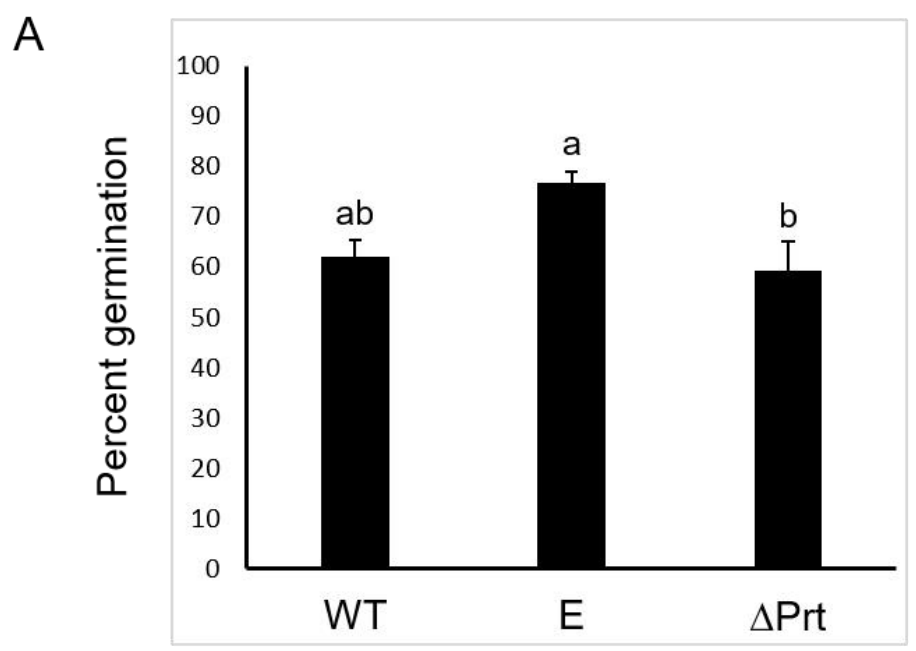

B

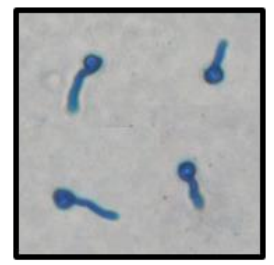

WT

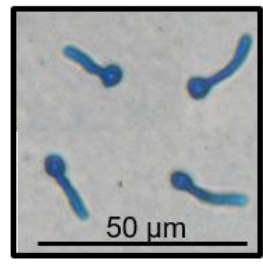

$\mathrm{E}$

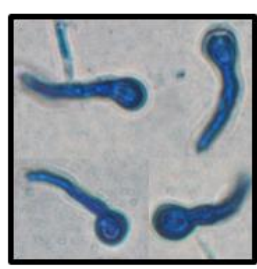

$\Delta P r t$

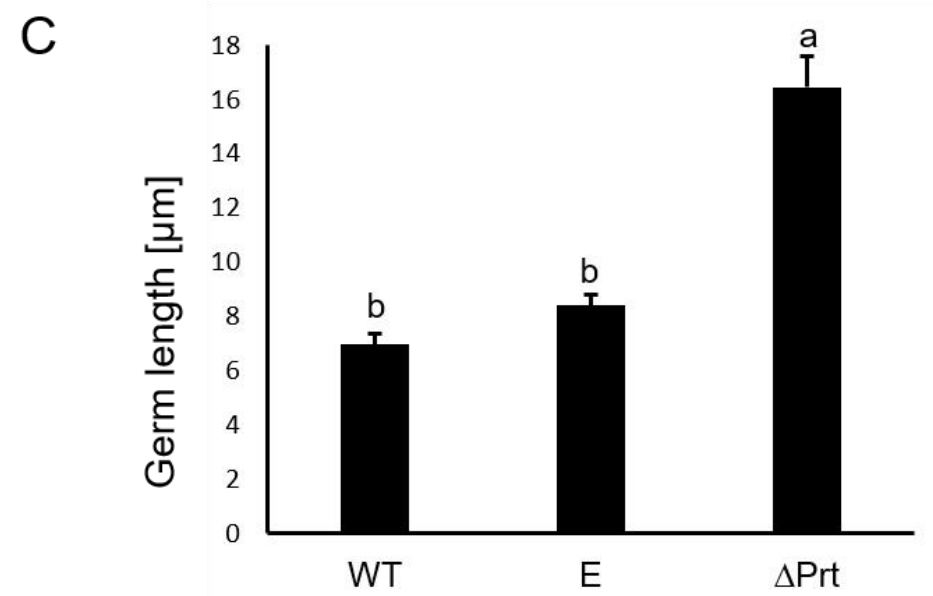

Figure 8: Effect of PePRT target deletion on spore germination.

Percent of germinating spores (A), microscope observation of the germination of spore (B) and the length of the germ tubes (C) $18 \mathrm{hr}$ post inoculation on 1.5\% agar plates. Percent of germination is an average of 20 different microscopic fields including 20-30 spores each. Length of the germs is an average of more than 50 measurements. Bars indicate standard error. Different letters indicate significant differences at $P<0.05$ based on nested one-way ANOVA followed by Tukey's honest significant difference (HSD) test. 


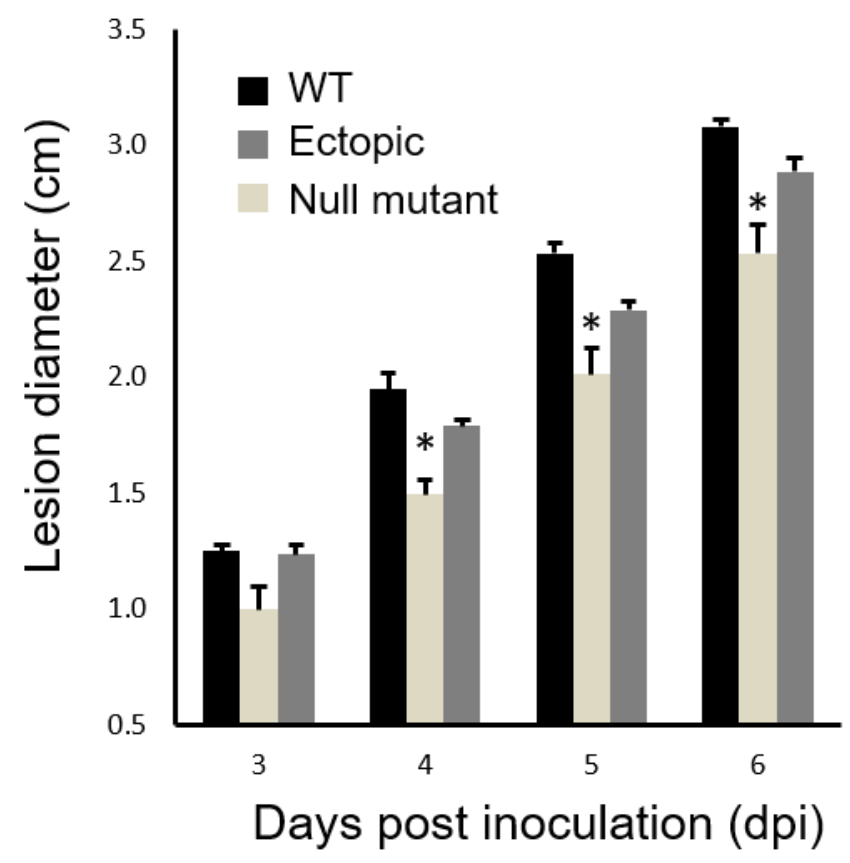

Figure 4: The effect of the PePRT deletion on pathogenicity of PEX2 on apples as expressed by rate of decay development on Golden delicious apples and compared to that of the WT and the ectopic mutant. Progression of rot development was expressed as lesion diameter $(\mathrm{cm})$ different time after inoculation (dpi).

Results are an average of three independent measurements. Bars indicate standard error. Asterics indicate significant differences at $P<0.05$ based on nested one-way ANOVA followed by Tukey's honest significant difference test. 


\section{Supplementary}

Table S1: Primers used in the study

\begin{tabular}{|c|c|c|}
\hline Name & Sequence & Explanation \\
\hline \multicolumn{3}{|c|}{ Gene expression analysis } \\
\hline PepI_F & GGT GAT GCC GAC GAG GAT GG & \\
\hline PepI_R & CCC GAG CCG TTA GAG CGA AG & \\
\hline 28S_F & GGA ACG GGA CGT CAT AGA GG & \\
\hline 28S_R & AGA GCT GCA TTC CCA AAC AAC & \\
\hline \multicolumn{3}{|c|}{ Knockout mutant construction and analysis } \\
\hline Prt_Prom_F & ggtcttaaUCG GCA CTT CCA CTG TCTC & \\
\hline Prt_Prom_R & ggcattaaUAT GAT GCA AGC GGG TAT TAC & \\
\hline Prt_Ter_F & ggacttaaUAT ACA TGG ATA AGT TCG GAC TGA & \\
\hline Prt_Ter_R & gggtttaaUGC ATC GGA ATT TGT TTG ATAG & \\
\hline HMBF1 & CTG TCG AGA AGT TTC TGA TCG & 3 \\
\hline HMBR 1 & CTG ATA GAG TTG GTC AAG ACC & 4 \\
\hline HPH1F & ACG AGG TCG CCA ACA TCT TCT TCT & 6 \\
\hline HPHPRO4 & GCA CCA AGC AGC AGA TGA TA & 7 \\
\hline Prt_center_F & CAA ATT GCT GGA TCA CTC AC & 13 \\
\hline
\end{tabular}


Prt_center_R GTT AGA GCG AAG AAC CTT GAC

Prt_check_F GGT AAA TTG CTT TCT CCC TGT CTG AC

Prt_check_R CGG TTC TGA TAC ATT CGA TAG ACA

16

RF-1

AAA TTT TGT GCT CAC CGC CTG GAC

Confirmation of

terminator fusion

into pRFHU2

plasmid

RF-6

ACG CCA GGG TTT TCC CAG TC

Confirmation of terminator

fusion into

pRFHU2

plasmid

$\mathrm{RF}-2$

TCT CCT TGC ATG CAC CAT TCC TTG

Confirmation of promoter fusion into pRFHU2 plasmid

RF-5

GTT TGC AGG GCC ATA GAC

Confirmation of promoter fusion into pRFHU2 plasmid

\section{Determination of T-DNA copy number}

PeTub_1F AGC GGT GAC AAG TAC GTT CC 
Prt_RT_F ATG ATG TGA TGG GCT TCT CC

Prt_RT_R

ATG ATG TGA TGG GCT TCT CC

24

Numbers 1-24 refer to primers in Fig. S1 
Table S2: Small, Cysteine-rich proteins with unknown function.

\begin{tabular}{|c|c|c|c|}
\hline Gene name & size (aa) & \# Cys & High exp. (hpi) \\
\hline PEX2_000510 & 170 & 8 & \\
\hline PEX2_002470 & 273 & 5 & $24,48,72$ \\
\hline PEX2_006020 & 182 & 4 & \\
\hline PEX2_006280 & 149 & 5 & \\
\hline PEX2_007820 & 103 & 6 & \\
\hline PEX2_011820 & 221 & 16 & \\
\hline PEX2_020550 & 173 & 8 & \\
\hline PEX2_025800 & 194 & 6 & \\
\hline PEX2_026210 & 213 & 4 & \\
\hline PEX2_035430 & 276 & 17 & \\
\hline PEX2_038290 & 138 & 10 & 48,72 \\
\hline PEX2_056120 & 271 & 5 & \\
\hline PEX2_056460 & 176 & 4 & spores \\
\hline PEX2_063200 & 148 & 5 & \\
\hline PEX2_064300 & 259 & 4 & \\
\hline PEX2_074940 & 224 & 4 & \\
\hline PEX2_079250 & 122 & 7 & \\
\hline PEX2_080310 & 95 & 6 & \\
\hline PEX2_080970 & 244 & 7 & \\
\hline
\end{tabular}




\begin{tabular}{|c|c|c|}
\hline PEX2_085640 & 263 & 6 \\
\hline PEX2_088490 & 286 & 9 \\
\hline PEX2_090640 & 270 & 11 \\
\hline PEX2_092040 & 297 & 4 \\
\hline PEX2_095180 & 159 & 8 \\
\hline PEX2_108080 & 79 & 8 \\
\hline
\end{tabular}

Table S3: Proteins with known effector-domains

\begin{tabular}{llcc} 
Gene name annotation & NLS & \multicolumn{1}{c}{ PHI } & $\begin{array}{c}\text { High } \\
\text { expression }\end{array}$ \\
& $\underline{\text { http://www.phi- }}$ & (hpi) \\
& $\underline{\text { base.org/ }}$ &
\end{tabular}

\begin{tabular}{lll}
\hline PEX2_012920 PF03067 chitin- & binding
\end{tabular}

PEX2_053590 IPR018392 LysM

PEX2_091440 PF01476 LysM

PEX2_064530 IPR018392 LysM

PEX2_002570 PF01822.14 WSC

PEX2_105000 PF01822.14 WSC

PEX2_046410 PF02018.12 carbohydrate

-binding

PEX2_021580 PF03388.8 L-like lectin

PEX2_041810 PF03388.8 L-like lectin 
PEX2_028650 PF01828.12 Peptidase A4

PEX2_043920 PF05730 CFEM

PEX2_092030 PF05730 CFEM

PEX2_027670 PF05922.11; $\quad$ Inhibitor_I9; $\quad$ V $\quad 2117$, M.oryzae $\quad 48,72$ PF00082.17 Peptidase_S8

PEX2_065330 PF07249.7 Cerato- 3164, T. virens

platanin

PEX2_080220 PF05630.6 NPP-1

2342, B. elliptica $\quad 24,48,72$

(PHI data: white - not available, grey - no effect on pathogenicity, yellow - mixed output, green - reduced pathogenicity, purple - lethal) 
Table S4: NLS-carrying proteins

Gene name annotation

PHI

High

expression

http://www.phi-base.org/

(hpi)

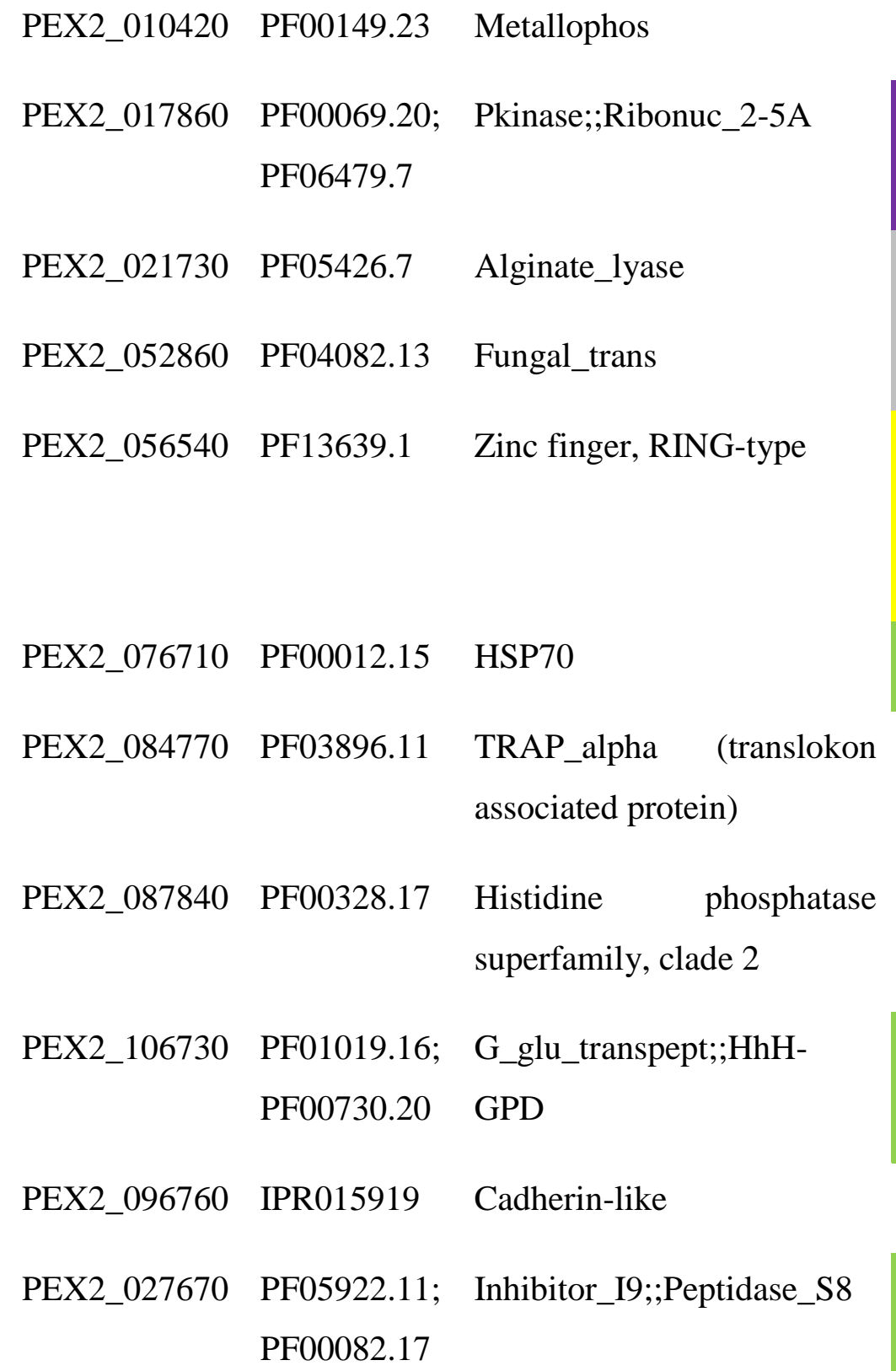

PEX2_010420 PF00149.23 Metallophos

PEX2_017860 PF00069.20; Pkinase;;Ribonuc_2-5A PF06479.7

PEX2_021730 PF05426.7 Alginate_lyase

PEX2_052860 PF04082.13 Fungal_trans

PEX2_056540 PF13639.1 Zinc finger, RING-type

PEX2_076710 PF00012.15 HSP70
PEX2_084770 PF03896.11 TRAP_alpha (translokon associated protein)

PEX2_087840 PF00328.17 Histidine phosphatase superfamily, clade 2
PEX2_106730 PF01019.16; G_glu_transpept;;HhH- PF00730.20 GPD

PEX2_096760 IPR015919 Cadherin-like

PEX2_027670 PF05922.11; Inhibitor_I9;;Peptidase_S8 PF00082.17

1225 Gibberella_zeae

1846 Gibberella_zeae

1800 Gibberella_zeae
2401 vesicatoria

2058 Magnaporthe_oryzae

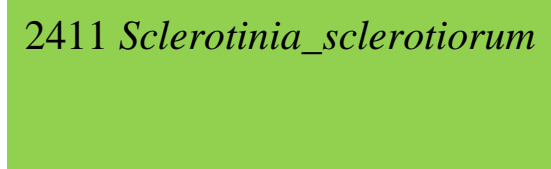


PEX2_047400 PF00085.15 Thioredoxin

$\begin{array}{lll}\text { PEX2_051040 } & \text { PF00226.26 } & \text { Heat shock protein DnaJ } \\ \text { PEX2_061790 } & \text { PF12697.2 } & \text { Abhydrolase_6 } \\ \text { PEX2_087920 } & \text { PF00491.16 } & \text { Arginase } \\ \text { PEX2_035730 } & \text { IPR013320 } & \begin{array}{l}\text { Concanavalin } \\ \text { lectin/glucanase domain }\end{array}\end{array}$

PEX2_018330

PEX2_071030

PEX2_085110

(PHI data: white - not available, grey - no effect on pathogenicity, yellow - mixed output, green - reduced pathogenicity, purple - lethal)

\section{4}

Salmonella_enterica_serovar

_Typhimurium 
Table S5: Genes homologous to effectors found in PHI database.

PHI

High

\section{Annotation}

NLS exp.

Gene name

(hpi)

\begin{tabular}{|c|c|c|c|}
\hline PEX2_000290 & $\begin{array}{l}\text { PF07732.10; } \\
\text { PF00394.17; } \\
\text { PF07731.9 }\end{array}$ & $\begin{array}{l}\mathrm{Cu} \text {-oxidase_3;Cu- } \\
\text { oxidase;Cu-oxidase_2 }\end{array}$ & $\begin{array}{l}\text { 2921Colletotrichum_grami } \\
\text { nicola }\end{array}$ \\
\hline PEX2_000950 & $\begin{array}{l}\text { PF13802.1;P } \\
\text { F01055.21 }\end{array}$ & $\begin{array}{l}\text { Gal_mutarotas_2; Glyco } \\
\text { _hydro_31 }\end{array}$ & 1071Ustilago_maydis \\
\hline PEX2_006870 & $\begin{array}{l}\text { PF07732.10; } \\
\text { PF00394.17; } \\
\text { PF07731.9 }\end{array}$ & $\begin{array}{l}\mathrm{Cu} \text {-oxidase_3;Cu- } \\
\text { oxidase;Cu-oxidase_2 }\end{array}$ & $\begin{array}{l}2700 \\
\text { Colletotrichum_orbiculare }\end{array}$ \\
\hline PEX2_010260 & PF00332.13 & Glyco_hydro_17 & 61 Candida_albicans \\
\hline PEX2_013190 & PF01095.14 & Pectinesterase & 1028 Botrytis_cinerea \\
\hline PEX2_016450 & PF00544.14 & Pec_lyase_C & $\begin{array}{l}222 \\
\text { Colletotrichum_gloeospori } \\
\text { oides }\end{array}$ \\
\hline PEX2_017860 & $\begin{array}{l}\text { PF00069.20; } \\
\text { PF06479.7 }\end{array}$ & Pkinase;Ribonuc_2-5A & $\begin{array}{l}1225 \\
\text { Gibberella_zeae_(related:_ } \\
\text { Fusarium_graminearum) }\end{array}$ \\
\hline PEX2_019000 & PF01764.20 & Lipase_3 & $\begin{array}{l}1166 \\
\text { Gibberella_zeae_(related:_ } \\
\text { Fusarium_graminearum) }\end{array}$ \\
\hline PEX2_022780 & PF01565.18 & FAD_binding_4 & $\begin{array}{l}1046 \\
\text { Cercospora_nicotianae }\end{array}$ \\
\hline
\end{tabular}


PEX2_027670 PF05922.11; Inhibitor_I9;Peptidase_ PF00082.17 S8

PEX2_030850 PF00933.16; Glyco_hydro_3;Glyco PF01915.17; hydro_3_C;Fn3-like PF14310.1

$\begin{array}{lll}\text { PEX2_031340 } & \text { PF00295.12 } & \text { Glyco_hydro_28 } \\ \text { PEX2_031470 } & \text { PF00544.14 } & \text { Pec_lyase_C } \\ & & \\ \text { PEX2_032490 } & \text { PF13561.1;P } & \text { adh_short_C2;ketoacyl- } \\ & \text { F00109.21;P } & \text { synt;Ketoacyl-synt_C } \\ & \text { F02801.17 } & \end{array}$

PEX2_036960 PF01565.18; FAD_binding_4;BBE PB001685;P

F08031.7

$\begin{array}{lll}\text { PEX2_037380 } & \text { PF00254.23 } & \text { FKBP_C } \\ \text { PEX2_039220 } & \text { PF07732.10; } & \text { Cu-oxidase } \\ & \text { PF00394.17; } & \\ & \text { PF07731.9 } & \\ & & \\ \text { PEX2_042850 } & \text { PF13802.1;P } & \text { Gal_mutarotas_2;Glyco } \\ & \text { F01055.21 } & \text { _hydro_31 }\end{array}$

PEX2_044440 IPR001579 Glycoside hydrolase chitinase active site

\section{7 \\ V 48,72 \\ Magnaporthe_oryzae_(relat ed:_Magnaporthe_grisea)

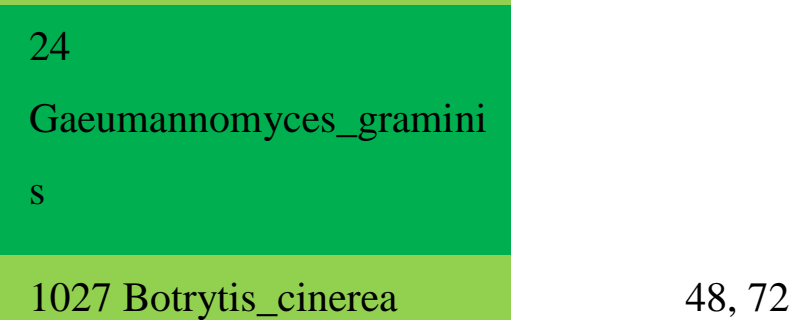

3226

Penicillium_digitatum_

96 Candida_albicans

1046

Cercospora_nicotianae

2305B Botrytis_cinerea

2700

Colletotrichum_orbiculare

1071 Ustilago_maydis

2388

Metarhizium_anisopliae 


\begin{tabular}{|c|c|c|c|}
\hline PEX2_047400 & $\begin{array}{l}\text { PF00085.15; } \\
\text { PB015947 }\end{array}$ & Thioredoxin & $\begin{array}{l}2644 \\
\text { Salmonella_enterica_serov } \\
\text { ar_Typhimurium }\end{array}$ \\
\hline PEX2_048400 & $\begin{array}{l}\text { PF03198.9;P } \\
\text { F07983.8 }\end{array}$ & Glyco_hydro_72;X8 & $\begin{array}{l}2808 \\
\text { Fusarium_oxysporum_f._s } \\
\text { p._Lycopersici }\end{array}$ \\
\hline PEX2_051820 & $\begin{array}{l}\text { PF01565.18; } \\
\text { PB012605;P } \\
\text { B003699 }\end{array}$ & FAD_binding_4 & $\begin{array}{l}1046 \\
\text { Cercospora_nicotianae }\end{array}$ \\
\hline PEX2_052110 & $\begin{array}{l}\text { PF03636.10; } \\
\text { PF03632.10; } \\
\text { PF03633.10 }\end{array}$ & $\begin{array}{l}\text { Glyco_hydro_65N;Glyc } \\
\text { o_hydro_65m;Glyco_h } \\
\text { ydro_65C }\end{array}$ & $\begin{array}{l}3076 \\
\text { Candida_parapsilosis__ }\end{array}$ \\
\hline PEX2_054250 & $\begin{array}{l}\text { PF00331.15; } \\
\text { PF00734.13 }\end{array}$ & $\begin{array}{l}\text { Glyco_hydro_10;CBM } \\
{ }_{-} 1\end{array}$ & $\begin{array}{l}2208 \\
\text { Magnaporthe_oryzae_(relat } \\
\text { ed:_Magnaporthe_grisea) }\end{array}$ \\
\hline PEX2_056540 & $\begin{array}{l}\text { PB005982;P } \\
\text { F13639.1 }\end{array}$ & zf-RING_2 & $\begin{array}{l}2401 \\
\text { Xanthomonas_campestris_ } \\
\text { pv_vesicatoria }\end{array}$ \\
\hline PEX2_065330 & PF07249.7 & Cerato-platanin & 3164 Trichoderma_virens_ \\
\hline PEX2_067560 & PF00457.12 & Glyco_hydro_11 & 546 Botrytis_cinerea \\
\hline PEX2_070420 & PF00704.23 & Glyco_hydro_18 & $\begin{array}{l}2388 \\
\text { Metarhizium_anisopliae }\end{array}$ \\
\hline PEX2_076170 & $\begin{array}{l}\text { PF00454.22; } \\
\text { PF02260.15 }\end{array}$ & PI3_PI4_kinase;FATC & $\begin{array}{l}1224 \\
\text { Gibberella_zeae_(related:_ } \\
\text { Fusarium_graminearum) }\end{array}$ \\
\hline
\end{tabular}


PEX2_076710 PF00012.15 HSP70

PEX2_081580 PF00328.17 His_Phos_2

PEX2_082100 PF00067.17 p450

PEX2_085170 PF00026.18 Asp

PEX2_086800 PF00085.15; Thioredoxin;Thioredoxi PF00085.15; n;ERp29

PF07749.7

PEX2_088440 PF01565.18 FAD_binding_4

PEX2_089670 PF13933.1 HRXXH

PEX2_093030 PF07335.6 Glyco_hydro_75

PEX2 $097030 \quad$ PF07732.10; $\quad \mathrm{Cu}$-oxidase 3; $\mathrm{Cu}-$ PF00394.17; oxidase;Cu-oxidase_2 PF07731.9

PEX2_097510 PF01055.21 Glyco_hydro_31

PEX2_098230 PF01793.11 Glyco_transf_15

PEX2_099670 PF01735.13 PLA2_B

PEX2_099890 PF00150.13 Cellulase

\section{8}

Magnaporthe_oryzae_(relat ed:_Magnaporthe_grisea)

3236

Cryptococcus_neoformans

$-$

438 Botrytis_cinerea

126 Candida_albicans

2644

Salmonella_enterica_serov ar_Typhimurium

1046

Cercospora_nicotianae

\section{7}

Blumeria_graminis_f._sp. hordei

2403PHI:2403CSN1A9QU

B2169388Fusarium_solani

2920

Colletotrichum_graminicol a

\section{Ustilago_maydis}

3096 Beauveria_bassiana_

105 Candida_albicans

323 Verticillium_fungicola 


$\begin{array}{lllll}\text { PEX2_104640 } & \text { IPR017853 } & \text { Glycoside hydrolase } & 816 \text { Magnaporthe_oryzae } & \\ \text { PEX2_106730 } & \text { PF01019.16; } & \text { G_glu_transpept;HhH- } & 2411 \\ & \text { PF00730.20 } & \text { GPD } & \text { Sclerotinia_sclerotiorum } & \text { V } \\ \text { PEX2_107230 } & \text { PF00544.14 } & \text { Pec_lyase_C } & 3226 \\ & & & \text { Penicillium_digitatum_ } \\ \text { PEX2_107240 } & \text { PF01425.16 } & \text { Amidase } & \text { 2654 Candida_albicans } \\ \text { PEX2_108490 } & \text { PF00085.15; } & \text { Thioredoxin;Thioredoxi } & \text { 2644 } \\ & \text { PF13848.1 } & \text { n_6 } & \text { Salmonella_enterica_serov } \\ & & & \text { ar_Typhimurium }\end{array}$

(PHI data: yellow - mixed output, light green - reduced pathogenicity, dark green - loss of pathogenicity; purple lethal, brown - effector) 
Table S6: Degrading enzymes.

$\begin{array}{lll}\text { Gene name } & \text { annotation } & \\ \text { PEX2_061790 } & \text { PF12697.2 } & \text { Abhydrolase_6 } \\ \text { PEX2_068420 } & \text { PF12697.2 } & \text { Abhydrolase_6 } \\ \text { PEX2_038250 } & \text { PF12695.2 } & \text { Abhydrolase_5 } \\ \text { PEX2_109950 } & \text { PF12695.2 } & \text { Abhydrolase_5 } \\ \text { PEX2_021730 } & \text { PF05426.7 } & \text { Alginate_lyase }\end{array}$

Gibberella_zeae_(related:

_Fusarium_graminearum)

PEX2_002760 PF00128.19 Alpha-amylase

PEX2_068560 PF06964.7 Alfa-L-

arabinofuranosidase C-

terminus

PEX2_107960 PF06964.7 Alfa-L-

arabinofuranosidase C-

terminus

PEX2_092140 PF05592.6 Bacterial alpha-L-

rhamnosidase

(Glyco_hydro78)

PEX2_099890 PF00150.13 Cellulase (Glyco-hydro 5) Verticillium_fungicola 
PEX2_036500 PF00135.23 COesterase

PEX2 $052910 \quad$ PF00135.23 COesterase

PEX2_082800 PF00135.23 COesterase

PEX2_108390 PF00135.23 COesterase

PEX2_101220

PEX2_000950

PF01055.21; Glyco_hydro_31;

PF13802.1 Gal_mutarotas_2

PEX2_042850 PF01055.21; Glyco_hydro_31;

PF13802.1 Gal_mutarotas_2

PEX2_015850 PF12999.2; Glucosidase Beta subunit-

PF13015.1 like

PEX2_003900 PF00722.16 Glyco_hydro_16

PEX2_004230 PF00933.16; Glyco_hydro_3;

PF01915.17; Glyco_hydro_3_C;

PF14310.1 Fn3-like

PEX2_004580 PF04616.9 Glyco_hydro_43

PEX2_005800 PF01532.15 Glyco_hydro_47
Magnaporthe_oryzae_(rel ated:_Magnaporthe_grisea )

Botrytis_cinerea

Magnaporthe_oryzae_(rel ated:_Magnaporthe_grisea )

Magnaporthe_oryzae_(rel ated:_Magnaporthe_grisea )

Ustilago_maydis

Ustilago_maydis
Ustilago_maydis

Aspergillus_fumigatus 


\begin{tabular}{|c|c|c|}
\hline PEX2_010260 & PF00332.13 & Glyco_hydro_17 \\
\hline \multirow[t]{3}{*}{ PEX2_011360 } & PF00933.16; & Glyco_hydro_3; \\
\hline & PF01915.17; & Glyco_hydro_3_C; \\
\hline & PF14310.1 & Fn3-like \\
\hline \multirow[t]{2}{*}{ PEX2_013620 } & PF00251.15; & Glyco_hydro_32N; \\
\hline & PF08244.7 & Glyco_hydro_32C \\
\hline \multirow[t]{2}{*}{ PEX2_016360 } & PF02838.10; & Glyco_hydro_20b; \\
\hline & PF00728.17 & Glyco_hydro_20 \\
\hline PEX2_020130 & PF01670.11 & Glyco_hydro_12 \\
\hline \multirow[t]{3}{*}{ PEX2_030850 } & PF00933.16; & Glyco_hydro_3; \\
\hline & PF01915.17; & Glyco_hydro_3_C; \\
\hline & PF14310.1 & Fn3-like \\
\hline
\end{tabular}

PEX2_031200 PF04616.9 Glyco_hydro_43

PEX2_031290 PF00722.16 Glyco_hydro_16

PEX2_031340 PF00295.12 Glyco_hydro_28

PEX2_034450 PF03443.9 Glyco_hydro_61

PEX2_037880 PF00933.16; Glyco_hydro_3;

PF01915.17; Glyco_hydro_3_C;

PF14310.1 Fn3-like

PEX2_038010 PF14845.1; Glycohydro_20b2;

PF00728.17 Glyco_hydro_20
Candida_albicans

Ustilago_maydis

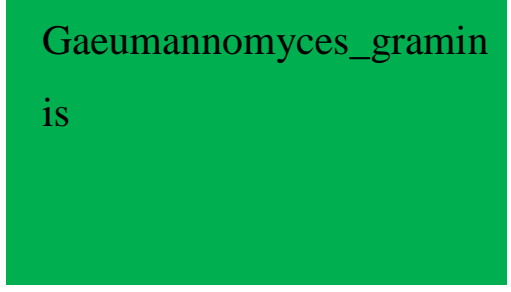

Botrytis_cinerea

Gibberella_zeae_(related:

_Fusarium_graminearum)

Septoria_lycopersici 


$\begin{array}{lll}\text { PEX2_043650 } & \text { PF00933.16; } & \text { Glyco_hydro_3; } \\ & \text { PF01915.17; } & \text { Glyco_hydro_3_C; } \\ & \text { PF14310.1 } & \text { Fn3-like } \\ \text { PEX2_044530 } & \text { PF02055.11 } & \text { Glyco_hydro_30 } \\ \text { PEX2_047370 } & \text { PF00722.16 } & \text { Glyco_hydro_16 } \\ \text { PEX2_048400 } & \text { PF03198.9; } & \text { Glyco_hydro_72; } \\ & & \\ & \text { PF07983.8 } & \text { X8 } \\ & \text { PF03636.10; } & \text { Glyco_hydro_65N; } \\ & \text { PF03632.10; } & \text { Glyco_hydro_65m; } \\ \text { PEX2_052110 } & \text { PF03633.10 } & \text { Glyco_hydro_65C } \\ & \text { PF00933.16 } & \text { Glyco_hydro_3 } \\ \text { PEX2_052250 } & \text { PF00331.15; } & \text { Glyco_hydro_10; }\end{array}$

PF00734.13 CBM_1

$\begin{array}{lll}\text { PEX2_056100 } & \text { PF03659.9 } & \text { Glyco_hydro_71 } \\ \text { PEX2_059920 } & \text { PF03443.9 } & \text { Glyco_hydro_61 }\end{array}$

PEX2_067240 PF00933.16 Glyco_hydro_3

PEX2_067560 PF00457.12 Glyco_hydro_11

PEX2_068000 PF00722.16 Glyco_hydro_16

PEX2_069880 PF00295.12 Glyco_hydro_28

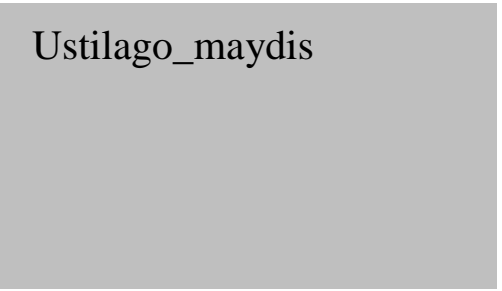

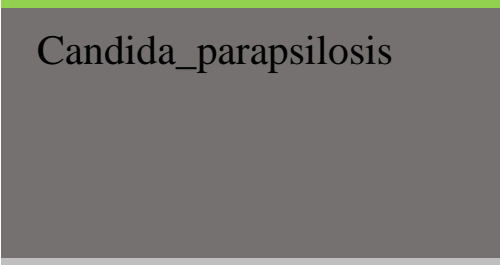

Ustilago_maydis

Magnaporthe_oryzae_(rel ated:_Magnaporthe_grisea )

Gibberella_zeae_(related: _Fusarium_graminearum)

Botrytis_cinerea

Cochliobolus_carbonum 


$\begin{array}{lll}\text { PEX2_070420 } & \text { PF00704.23 } & \text { Glyco_hydro_18 } \\ \text { PEX2_071120 } & \text { PF00251.15; } & \text { Glyco_hydro_32N } \\ & \text { PF08244.7 } & \text { Glyco_hydro_32C } \\ \text { PEX2_072090 } & \text { PF01670.11 } & \text { Glyco_hydro_12 } \\ \text { PEX2_074460 } & \text { PF03659.9 } & \text { Glyco_hydro_71 } \\ \text { PEX2_075490 } & \text { PF03663.9 } & \text { Glyco_hydro_76 } \\ \text { PEX2_076310 } & \text { PF07971.7 } & \text { Glyco_hydro_92 } \\ \text { PEX2_076830 } & \text { PF01301.14; } & \text { Glyco_hydro_35; } \\ & \text { PF10435.4; } & \text { BetaGal_dom2; } \\ & \text { PF13363.1; } & \text { BetaGal_dom3; } \\ & \text { PF13364.1 } & \text { BetaGal_dom4_5 }\end{array}$

PEX2_080380 PF02837.13; Glyco_hydro_2_N;

PF00703.16 Glyco_hydro_2

PEX2_090750 PF00722.16 Glyco_hydro_16

PEX2_093030 PF07335.6 Glyco_hydro_75

PEX2_094840 PF00295.12 Glyco_hydro_28

PEX2_095490 PF00295.12; Glyco_hydro_28;

PF00465.14 Fe-ADH

PEX2_097510 PF01055.21 Glyco_hydro_31

PEX2_109740 PF03663.9 Glyco_hydro_76

PEX2_110470 PF00295.12 Glyco_hydro_28

PEX2_038220 PF10282.4 Lactonase

\section{Metarhizium_anisopliae}

Magnaporthe_oryzae

\section{Fusarium_solani}

Cochliobolus_carbonum

24

Cochliobolus_carbonum

Ustilago_maydis 
PEX2_084130 PF10282.4 Lactonase

PEX2_044440 GH18.hmm Glyco_hydro_18

$8.20 \mathrm{E}-25$

$(\mathrm{dbCAN})$

PEX2_080610 GH16.hmm Glyco_hydro_16

$1.80 \mathrm{E}-18$

$(\mathrm{dbCAN})$

$\begin{array}{ll}\text { PEX2_104640 } & \text { GH17.hmm Glyco_hydro_17 } \\ & 1.90 \mathrm{E}-21 \\ & (\mathrm{dbCAN})\end{array}$

PEX2_013190 PF01095.14 Pectinesterase

PEX2_016450 PF00544.14 Pec_lyase_C

PEX2_031470 PF00544.14 Pec_lyase_C

PEX2_107230 PF00544.14 Pec_lyase_C

PEX2_076520 PF12708.2 Pectate_lyase_3

PEX2_079420 PF12708.2 Pectate_lyase_3

PEX2_092020 PF12708.2 Pectate_lyase_3

PEX2_013030 PF14099.1 Polysacc_lyase

PEX2_040240 PF07915.8 PRKCSH

PEX2_087190 CE1 hmm.

6.30E-20

(dbCAN) Putative esterase

PEX2_107240 PF01425.16 Amidase

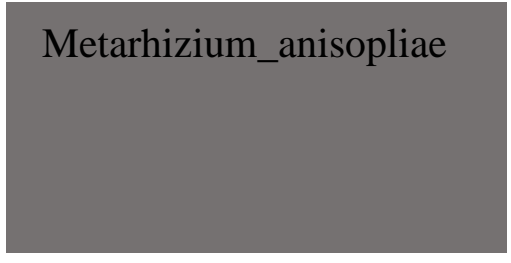

Magnaporthe_oryzae

Botrytis_cinerea

Colletotrichum_gloeospor ioides

Penicillium_digitatum

Penicillium_digitatum
Gibberella_zeae_(related:

_Fusarium_graminearum)

Candida_albicans 


$\begin{array}{llll}\text { PEX2_006100 } & \text { PF00026.18 } & \text { Aspartic protease } & \text { Leptosphaeria_maculans } \\ \text { PEX2_009280 } & \text { PF00026.18 } & \text { Aspartic protease } & \text { Leptosphaeria_maculans } \\ \text { PEX2_015270 } & \text { PF00026.18 } & \text { Aspartic protease } & \text { Leptosphaeria_maculans } \\ \text { PEX2_085170 } & \text { PF00026.18 } & \text { Aspartic protease } & \text { Candida_albicans } \\ \text { PEX2_089670 } & \text { PF13933.1 } & \text { HRXXH } & \text { Blumeria_graminis_f._sp. } \\ & & & \text {-hordei }\end{array}$

$\begin{array}{lll}\text { PEX2_079330 } & \text { PF00082.17 } & \text { Peptidase_S8 } \\ \text { PEX2_028650 } & \text { PF01828.12 } & \text { Peptidase_A4 } \\ \text { PEX2_039390 } & \text { PF01650.13 } & \text { Peptidase_C13 } \\ \text { PEX2_047070 } & \text { PF00246.19 } & \text { Peptidase_M14 } \\ \text { PEX2_037890 } & \text { PF02129.13 } & \text { Peptidase_S15 } \\ \text { PEX2_049380 } & \text { PF00450.17 } & \text { Peptidase_S10 } \\ \text { PEX2_062610 } & \text { PF04389.12 } & \text { Peptidase_M28 } \\ \text { PEX2_084380 } & \text { PF00450.17 } & \text { Peptidase_S10 } \\ \text { PEX2_087490 } & \text { PF00450.17 } & \text { Peptidase_S10 } \\ \text { PEX2_089620 } & \text { PF00450.17 } & \text { Peptidase_S10 } \\ \text { PEX2_106910 } & \text { PF05577.7 } & \text { Peptidase_S28 } \\ \text { PEX2_027670 } & \text { PF05922.11; } & \text { Inhibitor_I9; }\end{array}$

Ustilago_maydis

Ustilago_maydis

Ustilago_maydis

Ustilago_maydis

48,72

Magnaporthe_oryzae_(rel ated:_Magnaporthe_grisea ) 


$\begin{array}{llll}\text { PEX2_013750 } & \text { PF07519.6 } & \text { Tannase } & \\ \text { PEX2_075320 } & \text { PF07519.6 } & \text { Tannase } & \\ \text { PEX2_022440 } & \text { PF00775.16 } & \text { Dioxygenase_C } & \text { Gibberella_zeae_(related: } \\ \text { PEX2_019000 } & \text { PF01764.20 } & \text { Lipase_3 } & \text { _Fusarium_graminearum) } \\ \text { PEX2_099670 } & \text { PF01735.13 } & \text { PLA2_B } & \text { Candida_albicans } \\ \text { PEX2_010420 } & \text { PF00149.23 } & \text { calcineurin-like } & \\ & & \text { phosphoesterases } & \\ \text { PEX2_012250 } & \text { PF01083.17 } & \text { Cutinase } & \end{array}$

(PHI data: white - not available, grey - no effect on pathogenicity, yellow - mixed output, light green - reduced pathogenicity, dark green - loss of pathogenicity; purple - lethal) 
Figure S1. Deletion of PePrt in Penicillium expansum PEX2. (A) Diagram of the wild type and deleted PePrt loci. The hygromycin selectable marker present in the T-DNA of plasmids pRFHU2-PePrt replaces the corresponding PePrt gene by homologous recombination, to generate the $\Delta$ PePrt null mutant (B) Polimerase chain reaction amplification of the wild type, $\Delta \mathrm{PePrt}$ null mutants and their respective ectopic mutants with diagnostic primers. 


\section{Introduction}

Necrotrophic fungi promote host cell death and acquire nutrients for growth from dead cells. In recent years, there is a growing understanding of the fact that the interaction between necrotrophic fungi and plants is complex and involves sophisticated recognition and signaling networks. Wide-range of virulence strategies are used by necrotrophic fungi to overcome host innate immune system. Among them, diverse phytotoxic compounds, cell-degrading enzymes and proteinaceous effectors (Wang et al. 2014). Majority of protein effectors in necrotrophic pathogens are unknown and molecular mechanisms of the interactions between them and host plants are not yet elucidated.

In general, effectors are species-specific and lack common features within and cross species. However, there are several effector families that was shown to be secreted by several unrelated pathogens. Among the most studied fungal effectors are necrosis and ethylene-inducing peptide 1-like proteins (NLP) that have been identified, mostly in plantrelated microorganisms of both prokaryotic (gram-negative and gram-positive bacteria) and eukaryotic (fungi and oomycetes) origin (Oome and Ackerveken 2014, Gijzen and Nürnberger 2006; Pemberton and Salmond 2004). First member of this widely occurring protein family was isolated by Bailey (1995) from culture filtrate of Fusarium oxysporum and was shown to induce ethylene production and necrosis in leaves of Erythroxylum coca. Analysis of more than 500 available NLP sequences from fungi, oomycetes and bacteria revealed four different groups belonging to three phylogenetic types (Oome and Ackerveken 2014). Type 1 NLP found almost exclusively in plant-associated microbes and carry all the features known to be required for cytotoxicity. Type $1 \mathrm{a}$ is strongly expanded in oomycetes.It diverged from type 1 , but luck the ability to induce necrosis probably due to substitution in the acidic cation-binding pocket. Type 2 is distinguished from type 1 by a second conserved disulfide bridge as well as by the presence of putative calcium-binding domain. The $\mathrm{N}$ - and $\mathrm{C}$-terminal parts of type 3 NLP were found to be very different from other two types, however our knowledge of type 3 is still very limited (Oome and Ackerveken 2014). NLP are best known for their ability to induce necrosis and ethylene production when infiltrated into the extracellular space in leaves of dicot, but not monocot, plant species (Oome and Ackerveken 2014, Gijzen and Nürnberger 2006). However, there are evidence for functional diversification within NLP family. In addition to cytotoxic NLP, many noncytotoxic NLP have been described that do not induce necrosis. Two of three tested NLP of Phytophthora infestans (Kanneganti et al. 2006), 11 of the 19 tested NLP of Phytophthora sojae (Dong et al. 2012), all 12 NLP of Hyaloperonospora arabidopsidis (Cabral et al. 2012), five of the seven full-length NLP of Verticillium dahliae V592 (Zhou et al. 2012), and one of two tested NLP of Colletotrichum higginsianum (Kleemann et al. 2012) did not cause necrosis when transiently expressed in plants. 10 different noncytotoxic NLP of the biotrophic downy mildew pathogen Hyaloperonospora arabidopsidis do not cause necrosis however act as potent activators of the plant immune system in Arabidopsis thaliana (Oome et al. 2014). Authors found that small, highly conserved peptide of noncytotoxic as well as cytotoxic type 1 NLP sufficient to trigger an effective immune response in Arabidopsis, indicating that some NLP act as a microbe-associated molecular pattern (MAMP). Further, only 2 of 7 NLP of Verticillium dahlia VdLs induces plant cell death. Intriguingly, targeted deletion of NLP1, one of the two cytotoxic NLP in Verticillium dahlia $V d L s$ affected vegetative growth and conidiospore production. Moreover, deletion of either of the two genes (NLP1 and NLP2) compromised Verticillium dahlia VdLs virulence. (Santhanam et al. 2013). Additional NLP were shown to contribute to 
the virulence of several pathogenic microorganisms. For instance, NLPPcC of the soft-rot bacterium Erwinia (Pectobacterium) carotovora subsp. Carotovora was shown to be essential for virulence on potato tubers (Mattinen et al. 2004). Further, NLP from Sclerotinia sclerotiorum, named SsNep1 and SsNep2 induced necrosis when expressed transiently in tobacco leaves and reduced or abolished SsNep2 expression coincident with a partial or total loss of virulence, respectively (Dallal-Bashi et al. 2009). BcNEP1 and BcNEP2, two paralogous of NLP from Botrytis cinerea caused necrosis in dicotyledonous plant species, however they role in B. cinerea virulence is still unclear (Schouten et al. 2007). In several (fungal) species containing multiple NLPs, the loss of a single NLP gene did not affect virulence (Arenas et al. 2010; Santhanam et al. 2013; Staats et al. 2007; Zhou et al. 2012), possibly due to genetic redundancy. Moreover, virulence of the wheat pathogen Mycosphaerella graminicola was not affected by deletion of its sole NLP gene (Motteram et al. 2009) suggesting that in some organisms, NLP do not play an essential role in virulence.

Penicillium is a diverse fungal genus with 354 accepted species today (Visagie et al., 2014b), occurring worldwide in various substrates, from soil to food. Among them, Penicillium. expansum is widely recognized as necrotrophic pathogen on wide range of fruits including pome and various stone fruit (Capellini et al., 1987 and Jurick et al., 2011). It infects fruit hosts through surface wounds where nutrients stimulate spore germination, which is then followed by penetration and colonization of fruit tissue. The virulence factors that mediate pathogenicity in P. expansum, have not been fully defined, including if and how the pathogen suppresses fruit defense mechanisms.

In this study, we identified two NLP in the genome of $P$. expansum. Both genes coding cysteine-rich proteins that were predicted to be secreted. PeNLP1 and PeNLP2 were found to belong to type 1 and type 3 NLP respectively. PeNLP1 expression was found to be induced during vegetative growth, while PeNLP2 is induced in spores. PeNLP1 was found to be phytotoxic when transiently expressed in Nicotiana bentamiana leaves and its loss was shown to affect $P$. expansum virulence on apples 


\section{Materials and Methods}

\section{Construction of phylogenetic tree.}

The aligngment of the NLP protein sequences was done by MEGA 6 (ClastalW, standart setting) and the neighbor- joining tree was created by FigTree v1.4.2

\section{Plant material.}

Apple fruits (Golden delicious) were obtained from a local breeder and used shortly after harvest or stored at $0^{\circ} \mathrm{C}$ until use. Prior to inoculation, fruits were sterilized by drenching in a water solution of $0.05 \%$ hypochlorite for $2 \mathrm{~min}$ and washed thoroughly with tap water.

\section{Fungal cultures.}

Strains of $P$. expansum were obtained from the pathogen collection of the Department of Postharvest Science, Volcani Center, Israel. Pathogens were cultivated on a potato dextrose agar (PDA) plate at $25^{\circ} \mathrm{C}$. Conidia suspensions were prepared by harvesting the spores from 2- to 3-weekold cultures using a bacteriological loop and suspending them in sterile distilled water. Spores were precipitated by centrifugation at 10,000 rpm for $5 \mathrm{~min}$ and resuspended in sterile distilled water to remove any remaining nutrients. Final spore concentrations were adjusted with a hemacytometer.

\section{In vitro fungal culture.}

Pathogens were cultivated on a potato dextrose broth (PDB) medium or potato dextrose agar (PDA) plates at $25^{\circ} \mathrm{C}$.

\section{Fruit wounding, inoculation, and disease assessment.}

'Golden Delicious' apples (Malus $\times$ domestica Borkh), obtained from a local grocery. Apples were submerged for $5 \mathrm{~min}$ in a $5 \%$ commercial bleach solution, were rinsed extensively with tap water, and were allowed to dry at room temperature. Fruits were wounded with a sterilized needle ( $3 \mathrm{~mm}$ in depth) and were immediately inoculated by adding $10 \mu$ lit of conidia suspension adjusted to $10^{5} \mathrm{conidia} / \mathrm{ml}$. For each treatment fifteen infected fruit with four wounds per fruit were placed on plastic boxes and were incubated at $25^{\circ} \mathrm{C}$ and 90 to $95 \%$ relative humidity. For pathogenicity assays, disease incidence was examined at 3, 4, 5, and $6 \mathrm{dpi}$. The percentage of infected wounds and the diameter of the decay was measured. Three independent experiments were preformed.

\section{RNA extraction and CDNA synthesis}

Total RNA was extracted from $P$. expansum-infected apple fruit tissue at different times after inoculation, following the protocol described by (Chang et al., 1993). Inoculated sites and decayed tissue were cut from apples, frozen immediately in liquid nitrogen and then freeze-dried. For each sample, 1gr of lyophilized tissue was grounded in liquid nitrogen using mortar and pestle. The grounded powder was dissolved in $10 \mathrm{ml}$ extraction buffer ( $2 \%$ C-TAB, $2 \%$ polyvinylpyrrolidone (PVP), $0.1 \mathrm{M}$ Tris- $\mathrm{HCl}(\mathrm{pH} 8), 25$ mM EDTA, $2 \mathrm{M} \mathrm{NaCl}, 2 \% \beta$-mercaptoethanol) preheated to $65^{\circ} \mathrm{C}$. After mixing for 2 min by vortex, the 
samples were incubated at $60^{\circ} \mathrm{C}$ for $15 \mathrm{~min}$ and mixed occasionally. After incubation, an equal volume of Chloroform:Isoamyl alcohol (Chl:laa) (24:1 v/v) was added to each sample, mixed by vortex for 2 min and centrifuged at $12,000 \mathrm{~g}$ for $20 \mathrm{~min}$ at $4^{\circ} \mathrm{C}$. The upper phase was transferred to a clean tube and the RNA was re-extracted with an equal volume of Chl:laa. The supernatant was transferred to a clean $50 \mathrm{ml}$ tube, mixed with $1 / 3$ volume of $7.5 \mathrm{M} \mathrm{LiCl}$ and incubated $\mathrm{ON}$ at $4^{\circ} \mathrm{C}$. RNA was precipitated by centrifugation at $12,000 \mathrm{~g}$ for $50 \mathrm{~min}$ at $4^{\circ} \mathrm{C}$. The pellets were washed by $5 \mathrm{ml} 75 \% \mathrm{EtOH}$, air dried and dissolved in $500 \mu \mathrm{l}$ SSTE buffer (0.5\% SDS, $1 \mathrm{M} \mathrm{NaCl}, 10 \mathrm{mM}$ Tris- $\mathrm{HCl}$ (pH 8), $1 \mathrm{mM}$ EDTA) preheated to $65^{\circ} \mathrm{C}$. The RNA was reextracted again by adding an equal volume of Chl:Iaa, mixing by vortex for 2 min and centrifugation at $14000 \mathrm{~g}$ for $10 \mathrm{~min}$ at $4^{\circ} \mathrm{C}$. The upper phase was transferred to a clean microcentrifuge tube. RNA was precipitated by addition of 2 volumes of $100 \% \mathrm{EtOH}$, incubation at $-80^{\circ} \mathrm{C}$ for $30 \mathrm{~min}$ and centrifugation at $14000 \mathrm{~g}$ for $20 \mathrm{~min}$ at $4^{\circ} \mathrm{C}$. The pellets were washed by $1 \mathrm{ml} 75 \%$ ethanol, air dried and dissolved in $50 \mu$ lit Nuclease-free water.

The mycelium from in vitro culture was collected by filtration through whatman filter and frozen immediately in liquid nitrogen and then freeze-dried. The RNA extraction was done using SV Total RNA Isolation System (Promega). Quality and concentration of total RNA was analyzed by gel electrophoresis and a spectrophotometer ND-1000, respectively (NanoDrop, Wilmington, DE, USA). First-strand cDNA was synthesized with a Verso cDNA Kit following manufacturer's guidelines (Thermo Fisher Scientific, Epson, UK), from $1 \mu \mathrm{g}$ of total RNA that had been pretreated with 0.25 units of recombinant DNase I (Takara Bio Inc., Shiga, Japan).

\section{PCR and Real-time quantitative PCR}

PCR reaction was done using labcycler (Senso Quest, Göttingen, Germany). Each PCR reaction contained $1 U$ DreamTaq DNA polymerase (Thermo Scientific), DreamTaq buffer, $0.2 \mathrm{mM}$ DNTPs, $0.4 \mu \mathrm{M}$ of each primer as detailed below, $1 \mathrm{ng}-1 \mu \mathrm{g}$ template DNA. The cycling conditions were: $5 \mathrm{~min}$ at $94^{\circ} \mathrm{C}$, following $35-40$ cycles of: $30 \mathrm{sec}$ at $94^{\circ} \mathrm{C}, 15 \mathrm{sec}$ at $54-58^{\circ} \mathrm{C}, 1-3 \mathrm{~min}$ at $72^{\circ} \mathrm{C}$; and $10 \mathrm{~min}$ at $72^{\circ} \mathrm{C}$. Primer sequences are listed in Table 1.

Real-time quantitative PCR was performed with the StepOnePlus ${ }^{\mathrm{TM}}$ Real-Time PCR System (AB applied biosystems, California, USA). PCR amplification was performed with $3 \mu$ l of cDNA template in $10 \mu \mathrm{l}$ of a reaction mixture containing $5 \mu \mathrm{l}$ of Fast SYBR ${ }^{\circledR}$ Green Master Mix (Applied Biosystems) and $300 \mathrm{nM}$ primers as detailed below. Cycling conditions were $20 \mathrm{sec}$ at $95^{\circ} \mathrm{C}$, followed by 40 cycles of $3 \mathrm{sec}$ at $95^{\circ} \mathrm{C}$ and $30 \mathrm{sec}$ at $60^{\circ} \mathrm{C}$.

Results were analyzed with the LinRegPCR version 2014.8 (Ruijiter et al 2009, Tuomi et al 2010, Ruijiter et al 2014). The 28S rRNA gene, 37S rRNA gene s24 and Histone H3 served as an endogenous control and the spore sample was a calibration sample. Relative quantification was calculated using the mathematical model of Michael W. Pfaffl (Pfaffl 2001).

Each experiment was performed at least in triplicate, and three different biological experiments were conducted.

\section{RNA-Seq analysis.}

The libraries were prepared and the RNA-Seq data was generated as described by Ballester et al (2015). 


\section{Construction and analysis of knockout mutants.}

PeNLP1 and PeNLP2 knock out mutants were constructed as described previously by Ballester et al. (2015). Basically, flanking regions of the genes, 5' upstream and 3' downstream of PEX2_080050 and PEX2_071010, were PCR amplified from genomic DNA of P. expansum MD8, using specific primer pairs (primers 19 to 26). The cycling protocol consisted of $4 \mathrm{~min}$ at $94^{\circ} \mathrm{C}$ for pre-incubation, then 40 cycles of 30 $\mathrm{s}$ at $94^{\circ} \mathrm{C}$ for denaturation, $15 \mathrm{~s}$ at $56^{\circ} \mathrm{C}$ for annealing, and $2 \mathrm{~min}$ at $72^{\circ} \mathrm{C}$ for extension, and a final elongation step of $10 \mathrm{~min}$ at $72^{\circ} \mathrm{C}$. Both DNA fragments, corresponding to promoter and terminator regions, and the pRFHU2 vector (Frandsen et al. 2008) digested by Pacl and $\mathrm{NtBbvCl}$ ( $\mathrm{New}$ England Biolabs) were mixed together and were treated with the USER enzyme (New England Biolabs) to obtain plasmids pRFHU2-PeNLP1 and pRFHU2-PeNLP2. An aliquot of the mixture was used directly in chemical transformation of Escherichia coli JM109 cells (Promega) without prior ligation. Kanamycin-resistant transformants were screened by PCR. Proper fusion was confirmed by DNA sequencing. Then, plasmids were introduced into chemically competent Agrobacterium tumefaciens AGL-1 cells, which were subsequently used to transform P. expansum PEX2, as described previously (Buron-Moles et al. 2012). Analysis of transformants for gene disruption events was done by PCR. Figure 4A shows schemes of the respective wild-type and gene-disrupted loci. The insertion of the selection marker was checked with primer pair 3/4 (Figs. 4A and B). The testing of deletion of the target genes PeNLP1 and PeNLP2 genes was checked by $1 / 2$ and $9 / 10$ primer pairs respectively. Integration of the T-DNA by homologous recombination was examined with primer pairs $5 / 6$ and $7 / 8$ for PeNLP1 and with $11 / 6$ and $7 / 12$ for PeNP2. Real-time genomic PCR analysis was carried out in order to determinate the number of T-DNA copies that had been integrated in the genome of the transformants, following basically the protocol described by Crespo-Sempere and associates (2013), using PEX2 as control. Two primer pairs, 13/14, and 15/16 were designed within the T-DNA in the promoter regions of the target genes, close to the selection marker. The P. expansum $\beta$-tubulin gene (AY674401) (Sanzani et al. 2009) was chosen as reference gene using the primer pair $17 / 18$. The expression of the target genes during apple infection was done by RT-PCR using NLP1_complete F/R and NLP2_complete F/R primer pairs.

\section{Growth, conidiogenesis, and germination assays.}

Radial growth was monitored by placing a $5-\mu \mathrm{l}$ droplet of a conidial suspension of $10^{6}$ conidia $/ \mathrm{ml}$ in the center of a PDA plate and incubating it at $25^{\circ} \mathrm{C}$. For quantification of conidia production, $5 \mathrm{ml}$ of water was added to the 11 days old plait and conidial suspensions were prepared by robbing the plate with sterile spreader. After collecting the suspension each plate was washed with additional $2 \mathrm{ml}$ sterile water to collect remaining spores. 50 fold diluted conidial suspensions were counted in a hemocytometer. To examine the germination of conidia, $15-\mu \mathrm{l}$ droplet of $2 * 10^{5} \mathrm{conidia} / \mathrm{ml}$ were inoculated on water with $15 \%$ agar plates. After incubation at $25^{\circ} \mathrm{C}$ for $18 \mathrm{~h}$ the plates were observed under a microscope.

\section{Transient expression in Necotiana Bentamiana leaves.}

Plasmid construction: PeNLP1 open reading frame with or without signal peptide was amplified from the cDNA using primer pairs $41 / 42$ and $43 / 42$ (Table 1 ) respectively. PCR products were cloned into pRTL2 
(Carrington et al. 1990) plasmid using BamHI and Xbal sites constructing pRTL2_NLP1_SP and pRTL2_NLP1_NS plasmids. Cassette containing the $35 \mathrm{~S}$ transcriptional promoter from cauliflower mosaic virus, the 5 ' nontranslated region sequence from tobacco etch virus, PeNLP1 open reading frame and $35 \mathrm{~S}$ transcriptional terminator was cut from pRTL2_NLP1_SP and pRTL2_NLP1_NS plasmids using Hind III restriction enzyme and cloned into binary plant transformation vector pBINPLUS/ARS (Belknap et al. 2008) resulting in pBINPLUS/ARS_NLP1_SP and pBINPLUS/ARS_NLP1_NS respectively. These plasmids were transformed into Agrobacterium tumefaciens GV3101 using electroporation.

Infiltration procedure: Transient expression in $N$. bentamiana leaves was done according to the protocol of Sparkes et al. (2006) with slight changes. Agrobacterium transformed with the binary vectors was grown over night at $28^{\circ} \mathrm{C}, 200 \mathrm{rpm}$ in YEB medium supplemented with $30 \mu \mathrm{gr} / \mathrm{ml}$ gentamicin and $50 \mu \mathrm{gr} / \mathrm{ml}$ kanamycin. Cells were collected by centrifugation at $2500 \mathrm{~g}$ for $10 \mathrm{~min}$ at RT, washed by infiltration medium ( $5 \mathrm{gr} /$ lit D-Glucose, $50 \mathrm{mM} \mathrm{MES}, 2 \mathrm{mM} \mathrm{Na}_{3} \mathrm{PO}_{4}, 0.1 \mathrm{mM}$ acetosyringone), centrifuged again. Finally, cells were diluted in infiltration medium to $\mathrm{OD}_{600}=0.1$. After incubation of $1.5 \mathrm{hr}$, cell suspension was infiltrated into leaves of around two-week old N. Bentamiana plants.

Detection of Beta-glucuronidase (GUS): Leave-discs of $1 \mathrm{~cm}$ diameter were cut around infiltration sight, placed in the 24-well, immersed in $1 \mathrm{ml}$ fresh staining buffer (0.1M sodium phosphate $\mathrm{pH}$ 7, $10 \mathrm{mM}$ EDTA $\mathrm{pH} 8,0.1 \%$ v/v Triton X-100, $1 \mathrm{mM} \mathrm{K}_{3} \mathrm{Fe}(\mathrm{CN})_{6}, 2 \mathrm{mM}$ X-Gluc (5-bromo-4-chloro-3-indolyl-beta-D-glucuronic acid)) and incubated at $37^{\circ} \mathrm{CON}$.

\section{Yeast two hybrid}

$\mathrm{Y} 187$ and $\mathrm{Y} 2 \mathrm{H}$ Gold yeast strains were used in the yeas two hybrid experiments. Yeast were grown on YPDA or selective minimal medium. Yeast transformation was conducted using the Yeastmaker yeast transformation system 2 (Clontech Laboratories, Inc. Mountain View, CA 94043 USA. Cat.N0. 630439)

For the construction of the GAL4 Activation Domain plasmid (Gal4-AD prey cDNA library), total RNA was isolated from 'Royal Gala' apple fruit collected at three different stages of development (early, midseason, and mature). Fruit were either left unwounded, wounded, or wounded-inoculated with Penicillium expansum. RNA was extracted from the fruit tissues as described in Ballester et al. (2015) and pooled prior to generating cDNA using a SMART (ClonTech CA USA. Cat. No. 630490) cDNA synthesis kit according to the manufacturer's instruction. The library was packaged into the pGADT7-Rec vector which was then used to transform yeast strain Y187.

Construction of the GAL4 DNA binding domain plasmid (Gal4 Bait DNA-BD): PeNLP1 ORF was amplified from cDNA using NLP1_complete_F and NLP1_complete_R primers (Table 1) and cloned into pGEM_T Easy vector (Promega USA. Cat. No. A1360) constructing pGEM+PeNLP1. The PeNLP1 (used as a bait) was amplified from pGEM+PeNLP1 by PCR using 44/45 primers (Table 1). 24 bp of these primers are with homology to the bait and a 16 bp with homology to the linear ends of pGBKT7. The bait PCR fragment and linearized pGBKT7 vector were mixed together and "fused" using an in-fusion enzyme (ClonTech CA USA. Cat. No. 638909). The bait plasmid was then transformed into Y2H Gold yeast strain. 
Yeast Two-hybrid Assay: Yeast two-hybrid screening was performed using the Matchmaker Gold Yeast Two-Hybrid System (ClonTech CA USA. Cat. No.630489). The resulting candidate yeasts cell may contain one or more prey plasmids that do not express an interacting protein. Therefore, to increase the chance of rescuing the positive prey plasmid, the candidate yeast cells were re-streaked several (3-4) times on SD/-Leu-Trp (DDO)/X selective medium. Each time a single blue colony, indicating a positive interaction (blue), was picked for re-streaking. All positive interactions (clones) were confirmed by patching on high

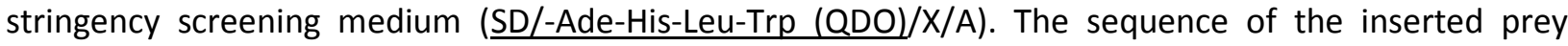
plasmids was obtained by PCR amplification with the primers specified by the manufacturer. The insertions were then sequenced at Macrogen, Inc. In order to further confirm that the interactions are genuine, prey plasmids from $E$. coli were transformed into the $\mathrm{Y} 2 \mathrm{H}$ yeast strain containing the bait plasmid and grown on selective medium QDO/X/A. 
Table 1: Primers used in the study.

\begin{tabular}{|c|c|c|}
\hline \# & name & sequence \\
\hline 1 & NLP1_center_F & TTT CCA GCT CCA AAG TCG \\
\hline 2 & NLP1_center_R & TAT TGA CTA ACG GGC TTC CT \\
\hline 3 & HMBR 1 & CTG ATA GAG TTG GTC AAG ACC \\
\hline 4 & HMBF1 & CTG TCG AGA AGT TTC TGA TCG \\
\hline 5 & NLP1_checkUP & GGT TGA GAT TCC CCA CAC GAT AGC \\
\hline 6 & HPH1F & ACG AGG TCG CCA ACA TCT TCT TCT \\
\hline 7 & HPHPRO4 & GCA CCA AGC AGC AGA TGA TA \\
\hline 8 & NLP1_checkDOWN & TGC CCG TTC CGA ATG A \\
\hline 9 & NLP2_center_F & ACC GGG CAT GAC TAG TAG GT \\
\hline 10 & NLP2_center_R & TGC ACT ACC CCA ATC AGC \\
\hline 11 & NLP2_checkUP & GCT TGA CTA TCT CCT AAT TGG TGG GC \\
\hline 12 & NLP2_checkDOWN & AGT TCT AGA CGG ACT TGC GG \\
\hline 13 & NLP1_CN_F & CGG ACC ATC TTT ATG CGT GA \\
\hline 14 & NLP1_CN_R & GAA CAA ATG CTA CTG CCA ATG C \\
\hline 15 & NLP2_CNPי-F2 & GCC GGT TCC ATT TCA AAG CA \\
\hline 16 & NLP2_CNP_R2 & TGA TCA TTC CAG AGC CCG TT \\
\hline 17 & PeTub_F & AGC GGT GAC AAG TAC GTT CC \\
\hline 18 & PeTub_R & ACC CTT AGC CCA GTT GTT AC \\
\hline 19 & NLP1_Prom_F & GGT CTT AAU CAG CAG GTG TCT TGG GTA C \\
\hline 20 & NLP1_Prom_R & GGC ATT AAU GAT CAA CCT TCA TAT AAT GCT CTC \\
\hline 21 & NLP1_Term_F & GGA CTT AAU TAG TGG AGG CTA GTA AAG TTC G \\
\hline 22 & NLP1_Term_R & GGG TTT AAU ATC TCG GTA CTT TTG CTA GTC C \\
\hline 23 & NLP2_Prom_F & GGT CTT AAU GCC AAC GAA GTC AAG ACT G \\
\hline 24 & NLP2_Prom_R & GGC ATT AAU ATC ACA GTC GTC AAG CTG C \\
\hline 25 & NLP2_Term_F & GGA CTT AAU ATC TGG TCA CTG GCA TTC TC \\
\hline 26 & NLP2_Term_R & GGG TTT AAU GGA CGT TGG TAT AAC TAT AGG TAG ACT \\
\hline 27 & NLP1_complete_F & ATG CTT CCT CAA CTA ATT ACT GC \\
\hline 28 & NLP1_complete_R & TCA GTA GGT TGC CTT TGC TAG \\
\hline 29 & NLP2_complete_F & ATG CAC CTA AAG CTA GGA GCT AG \\
\hline 30 & NLP2_complete_R & CTA TGA TGC CTT ACA CAC ACC A \\
\hline 31 & NLP1_RT_F & GAT GCA AAC GGA AAC ACG AA \\
\hline 32 & NLP1_RT_R & ACT TGC CCA GTG CTC GAA CT \\
\hline 33 & NLP2_RT_F3 & GAA TCA GCC ACC CTG CTA TCC \\
\hline 34 & NLP2_RT_R3 & TCC TGT GGG CAT CGT CAT ATA C \\
\hline 35 & $28 S_{-} \mathrm{F}-$ & GGA ACG GGA CGT CAT AGA GG \\
\hline 36 & $28 S \_R$ & AGA GCT GCA TTC CCA AAC AAC \\
\hline 37 & $37 S_{-}^{-} \mathrm{F}$ & GCT CTG GTC TAC GAC TCC TC \\
\hline 38 & $37 S \_R$ & GGA AGC CTT CTC GAT CTT GC \\
\hline 39 & His3_F2 & TCT CCG CTT CCA GTC CTC TG \\
\hline 40 & His3_R2 & TTG GTG TCC TCG AAG AGA GAG AC \\
\hline 41 & F_BamHI_SP_NLP1 & AGTCGGATCCATGCTTCCTCAACTAATTACTGC \\
\hline 42 & $\mathrm{R} \times$ Xbal NLP1 & AGTCTCTAGATCAGTAGGTTGCCTTTGCTAG \\
\hline 43 & $F^{-}$Bam $\bar{H}$ NS NLP1 & AGTCGGATCCATGAGCCCGCTTGAGTTGTC \\
\hline
\end{tabular}

44 NLP1_Forward
CATGGAGGCCGAATTCATGCTTCCTCAACTAATTACTGCG

\section{explanation}

testing of deletion of PeNLP1

testing of deletion of PeNLP1

insertion of the selection marker

insertion of the selection marker

upstream integration of PeNLP1

upstream integration of the T-DNA

downstream integration of the T-DNA

downstream integration of PeNLP1

testing of deletion of PeNLP2

testing of deletion of PeNLP2

upstream integration of the PeNLP2

downstream integration of PeNLP2

determination of T-DNA copy number determination of T-DNA copy number determination of T-DNA copy number determination of T-DNA copy number determination of T-DNA copy number determination of T-DNA copy number 5' flanking region PeNLP1

5 ' flanking region $P e N L P 1$

3' flanking region PeNLP1

3 ' flanking region $P e N L P 1$

5 ' flanking region PeNLP2

5 ' flanking region PeNLP2

3 ' flanking region PeNLP2

$3^{\prime}$ flanking region PeNLP2

PENLP1 ORF

PENLP1 ORF

PENLP2 ORF

PENLP2 ORF

$P$ PNLP1 relative expression $\mathrm{QRT}$-PCR $P e N L P 1$ relative expression $\mathrm{QRT}-\mathrm{PCR}$ $P e N L P 2$ relative expression $\mathrm{qRT}-\mathrm{PCR}$ $P e N L P 2$ relative expression $\mathrm{qRT}-\mathrm{PCR}$ qRT-PCR endogenous control qRT-PCR endogenous control qRT-PCR endogenous control qRT-PCR endogenous control qRT-PCR endogenous control qRT-PCR endogenous control PeNLP1 ORF for cloning into PRTL2 PeNLP1 ORF for cloning into $P R T L 2$ PeNLP1 ORF without signal peptide for cloning into $P R T L 2$

PeNLP1 for bait plasmid construction 


\section{Results}

\section{There are two genes coding NEP-1 like proteins in the genome of $P$. expansum.}

The genome of P. expansum MD-8 (Ballester et. al 2015) (473X coverage) was searched by blastp algorithm using necrosis and ethylene inducing peptide from Fusarium oxysporum f. sp. Erythroxyli AAC97382 (Nelson et. al 1998), and Bcnep1(DQ211824) and Bcnep2 (DQ211825) from Botrytis cinerea (Staats et.al 2007) as a queries. Only PEX2_080050 sequence showed significant similarity in all three searches. Interestingly, when the searched was done using blasn algorithm (Altschul, Stephen F., Thomas L. Madden, Alejandro A. Schaffer ,Jinghui Zhang, Zheng Zhang, Webb Miller, and David J. Lipman (1997,( "Gapped BLAST and PSI-BLAST: a new generation of protein database search programs", Nucleic Acids Res. 25:3389-3402.)no sequences with significant similarity were found, perhaps due to significant differences in codon usage between these fungi species. Further, no other sequences homologous to PEX2_080050 were found in the P. expansum MD-8 genome neither using blastn no blastp algorithms. However, in the annotation of the genome an additional gene PEX2_071010 was found to have NPP-1 domain (IPR008701). We conclude that PEX2_080050 (PeNLP1) and PEX2_071010 (PeNLP2) represent the entire NLP content in the genome.

\section{PeNLP1 and PeNLP2 are type 1 and type 3 NLPs respectively.}

To analyze to which NLP subfamilies belong PeNLP1 and PeNLP2, phylogenetic analysis of PeNLPs together with seven representatives of type 1 fungal NLPs, five fungal type 2 NLPs and five fungal type 3 NLPs was preformed. This analysis resulted in a neighbor-joining tree that showed clearly distinguishable three groups (Fig 1A), whereas PeNLP1 is present in the type 1 group and PeNLP2 in the type 3 group. Both proteins have predicted N-terminal signal peptide, suggesting that they are secreted. PeNLP1 and PeNLP2 has 5 and 6 cysteines respectively. Only PeNLP1 has an intact heptapeptide "GHRHDWE" motif whereas, in the PeNLP2, the third amino acid of this motif is changed from Arg to Asp, and the fourth amino acid is changed from His into Tyr (Fig 1B). Prediction of disulfide bonds

\section{PeNLP1 PeNLP2 have different expression patterns during apple infection as well is on PDB.}

To investigate expression pattern of the PeNLP genes, $P$. expansum spores were inoculated into wounds on apple fruits (Golden Delicious) and infected tissue was collected 24, 48, 72 and 96 hours post inoculation. Concurrently, the spores were inoculated into PDB medium and mycelium was collected at the same time points. After RNA isolation and CDNA synthesis, real-time polymerase chain reaction (PCR) was performed to assess PeNLP1 and PeNLP2 transcript levels that were calibrated using transcript levels of the three housekeeping genes (28S rRNA, 37S ribosomal protein s24 PEXP_041240, and histone h3 PEXP_016920) as a references. This analysis demonstrated that PeNLP1 is strongly induced both in planta, and in growth medium with a similar expression pattern that rich the maximum at approximately $24 \mathrm{hpi}$ (Fig. 2A) and remains constant. Similar expression pattern was seen analyzing the transcriptome of $P$. expansum isolate from Spain (Fig.2B). On the other hand, the level of PeNLP2 is relatively high in spores 
and decreases approximately five fold during growth in planta or in vitro. However, no evidence for the PeNLP2 expression was found in the transcriptome of $P$. expansum isolate from Spain.

\section{PeNLP2 has three splice variants.}

Full length ORF of PeNLP1 and PeNLP2 was amplified using PCR reaction from cDNA from spores and apple and PDB culture respectively. The product was separated on agarose gel. Surprisingly, three bends were observed for PeNLP2 product (Fig. 3A). Whereas in spores the largest bend was the main product, at 72 and 96 hours post inoculation two smaller products got stronger. Each of the three bends was extracted from the gel, cloned into pGEM vector. Sequence analysis of the clones revealed three splice variants: first - 993 bp with no introns, second - 891 bp has one 102 bp intron, and third - 879 bp with two introns is similar to the prediction in the P. expansum MD-8 genome (Fig. 3B).

\section{Knock out of the PeNLP1 and PeNLP2 genes.}

The role of PeNLP1 and PeNLP2 in pathogenicity of $P$. expansum was examined by constructing knockout mutants in the PEX2 using Agrobacterium tumefaciens-mediated transformation according to the protocol described by (Ballester et. al 2015) (Fig. 4A). Proper T-DNA integration was checked by PCR analysis using locus-specific primers for i) the hygromycin resistance cassette, ii) the correct insertion of the T-DNA between the promoter and the terminator of the target gene, and iii) the absence of the target gene (Fig. 4B). The lack of expression of the deleted genes in the null-mutants during apple infection was shown by RT-PCR (Fig. 4C). For further testing one knockout mutant containing a single T-DNA integration was selected for each gene, along with an ectopic transformant possessing the wild-type gene. Importantly, deletion of the target genes did not affect growth rate and colony morphology, on PDA medium (Fig. 5). Spore production as well as germination of the conidiospores was also similar for null mutants of both NLP genes and compared to wild type (Fig. 6).

To examine the effect of the deletion on the pathogenicity, Golden delicious apples were infected with the null mutants. Infection progression rate and percent of infected wounds were compared between null mutants, ectopic mutants and the wild type. Deletion of PeNLP2 gene had no effect on the decay progression (Fig. 7). However, the diameter of the decay caused by $\triangle P e N L P 1$ mutant was around $12 \%$ smaller compare to that caused by the WT and the ectopic mutant (Fig. 7), although, the percent of visible lesions in the apples inoculated with $\triangle P e N L P 1$ was similar to that of WT and ectopic mutant respectively (Fig. 7).

\section{PeNLP1 displays cytotoxic activity}

Of 14 tested fungal type 1 NLP described in the literature, 12 were found to induce necrosis (Oome and Ackerveken 2014). To test the necrosis-inducing activity of PeNLP1, transient expression of the gene in $N$. Bentamiana by agroinfiltration was pursued. To this end, ORF of PeNLP1 with or without sequence coding for endogenous signal peptide was cloned under $35 \mathrm{~S}$ transcriptional promoter from cauliflower mosaic virus and inserted into pBINPLUS/ARS vector (Belknap et al. 2008) and transformed into Agrobacterium tumefaciens GV3101. Subsequently, the transgenic $A$. tumefaciens strains were infiltrated into the leaves 
of $N$. Bentamiana plants. Three to five days after agroinfiltration chlorotic spots appeared in the infiltration area. In the leaves infiltrated with constructs coding for PeNLP1 with signal peptide, necrosis developed ten days after the infiltration (Figure $\mathrm{X}$ ). Infiltration of constructs without signal peptide resulted only in minor chlorosis and several necrotic spots. In contrast, no necrosis or visible damage could be observed upon agroinfiltration of GUS gene.

\section{Identification of putative apple proteins interacting with PeNLP1 effectors.}

In order to understand the role of PeNLP1 putative effector in the fruit- pathogen relations, we used Y2H system to find apple proteins interacting with it. To this end, PeNLP1 was amplified by PCR, cloned fused to the GAL4 DNA binding domain in the PGBKT7 vector and used as a bait. To construct prey library, total RNA was isolated from 'Royal Gala' apple fruit collected at three different stages of development (early, mid-season, and mature). Fruit were either left unwounded, wounded, or wounded-inoculated with Penicillium expansum. RNA was extracted from the fruit tissues and pooled prior to generating cDNA. The library was packaged into the prey vector fused to the GAL4 activation domain. After several (3-4) rounds of screening to reduce the number of false positives, we got ??? positive colonies. The alignment of the hits and BLAST against $M$. domestica genome resulted in 16 genes (Table 2).

Three genes (MDP0000295540, MDP0000533638, MDP0000827820) that belong to the same family of plant pathogenesis-related proteins found were identified. All three are located on the chr. 13, and carry Bet $\mathrm{v} I$ and START-like domains. Bet $\mathrm{v} 1$ belongs to family 10 of plant pathogenesis-related proteins (PR10). These proteins were identified as plant allergens and as pathogenesis-related proteins whose expression is induced by pathogen infection, wounding, or abiotic stress. They are seem to be involved in pathogen defense response (van Loon et al., 2006, Jain and Kumar, 2015).

TMHMM v2.0 analysis revealed one protein (MDP0000267916) with six transmembrane domains, which was identified as putative ATPase V0 complex subunit. Among proteins interacting with PeNLP1, another ATPase were found (MDP0000624197). MDP0000624197 is ATPase F1 complex subunit. V-ATPases hydrolyse ATP to drive a proton pump, and are involved in a variety of vital intra- and inter-cellular processes such as receptor mediated endocytosis, protein trafficking, active transport of metabolites, homeostasis and neurotransmitter release (Wilkens et al 2005). F-ATPases which are found in mitochondria, chloroplasts and bacterial plasma membranes where they are the prime producers of ATP, using the proton gradient generated by oxidative phosphorylation (mitochondria) or photosynthesis (chloroplasts) (Gruber et al 2001). Further, analysis of the protein sequences by SignalP 4.1, TargetP 1.1 $(R C<=2)$ showed no secreted proteins, one protein with unknown function (MDP0000361180) was predicted to mitochondria and three proteins were predicted to chloroplast: MDP0000232800 that carries SWIB/MDM2, GYF and Plus-3 domains and could be important for ligand recognition and binding and chromatin-remodelling facilitating transcription activation (Cristofaro et al 2001)., MDP0000236092, belongs to thiazole biosynthetic enzyme Thi4 family and to Glycosyl-phosphatidyl inositol-anchored protein family, MDP0000260339, which possess RNA-recognition and binding domain in addition to GTPase domain found in all tubulin chains and could be involved in polymer formation.

Several additional proteins that could play significant role in fruit-pathogen interaction were also found: two thiamine binding pyruvate decarboxylases (MDP0000287416, MDP0000750040), an aspartic 
peptidase (MDP0000201076) with Leucine-rich repeat domain (LRR), which could be involved in a variety of biological processes, including signal transduction, DNA repair, recombination, transcription, RNA processing etc., ethylene responsive element binding factor (ERF) (MDP0000517257) with DNA-binding domain, thiolase-like protein (MDP0000129664) that could be related to chalcone synthase, metallothionein (MDP0000153123) Belongs to the family of cysteine-rich, low molecular weight (MW ranging from 500 to $14000 \mathrm{Da}$ ) proteins that binds to heavy metals. They are localized to the membrane of the Golgi apparatus. MTs function is not clear, but experimental data suggest MTs may provide against oxidative stress. And ribosomal protein (MDP0000165757).

\section{Discussion}

Since the discovery of the first necrosis-and-ethylene inducing peptide (Nep1) of Fusarium oxysporum (Bailey et al 1995), many Nep1-like (NLP) proteins have been identified, mostly in plant related bacteria, fungi and oomycetes. In oomycetes especially the NLP family is significantly expanded. Feng and cowokers (2011) identified 42 putative NLPs containing the conserved GHRHDWE motif in the genome of Phytoftora capsici. Among these NPPs, 14 were single copy, while the rest were multicopies ranging from 2-12. 33 real and 37 pseudogenes compose the Phytoftora sojae NLP gene family (Dong et al 2012). In fungi, however number of NLP genes is much smaller. Similarly to $P$. expansum, two NLP genes were found in the genome of Botrytis cinerea (Staats, van Baarlen et al 2007). Four NLP genes were found in the genome of Magnaporthe grisea, eight in Verticillium dahliae and one in Mycosphaerella graminicola (Gijzen \& Nurenberger 2006, Santhanam et al 2013, Motteram et al 2009).

Three distinct types of NLPs were documented, and in in fungi species, all possible combinations of the three types are found (Oome and Van den Ackerveken, 2014). Type 1 is found mostly in plant associated species, whereas type 3 was found only in Ascomysete fungi with many different lifestyles (Oome and Van den Ackerveken, 2014).

As a vast majority of NLP genes analyzed by Oome and Van den Ackerveken, PeNLP1 and PeNLP2 have signal peptide for secretion. Analysis of 533 NLP showed that all of them have some variant of the conserved heptapeptide motif GHRHDWE. In type 3 NLP, the arginine and histidine residues (underlined) of the heptapeptide were found not to be conserved (Oome and Van den Ackerveken, 2014). Further, more than $98 \%$ of the type 1 contain the two conserved cysteine residues that is also present in PeNLP1. These cysteines form the disulfide bond in the published NLP structures (Oome and Van den Ackerveken, 2014). SsNEP1 from Sclerotinia sclerotiorum was shown to contain a third cysteine residue, and SsNEP2 contains three additional cysteines. The third cysteine in SsNEP1and two of the three additional cysteines in SsNEP2 are conserved among the orthologues in Botrytis species, but not so in other NLPs. (Dallal Bashi 2010). Typical to type 3 NLP, PeNLP2 has 6 conserved cysteines.

Conserved cysteine residues define the type or class of NLP. Both SsNEPs are Type I with two conserved cysteine residues at positions 47 and 73 in the mature protein (Fig. 1A). SsNEP1 contains a third cysteine residue, and SsNEP2 contains three additional cysteines. The third cysteine in SsNEP1 and two of the three additional cysteines in SsNEP2 are conserved among the orthologues in Botrytis species, but not so in other NLPs. 
Surprisingly, PENLP1 and PeNLP2 were found to have similar expression pattern both during apple infection and in liquid culture. This is in contrast to what was shown for MgNLP from Mycosphaerella graminicola which expression level in planta is more than 100-fold higher compared to in vitro expression (Motteram et al. 2009). Also expression of VdNLP transcripts was shown to be higher during infection of Verticillium dahlia on tomato compared to in vitro growth (Santhanam et al. 2013). VdNLP expression was also shown to be induced by supplementation of liquid medium with cotton roots (Zhou et al. 2012). Furthermore, SSNep1 and SSNep2 from S. Sclerotorium was shown to express only on leaves and not in liquid medium (Dallal Bashi et al. 2010). This inconsistent could be due to different lifestiles of $P$. expansum and other mentioned fungi. However, Bcnep1 and Bcnep2 transcripts of necrothrophic Botrytis cinerea strain B05.10 could not be detected during in vitro growth (Arenas et al. 2010). Nevertheless, from our previous experience, some of $P$. expansum LysM effectors also exhibited a stronger induction when grown in vitro compared to apple infection (our LysM paper).

PeNLP1 and PeNLP2 were found to have different expression patterns. While PeNLP1 is strongly induced after germination of spores, conversely, PeNLP2 expression level is higher in spores compared to the growing mycelium. Similarly, to PeNLP1, NLP-genes from other fungi were shown to be up regulated during host infection. In general, the expression peacks slightly before or corresponding with appearance of disease symptoms (Santhanam et al. 2013, Dallal Bashi et al. 2010, Arenas et al. 2010, Motteram et al. 2009). In the existing literature, we did not find any indication to NLP genes, which maximal expression level is in the spores. It is important to mention, that PeNLP2 is type 3 NLP to which very little experiment data is available. However, preliminary data reported by Oome and Ackerveken suggest that expression of $V$. dahlia type 3 NLP VDAG_07979T0 and also type 3 NLP from Metarhizium anisopliae and M. acridum is induced during infection of tomato and insects, respectively.

\section{Splice variants}

\section{Effect of targeted deletion on growth and pathogenicity}

Targeted deletion of PeNLP1 and PeNLP2 had no evident effect on colony morphology and growth rate on PDA medium. Moreover, deletion of both genes had no effect on germination process and on spore production in vitro. In the vascular wilt pathogen Verticillium dahlia, deletion of NLP1 and NLP2 also had no effect on radial growth or germination. However, NLP1 deletion strain appeared to have developed approximately $40 \%$ less conidiospores than NLP2 deletion strain, the wild-type strain and ectopic transformant. Moreover, NLP1 deletion strain was morphologically distinct (Santhanam et al 2013).

Only PeNLP1 deletion strain showed reduced virulence on apples. It appears that there is a functional diversification in the superfamily of NLP1-like proteins as some members contribute to virulence and others do not. NLP was shown to be essential for virulence of Erwinia carotovora on potato tubers (Mattinen et al. 2004). Deletion of VdNLP1 from wilt pathogen $V$. dahliea JR2 reduced virulence on tomato, Arabidopsis and N. Bentamiana, whereas deletion of VdNLP2 affected only virulence on tomato and Arabidopsis (Santhanam et al. 2013). On the other hand, single or double gene deletion of VdNLP1 and VdNLP2 in V. dahliea V592 had no effect on symptoms development on cotton (Zhou et al. 2012). Moreover, deletion of sole NLP gene from Mycosphaerella graminicola caused no detectable reduction in 
plant pathogenicity or virulence (Motteram et al. 2009). Further, in Botrytis cinerea and Botrytis elliptica containing two NLP genes each, loss of single NLP gene did not affect virulence (Arenas et al. 2010, Staats et al. 2007).

\section{Cytotoxic activity}

Following discovery of NEP1 in Fusarium oxysporum by Bailey et al. (1995) that was shown to cause cell death in dicots, many NEP1-like proteins was discovered in numerous fungi with different lifestyles. In addition to cytotoxic NLP, many NLP that do not induce necrosis were described. Each of 11 PCNLP genes from Phythophtora capsici were shown to induce chlorosis or necrosis in tobacco leaves (Feng et. al 2014). Likewise, NLP from B. elliptica, B. cinerea and S. sclerotiorum was shown to cause necrosis in $N$. Bentamiana leaves (Staats et al. 2007, Schouten et al. 2008, Dallal Bashi et al. 2010). However, 12 HaNLP from Hyaloperonospora arabidopsidis, 2 of 3 tested PiNPP from Phytophthora infestans, 11 of 19 tested NLP in Phytophthora sojae, 7 of 9 tested in V. dahliae V592, 6 out of 8 tested in V. dahliae JR2, and one ChNLP out of two tested in Colletotrichum higginsianum did not cause necrosis when transiently expressed in leaves (Cabral et al. 2012,Kanneganti et al. 2006, Dong et al. 2012, Zhou et al. 2012, Santhanam et al. 2013, Kleeman et al. 2012). Remarkably, there is no evident correlation between fungi lifestyle and cytotoxicity of its NLP. Moreover, there no correlation between the type of NLP to its ability to induce necrosis. We also noted that tim-period for necrosis development following leaves infiltration varies significantly for different NLP. Following agroinfiltration of PeNLP1 to N. Bentamiana leaves, necrosis has developed after 8-10 days, while agroinfiltration of NLP1 and NLP2 from V. dahlia JR2 caused clear necrosis already after 3 days (Santhanam et al. 2013). In general, the time for necrosis development varies between 3 to 12 days in different transient expression experiments (Santhanam et al. 2013, Kanneganti et al. 2006, Kleeman et al. 2012, Feng et al. 2014, Dallal Bashi et al. 2010). Those differences could result from diverse cytotoxic capabilities of various NLP as well as from the secretion efficiency or general experimental conditions. 


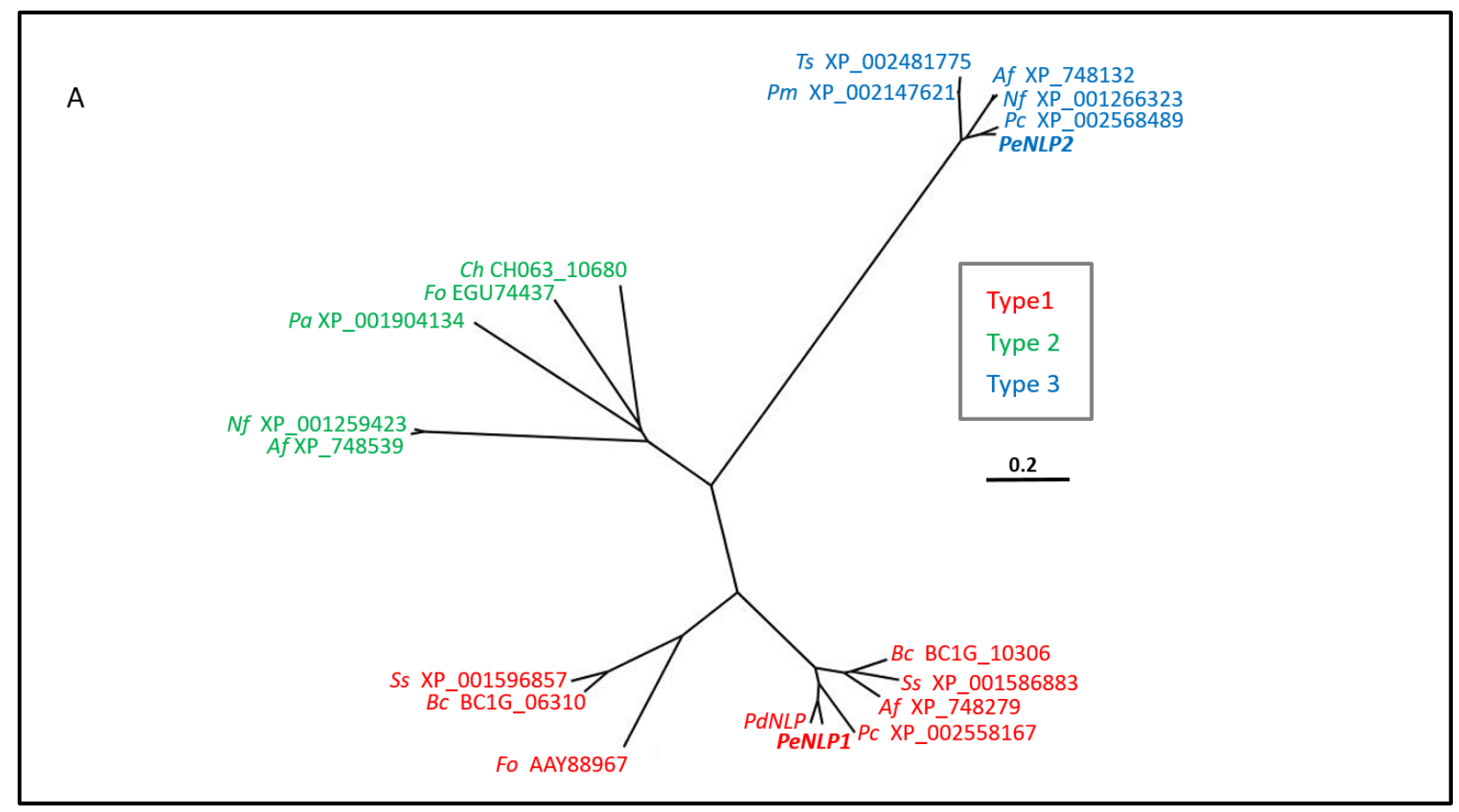

B

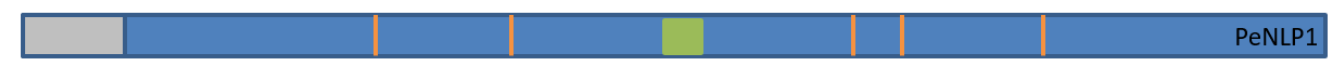

\begin{tabular}{l||l|l} 
& & \\
Signal peptide || Cysteine & Conserved heptapeptide
\end{tabular}

Figure 1 Characterization of the two NLP genes of P. expansum. A, Comparison of sequences encoding NLPs. An unrooted phylogenetic tree constructed from NLP sequences from GenBank. Protein sequences were aligned using Mega 6 and the phylogram was drawn in FigTree v.1.4.2. All protein sequences were from fungal species. NLP type is indicated by colour. The scale bar represents ??? weighted sequence divergence. The protein sequences are coded as follows: the first two letters in italics identify the organism, followed by the GenBank protein accession number. Af, Aspergillus fumigates Af293; Bc, Botrytis cinerea; Ch, Colletotrichum higginsianum; Fo, Fusarium oxysporum; Nf, Neosartorya fischeri NRRL181; Pa, Podospora anserine S mat+; Pc, Penicillium chrysogenum Wisconsin 54-1255; Pm, Penicillium marnefferi ATCC 18224; Ss, Sclerotinia sclerotiorum 1980 UF-70, Ts, Talaromyces stipitatus ATCC 10500. B, Schematic representation of PeNLP1 and PeNLP2. 

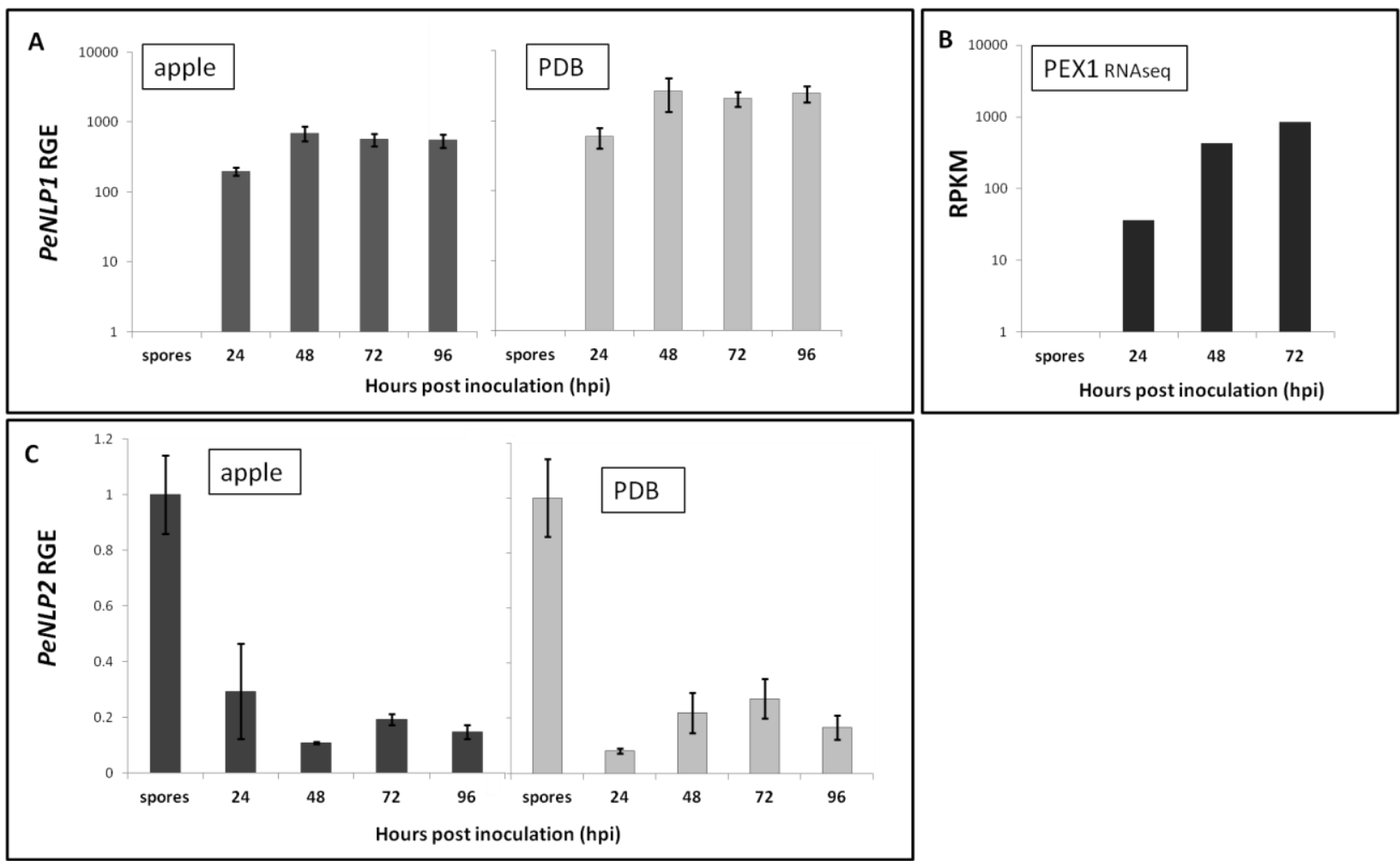

Figure 2 Expression of PeNLP1 and PeNLP2. Relative gene expression of the A, PeNLP1 and B, PeNLP2. Spore suspensions of P.expansum were inoculated into apple wounds or into $100 \mathrm{ml}$ ? of potato dextrose broth (PDB) and were incubated for up to 4 days at $25^{\circ} \mathrm{C}$ in the dark. Relative gene expression (RGE) in apples (dark gray bars), on PDB (light gray bars) after 24, 48, 72, and 96 hours post incubation. The expression levels are relative to the genes coding for a $28 \mathrm{~S}$ rRNA, histone 3 , and $37 \mathrm{~S}$ ribosomal protein s24. Error bars indicate standard deviations of three biological replicates. B, Expreswsion level of PeNLP1 based on RNA-seq analysis. RNA-Seq data were generated from four different libraries: a cDNA library synthesized from a mixture of RNAs obtained from P. expansum PEX1 spores collected after 7 days of growth in PDA and healthy, noninoculated fruits, and three libraries from $P$. expansum-infected apples at 24,48 , and $72 \mathrm{hpi}$, respectively. Sequencing was carried out using the Roche 454 GS FLX Titanium system. All high-quality reads for each sample were analyzed with the RNA-Seq analysis program of the CLC Genomics Workbench software (CLCbio) and were mapped to the predicted gene models of P. expansum PEX1 and Malus $\times$ domestica Borkh (Velasco et al. 2010). 

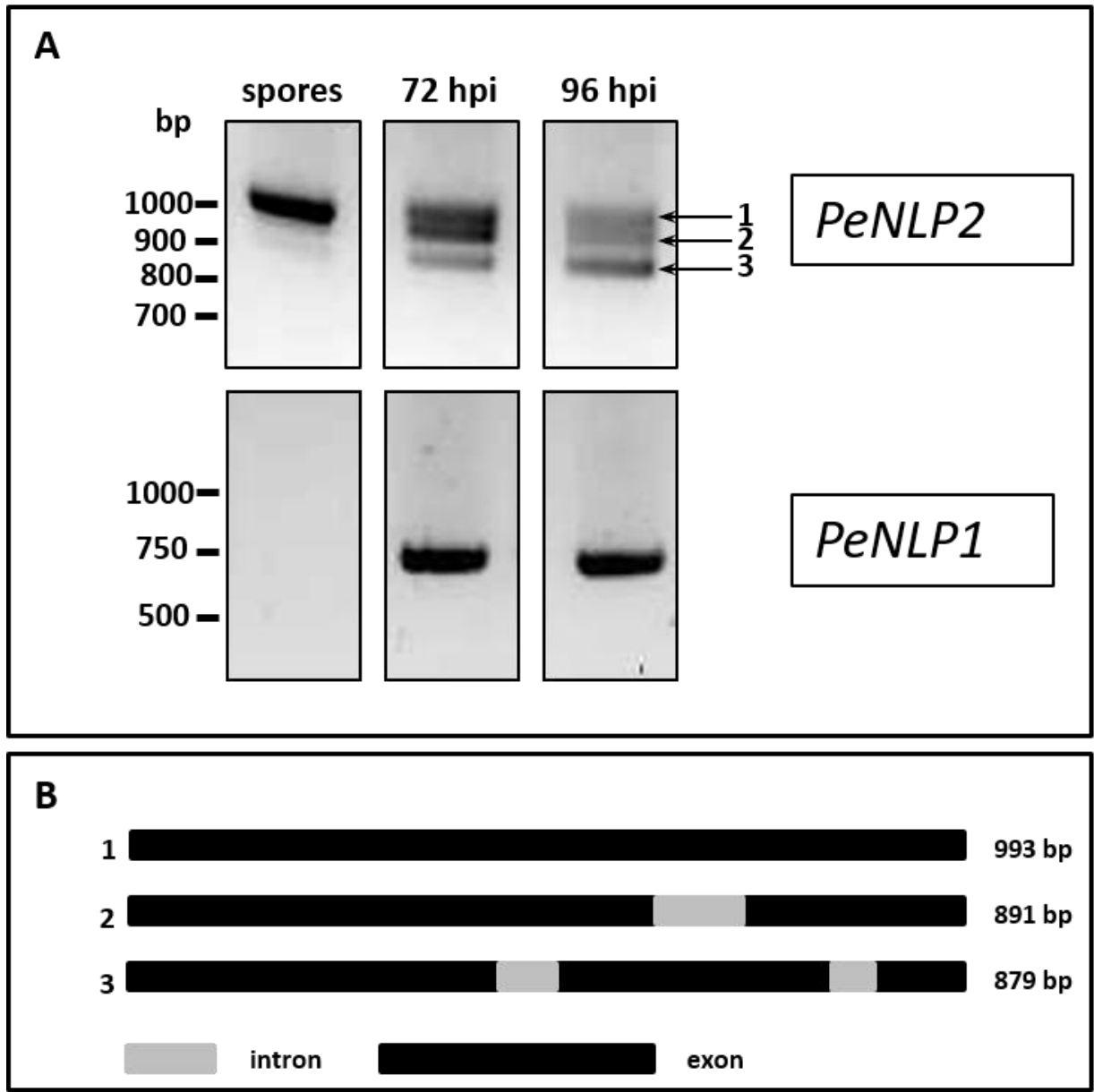

Figure 3 A, Three splice variants of the PeNLP2 gene. Spore suspensions of $P$.expansum were inoculated into $100 \mathrm{ml}$ ? of potato dextrose broth (PDB) and were incubated for 3 to 4 days at $25^{\circ} \mathrm{C}$ in the dark. Full lengths ORF of PENLP2 was amplified using PCR reaction and separated on agarose gel. B, Schematic representation of the tree splice variants. Black rectangles - exons, gray rectangles - introns. The size of the products in base-pares are written on the right. 


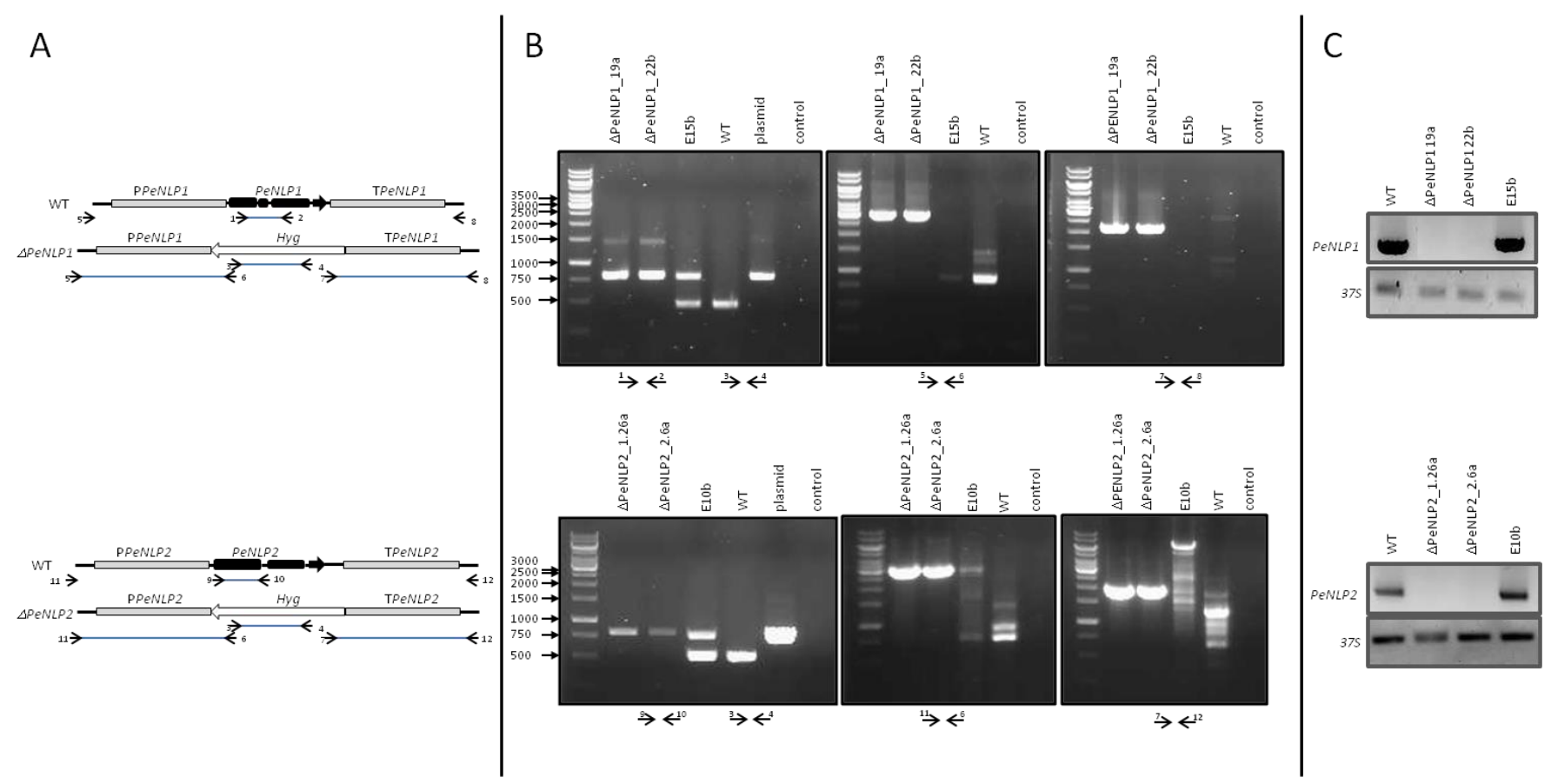

Figure 4 Deletion of PeNLP1 and PeNLP2 in Penicillium expansum MD8. A, Diagram of the wild type and deleted loci. The hygromycin selectable marker present in the T-DNA of plasmids pRFHU2-PeNLP1 or PRFHU2-PeNLP2 replaces the PeNLP1 or PeNLP2 gene respectively by homologous recombination, to generate the null mutants. B, Polimerase chain reaction amplification of the wild type, null mutants and its ectopic mutants with diagnostic primers. Plasmid - pRFHU2-PeNLP1 or pRFHU2-PeNLP2 carrying the hygromycin selectable marker; control - no template control. C, RT-PCR to compare the expression of PeNLP1 and PeNLP2 genes in wild type, null and ectopic mutants. CDNA was prepared from RNA extracted from apples 96 hpi to detect PeNLP1 expression and from spores to detect PeNLP2 expression. 375 ribosomal protein s24 was used as a control. 


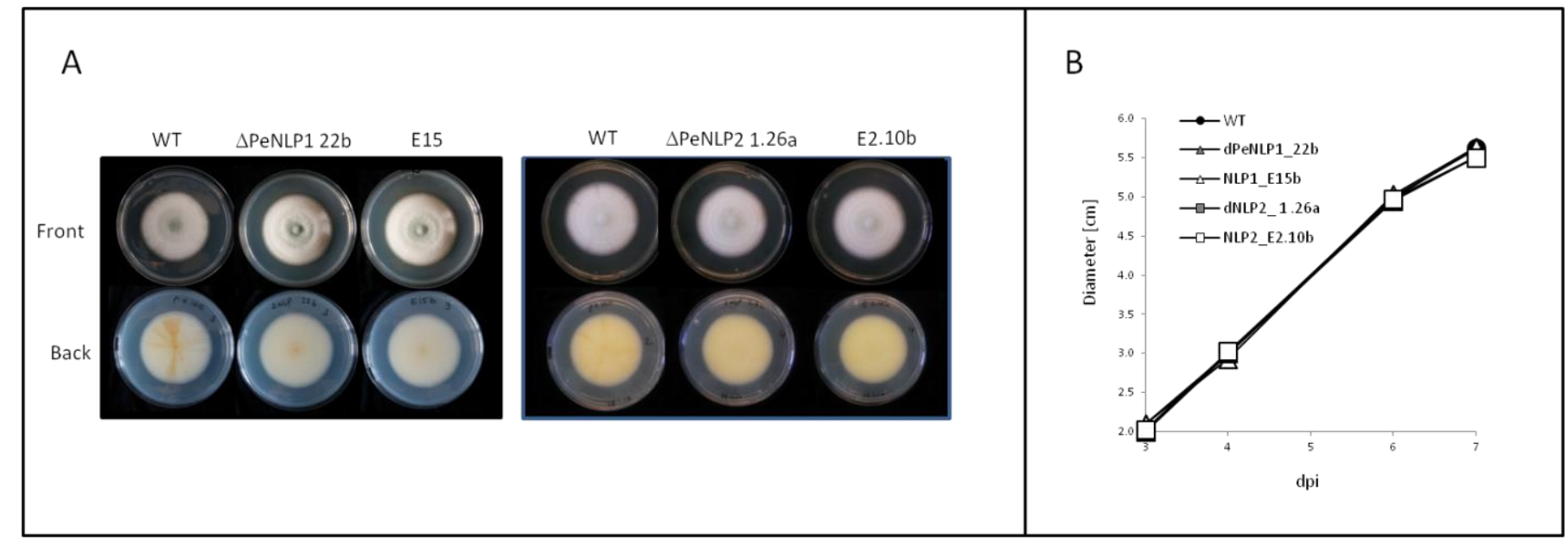

Figure 5 Targeted deletion of PeNLP1 or PeNLP2 genes does not affect radial growth and colony morphology. A, Colony morphology and B, radial growth on PDA medium. C, percent germination, E, average germ length, F, microscopic observation of the germination of condia at $18 \mathrm{~h}$ after inoculation on water + 1.5\% Agar plates. D, Average number of condia produced after 11 days of growth on PDA medium based on three independent experiments. 


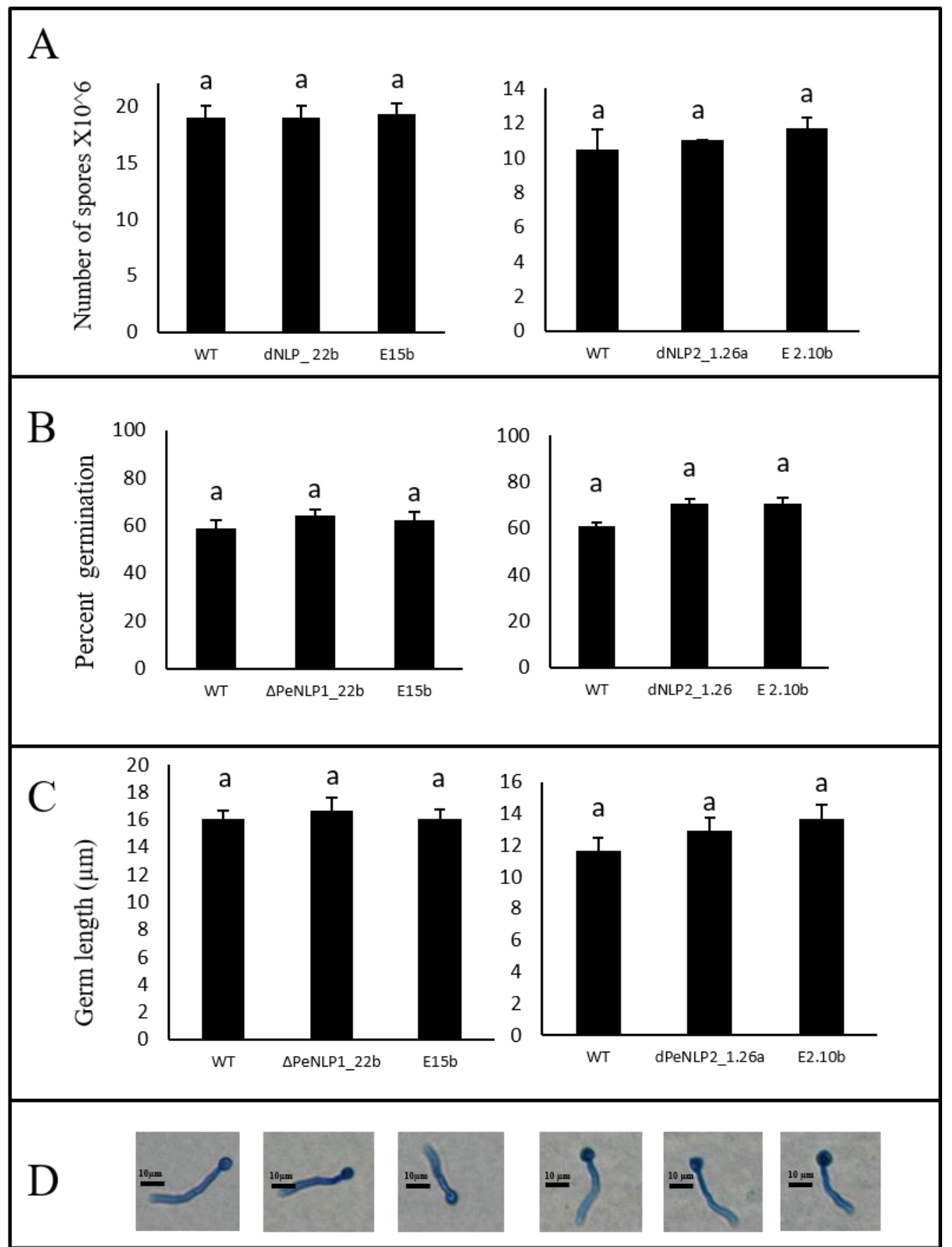

Figure 6 Targeted deletion of PeNLP1 or PeNLP2 genes had no significant affect on spore-production or germination. A , Average number of condia produced after 11 days of growth on PDA medium based on three independent experiments, B, average percent of condia germinated after $18 \mathrm{~h}$ inoculation on water $+1.5 \%$ Agar plates, E, average germ length, D, microscopic observation of the germinated condia. 


\section{PeNLP1}
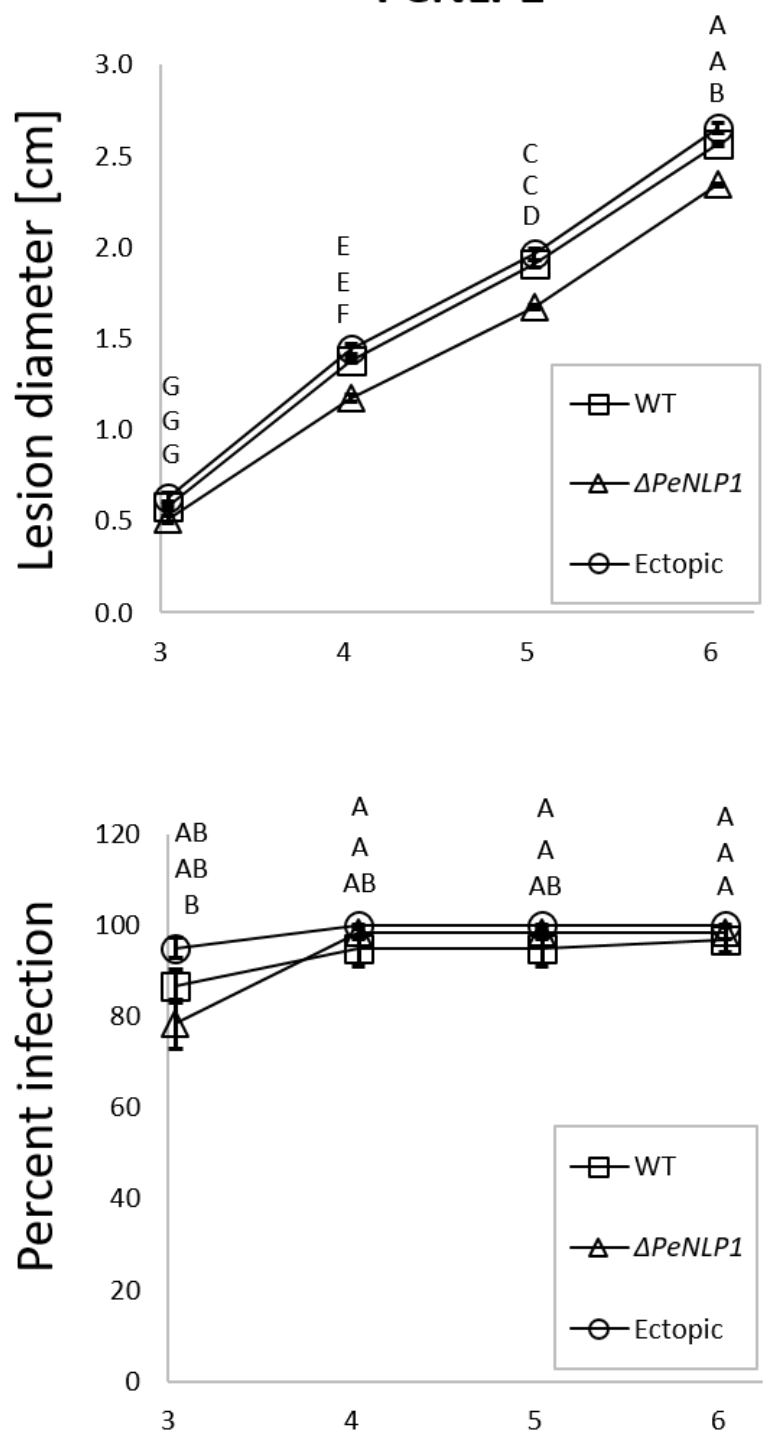

\section{PeNLP2}
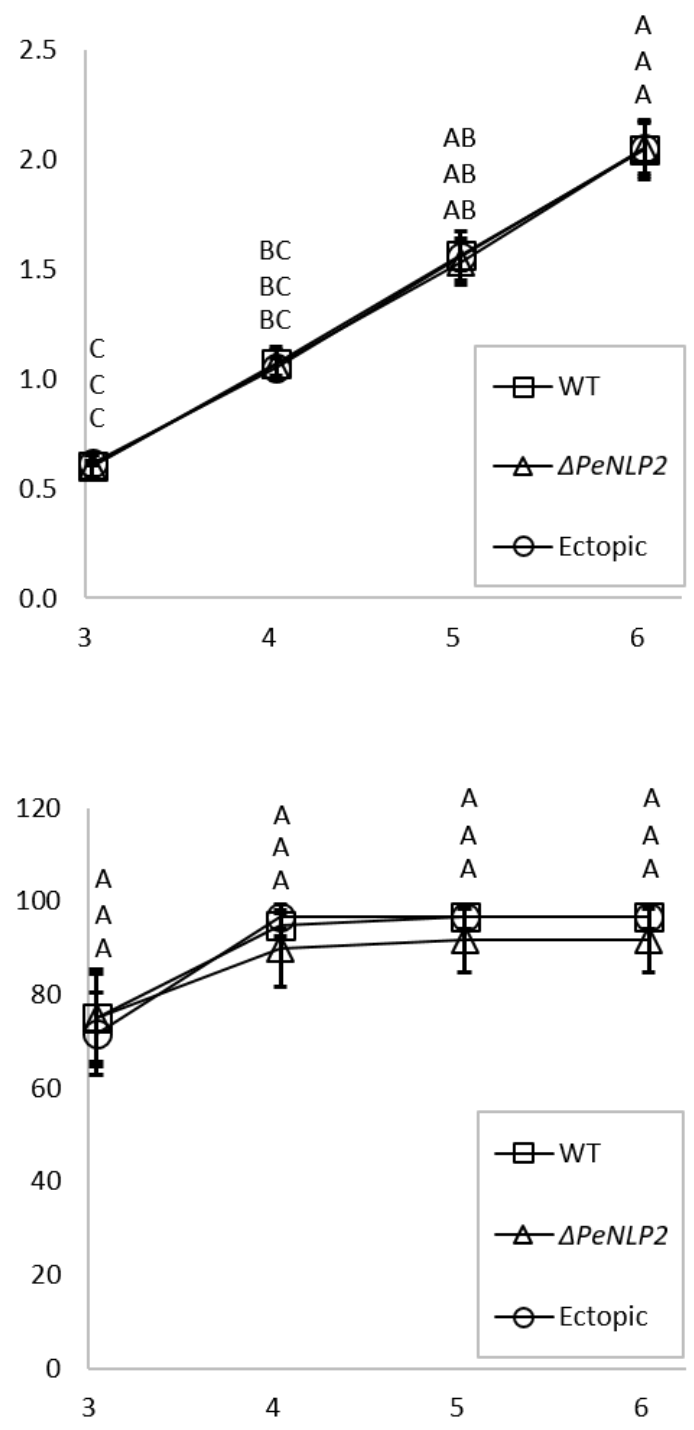

Days post inoculation (dpi)

Figure 7 The pathogenicity of $P$. expansum wild-type and transformant strains was examined by inoculation of 'Golden Delicious' apples. Fruits were wounded and inoculated by adding $10 \mu$ lit of conidia suspension adjusted to $10^{5}$ conidia/ml. For each treatment fifteen infected fruit with four wounds per fruit were used. Diameter of the decay and percentage of infected wounds were measured at 3, 4, 5, and $6 \mathrm{dpi}$. Results of one of the three independent experiments are presented. 


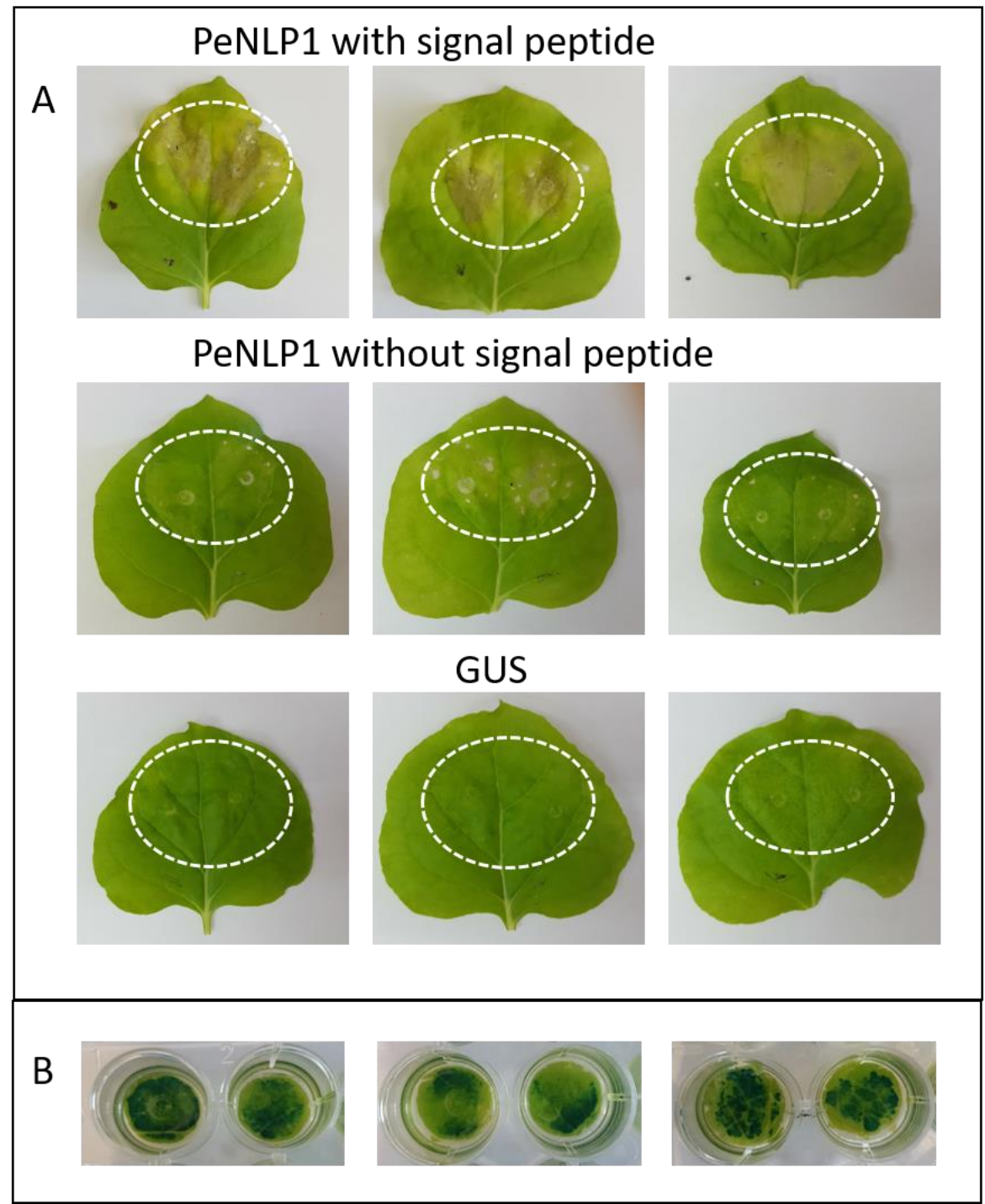

Figure 8 Expression of PeNLP1 induces cell death in N. Bentamiana leaves. A, Leaves of N.Bentamiana infiltrated with constructs for constitutive expression of PeNLP1 with or without signal peptide and constutive expression of GUS as negative control. Pictures were taken 10 days post infiltration B, Visualisation of GUS activity. 
Table 2: Apple proteins that found to create interactions with PeNLP1 by Y2H

\begin{tabular}{|c|c|c|c|c|c|c|}
\hline \# & Gene ID & Chrom. & Exp. & $\begin{array}{l}\# \text { of } \\
\text { hits }\end{array}$ & $\begin{array}{l}\text { Align } \\
\text { Length }\end{array}$ & Function \\
\hline 1 & MDP0000287416 & 12 & $1 e-04$ & 1 & 82 & $\begin{array}{l}\text { Thiamine pyrophosphate enzyme; Pyruvate } \\
\text { decarboxylase/indolepyruvate decarboxylase }\end{array}$ \\
\hline 2 & MDP0000750040 & 13 & $\begin{array}{l}1 \mathrm{e}-143 \\
1 \mathrm{e}-159\end{array}$ & 2 & 291 & $\begin{array}{l}\text { Thiamine pyrophosphate enzyme; Pyruvate } \\
\text { decarboxylase/indolepyruvate decarboxylase }\end{array}$ \\
\hline 3 & MDP0000361180 & 12 & $\begin{array}{l}7 e-83 \\
5 e-37 \\
5 e-83\end{array}$ & 3 & $\begin{array}{l}159 \\
121 \\
159\end{array}$ & Protein of unknown function DUF4323 \\
\hline 4 & MDP0000295540 & 13 & 0.0 & 1 & 480 & Bet v I type allergen; START-like domain \\
\hline 5 & MDP0000533638 & 13 & $3 e-05$ & 1 & 46 & Bet v I type allergen; START-like domain \\
\hline 6 & MDP0000827820 & 13 & 0.0 & 3 & 480 & Bet v I type allergen; START-like domain \\
\hline 7 & MDP0000201076 & 15 & $\begin{array}{l}1 e-34 \\
2 e-97\end{array}$ & 2 & $\begin{array}{l}150 \\
204\end{array}$ & Peptidase A1 \\
\hline 8 & MDP0000232800 & 15 & $1 e-10$ & 1 & 59 & SWIB/MDM2 domain; GYF; Plus-3 \\
\hline 9 & MDP0000165757 & 16 & $4 e-11$ & 1 & 35 & Ribosomal protein S13 \\
\hline 10 & MDP0000624197 & 2 & 0.0 & 1 & 697 & ATPase, F1 complex, delta/epsilon subunit \\
\hline 11 & MDP0000267916 & 8 & $1 e-152$ & 1 & 272 & ATPase, FO/VO complex, subunit C \\
\hline 12 & MDP0000236092 & 3 & 0.0 & 2 & 362 & $\begin{array}{l}\text { Thiamine biosynthesis Thi4 protein, Glycosyl- } \\
\text { phosphatidyl inositol-anchored }\end{array}$ \\
\hline 13 & MDP0000153123 & 4 & $1 e-100$ & 1 & 235 & Metallothionein, family 15 \\
\hline 14 & MDP0000517257 & 7 & $1 e-124$ & 1 & 232 & $\begin{array}{l}\text { AP2/ERF domain; DNA-binding, integrase- } \\
\text { type }\end{array}$ \\
\hline 15 & MDP0000260339 & 8 & $4 e-51$ & 1 & 102 & $\begin{array}{l}\text { RNA recognition motif domain; Tubulin/FtsZ, } \\
\text { GTPase domain; Nucleotide-binding, alpha- } \\
\text { beta plait }\end{array}$ \\
\hline 16 & MDP0000129664 & 9 & $\begin{array}{l}0.0 \\
1 \mathrm{e}-171\end{array}$ & 2 & $\begin{array}{l}866 \\
321\end{array}$ & Thiolase \\
\hline
\end{tabular}

